Illinois State University

ISU ReD: Research and eData

Theses and Dissertations

7-6-2021

\title{
Are Websites of Victim Service Organizations Representative of Women of Color? A Content Analysis
}

Loretta Addo-Danso

Illinois State University, frimponmaa13@gmail.com

Follow this and additional works at: https://ir.library.illinoisstate.edu/etd

\section{Recommended Citation}

Addo-Danso, Loretta, "Are Websites of Victim Service Organizations Representative of Women of Color? A Content Analysis" (2021). Theses and Dissertations. 1425.

https://ir.library.illinoisstate.edu/etd/1425

This Thesis is brought to you for free and open access by ISU ReD: Research and eData. It has been accepted for inclusion in Theses and Dissertations by an authorized administrator of ISU ReD: Research and eData. For more information, please contact ISUReD@ilstu.edu. 


\section{ARE WEBSITES OF VICTIM SERVICE ORGANIZATIONS REPRESENTATIVE OF WOMEN OF COLOR? A CONTENT ANALYSIS}

\section{LORETTA ADDO-DANSO}

\section{Pages}

Intimate partner violence continues to be on the rise among women of color in the country. Many scholars have attributed this to the multiple factors such as race, class and sexual orientation that intersect to influence women of color's experiences with intimate partner violence. Yet, there seems to be a gap in the services that are rendered to women of color who are survivors. To better understand how representative victim services are of women of color, a content analysis of victim service organizations' websites nationwide was conducted to ascertain the extent to which the organizations are inclusive of survivors/victims of color. The exploration includes both images and photographs on websites, as well as programmatic content. Findings revealed that the websites for a majority of victim service organizations were not representative of survivors/victims of color. Recommendations are highlighted.

KEYWORDS: content analysis; victim service organizations; women of color; intersectionality theory; websites; intimate partner violence 


\title{
ARE WEBSITES OF VICTIM SERVICE ORGANIZATIONS REPRESENTATIVE OF WOMEN OF COLOR? A CONTENT ANALYSIS
}

\author{
LORETTA ADDO-DANSO
}

A Thesis Submitted in Partial

Fulfillment of the Requirements for the Degree of

MASTER OF SCIENCE

Department of Criminal Justice Sciences

ILLINOIS STATE UNIVERSITY

2021 
(C) 2021 Loretta Addo-Danso 


\title{
ARE WEBSITES OF VICTIM SERVICE ORGANIZATIONS REPRESENTATIVE OF WOMEN OF COLOR? A CONTENT ANALYSIS
}

\author{
LORETTA ADDO-DANSO
}

COMMITTEE MEMBERS

Dawn Beichner, Chair

Miltonette Craig

Ralph Weisheit 


\section{ACKNOWLEDGMENTS}

My first gratitude goes to the Almighty God for providing me with the chance to obtain my master's degree from Illinois State University in the United States of America. I could not have done it without his divine protection and guidance, and I am forever grateful. My second profound gratitude goes to my supervisor and chair of my thesis committee, Dr. Dawn Beichner who has been instrumental in my success story. Her guidance and constructive criticism have helped me to produce this research study.

I also wish to acknowledge my parents Mr. and Mrs. Addo-Danso and siblings, whose support both spiritually and emotionally helped me to complete my studies and research. Without their love and support, I will not have made it this far. My sincere gratitude also goes to the Department of Criminal Justice Sciences and its wonderful staff members and lecturers for their support and guidance which helped me to attain the best throughout my education at the department. I am forever grateful.

I am thankful to the co-chair of my thesis committee in the person of Dr. Craig Miltonette and Dr. Ralph Weisheit whose advice and constructive criticisms enabled me to complete my thesis and become a better researcher in the field of Criminal Justice. I am thankful for your willingness to serve on my committee. May God bless you abundantly. I will end here with a quote by Mae West which states that, "you only live once, but if you do it right, once is enough."

L.A.D. 


\section{CONTENTS}

Page

ACKNOWLEDGMENTS

TABLES

CHAPTER I: INTRODUCTION 1

$\begin{array}{ll}\text { Problem statement } & 5\end{array}$

$\begin{array}{ll}\text { Research Questions and Objectives } & 8\end{array}$

CHAPTER II: LITERATURE REVIEW 99

$\begin{array}{ll}\text { Intimate Partner Violence } & 9\end{array}$

Effects of the Corona Virus Pandemic on IPV 11

Risk Factors and Negative Impacts Associated With Intimate Partner Violence 13

Intimate Partner Violence Among Women of Color in Heterosexual Relationships 15

Intimate Partner Violence Among Immigrant Women Of Color $\quad 18$

Intimate Partner Violence Among Women of Color in Same-Sex Relationships 21

Online Social Support for Victims of Intimate Partner Violence 22

$\begin{array}{ll}\text { Theoretical Framework } & 26\end{array}$

$\begin{array}{ll}\text { Intersectionality Theory } & 26\end{array}$

Summary And Present Study 29

$\begin{array}{ll}\text { CHAPTER III: METHODOLOGY } & 30\end{array}$

$\begin{array}{ll}\text { Purpose of The Study } & 30\end{array}$

$\begin{array}{ll}\text { Research Questions } & 30\end{array}$

$\begin{array}{ll}\text { Hypotheses } & 30\end{array}$

$\begin{array}{ll}\text { Study Design } & 30\end{array}$ 
Sampling of Data

Data Sampled

Pilot Study and Procedure

Measures/Coding

Measurement of Hypotheses

Reliability

CHAPTER IV: RESULTS

Census Data on Sampled States

Description of Websites

General Contents on Websites/Main Landing Pages

Hypotheses

CHAPTER V: DISCUSSION AND CONCLUSION

Discussion of Findings

Conclusions and Limitations

Recommendations

REFERENCES

APPENDIX A: RAW DATA 


\section{TABLES}

Table

Page

1. Census Data (2019)

2. Total Number of Websites

3. Content on websites 


\section{CHAPTER I: INTRODUCTION}

Violence against women is a phenomenon that continues to plague the world. Despite attempts by numerous governments, organizations and individuals, to eradicate this problem, the problem seems to persist. Women all over the world continue to experience persistent violence and abuse yet there seems to be a gap when asking similar questions involving women of color. Many scholars and non-scholars alike have hinted that the experiences of violence most especially intimate partner violence (IPV) seem to be the same for all women worldwide including how they are treated by the criminal justice system and other service providers. However, others have hinted that it will be deceiving to generalize the ways in which all women experience IPV, given the fact that many factors and identities exist and interlock to produce unique experiences for women. It is therefore of importance that we examine IPV, and the services provided to its victims taking into consideration age, sexual orientation, immigration status, race, religious background, cultural background and class.

IPV consists of a variety of behaviors that occurs within intimate relationships usually of adult nature (Kelley, 2011). This concept has been defined as any form of threats or the intentional use of physical violence, sexual violence, or both, with the prospective of causing some form of harm such as disability, injury or even death of an individual. It also encompasses psychological/emotional abuse, coercive behaviors or both following prior physical and or sexual violence or both, perpetrated against an individual by a current or former marital or non-marital partner (Saltzman et.al., 2002). There have been various attempts by scholars, organizations, governments, among others, who have conducted studies to better understand IPV to dismantle it, yet there seems to be no framework that can help in better understanding of the problem. As highlighted by Kelly (2011), numerous scholars and social activists have continuously tried to 
come up with explanations and theories as to the causes of IPV against women and how victims respond to their abuse. Additionally, Thomas (2020) states that extensive literature in various countries, cultures, and disciplines continues to contribute more knowledge on this phenomenon hence providing better explanations and understanding on why it continues to exist among loved ones, the family and the society at large.

Literature indicates that, in previous centuries, IPV was considered a private matter that occurred between two adults; however, this narrative has changed over time and intimate partner violence is recognized as a complex sociocultural and public health issue (Kelly, 2011). IPV occurs within different cultures, countries and communities and affects not only a portion of society, but also the society as a whole. Albeit it being in existence for years and across borders, nations, race, socioeconomic status, gender, among others, IPV continues to be a complex social issue that is not easy to fully understand and continues to have a negative generational impact (Barnett et al., 2011; Gelles, 1997; Gosselin, 2000). The terminology used to describe it has evolved over the years from domestic violence, domestic abuse, domestic terrorism, and IPV to gender-based violence (Breiding et al., 2015; UN Women, United Nations Entity for Gender Equality and the Empowerment of Women, 2013).

Despite the fact that IPV affects all people regardless of their gender, socioeconomic status, race, ethnicity, class and sexual orientation, studies have revealed that this act of violence is gendered as well as racially biased, in that victimization is prevalent among women of color. According to Bureau of Justice Statistics (2006), although IPV affects both males and females irrespective of their socioeconomic background, race, and age, the group that is more likely to experience victimization is women of color. In fact, as stated by Truman and Morgan (2014), African American women in particular experience IPV at a twenty percent higher rate than their 
fellow White women. Furthermore, as suggested by Sokoloff and Dupont (2013), the rates for IPV and sexual assault are higher for low-income Latina and African American women. In most cases, men are the perpetrators and women, victims. Collins (2005) also highlights that although IPV affects all women, its prevalence is much higher among women of color especially Black women, who suffer this violence at a twenty-five percent higher rate than White women. The use of severe violence within intimate partner relationships usually through control, termed "intimate terrorism," - is more often than not carried out by men against women with dire consequences inflicted on the women (Johnson, 2006; Johnson \&Leone, 2005).

Although IPV with its negative consequences continues to persist among women of color, it seems the problem has not received the needed attention required to deal with the problem effectively and efficiently, hence the focus of this study on women of color. In spite of the growing attention given to IPV as a social problem, there continues to be a lack of greater concentration on the issue by health professionals and the criminal justice agents (Potter, 2008). There seem to be differences in the ways that services are provided to victims of color. Many women of color perceive the services provided by governmental agencies, criminal justice agencies and non-profit organizations as unable to provide for their needs as victims of IPV (Lichtenstein \& Johnson, 2009). Studies indicate that women of color are reluctant to access victim support services or even to report their abuse because of the lack faith in them. Despite the prolonged existence of IPV among women of color, there is still a reluctance especially, on the part of Black women to access help. For example, they lack faith in their religious leaders whom they fear will spread rumors about their experiences around the community and may not be able to sympathize with them (Lichtenstein \& Johnson, 2009). 
Additionally, women of color believe the non-religious services established to cater for their needs as victims, lack the necessary resources and personnel. Many of these agencies for example, do not employ women of color hence, women of color may not believe they can relate to workers who are from a different racial or ethnical background, due to the belief that they cannot understand their culture (Bent-Goodley, 2004; Nash, 2005; Taylor, 2005; Few, 2005). Victims of color also believe that racially diverse staff are most of the time unable to understand the challenges they encounter (Gillum, 2008b, 2009; Laughon, 2007). This shows the disparities existing in the ways that women of color experience IPV and the need for us to examine these unique experiences from an intersectional approach.

Multiple and diverse theories have emerged to explain this act of violence against women and especially women of color. One such theory is intersectionality which was developed to aid in the explanation and understanding of the occurrence of IPV among women of color. The theory of intersectional comes from the contributions of Black feminist scholars and argues that various structural forms of oppressions and racism affect both Black women and men simultaneously unlike White women (Thomas, 2018). For this study, an intersectional theoretical approach will be used towards the understanding of IPV, and victims support services in relation to women of color. In examining and understanding violence against women, the elimination of the various differences that prevails with "identity politics" is somewhat deceptive being that violence suffered by women may be shaped by numerous factors of their identity, such as their race, immigration status, and socioeconomic background (Crenshaw, 1991). Women's daily life experiences results from a combination of factors that interlock to create those unique occurrences. It is of relevance then, that the issue of IPV be explained and understood in the context of varying elements such as gender, race, sexual orientation, among others that intersect to produce the unique experiences of 
women. As stated by Crenshaw (1991), ignoring the different parts of an individual's identity and its influence on their experiences may cause tension between them and other members of their group. For example, when a subset within a larger group realizes that the problems or experiences confronting members of the group are treated differently based on a number of things such as the exclusion of the multiple identities that interlock to create their unique circumstances with those problems, it may lead to some form of friction between members of the group. For women of color, the constant disregard for the IPV carried out against them by the society has led to some form of bitterness not only towards the larger female group of which they are members of, but the society in general.

\section{Problem statement}

IPV is a public health and sociocultural problem that affects women all around the world, however the violence suffered by women of color at the hands of their intimate partners seems to receive less attention than needed. Regardless of the higher number of women who suffer IPV according to surveys and arrests records, this subgroup of women seems to be ignored as a group. Potter (2008) suggests that women of color are usually overshadowed and paid no attention to,

mostly as a result of their gender, race, victim statuses and class, and their experiences with violence and abuse are usually not seen by the society. Even though there is a considerable increase in the rates at which women of color experience IPV as indicated by variety of studies, the exiting theories, strategies, and services created to help ameliorate the problem are limited (Potter, 2008). As Potter (2008) highlights, albeit the fact that women of color; Black, Latina and others, continue to be exposed to racism, discrimination, and sexism differently than White women and Black men, there are still limits in the ways that theories and practices have been set up to examine and help understand violence and/or abuse suffered by women as women are constantly treated as a 
homogenous group. The various theories and practices that have emerged over time have failed to understand that the experiences of a victim of color are most of the time very different from those of their fellow White women due to the numerous identities that converge to produce these encounters.

With the realization of IPV as a social phenomenon came with it multiple studies and policies to help find resolutions to the problem, and to help victims to access remedies and services, yet these studies and policies only served the interests of a portion of women, leaving out the rest. Both research and responses to IPV have not provided enough attention and consideration to the cultural, ethnic, and racial differences that exist among victims of IPV. Many of the studies and strategies consider women victims as having similar experiences, forgetting that Black women and other women of color have life experiences separate from White women (Potter, 2008). Over centuries now, programs designed to dismantle IPV has grown nation-wide, however, it seems there continues to be gaps in service provision programs, especially for the most marginalized and vulnerable of the female population (Kulkarni, 2019). Many services provided by the criminal justice system and other non-governmental agencies, have been criticized by victims of color as lacking the resources that are geared towards their needs as victims of color. Services are centered on just an aspect of their identity-their gender without regarding the multiplicity of factors such as race, immigration status, sexual orientation, and culture, which are all factors involved in shaping their experiences.

A pilot study was conducted to examine website contents of three victim support services available to abused women in Davenport, Scott County and Des Moines, Polk County, each located in the state of Iowa. Google and Microsoft Edge search engines were used to look for organizations and institutions that offer services, and search phrases such as "victim support services" and 
"domestic violence shelters" were input into the search engines. This produced a number of victim support services within the cities. Their websites were then critically analyzed for language, texts, types of services provided, and information provided. Results showed that the images used were mostly that of white women and children although a few of them of women of color, specifically African American women. Portraits of White women and children were rather large whereas those representing people of color seemed rather miniature. Information on the websites is only spelled out in English with no other kind of language used. Words such as "diversity," "trans men/women," "immigrants," "culturally inclusive" and "inclusion" were found on the websites indicating that service provision was inclusive of all. Additionally, almost all of the websites had services centered on victims/survivors of IPV. These findings suggest there is a need for some improvements in various websites of victim-support services.

The importance of examining the services provided to victims and survivors of color through the lens of intersectionality theory cannot be denied. Knowledge and the understanding gained through this will help to bring more attention to the need for policies, strategies and skills used in the provision and delivery of services to be revisited, and restructured to encompass policies, skills and strategies that will be beneficial to women of color whilst also considering the different identities and structures that interlock to produce the distinctive experiences of victims and survivors of IPV. Additionally, the study will highlight how representative and relatable advertised services are to women of color. This study seeks to build from the existing gaps and to address the differences existing in the services provided to victims and survivors of color nationwide. 


\section{Research Questions and Objectives}

My research question is: How inclusive are the websites of victim support services of women of color? Specifically, the study seeks to answer the questions; (1) Is the language used indicative of inclusivity of women of color? (2) How deeply embedded on the website is the information on survivors of color? (3) Is the visual content such as images used on the websites of victim support services consistent with inclusivity?

The main objective of this study is to examine the websites of services that are available to women who have experienced IPV or are continually experiencing it to determine how inclusive the available services are for women of color, as well as to make suggestions on how these can be improved. To answer the research question, an extensive qualitative content analysis of victims' support services websites from eight different randomly selected states to ascertain whether they are representative and inclusive of victims and survivors of color as well as the types of services they provide and how inclusive they are. Language, images, texts content regarding services and information found on the selected websites are some of the things that will be examined to determine how inclusive they are of women of color. 


\section{CHAPTER II: LITERATURE REVIEW}

\section{Intimate Partner Violence}

Women worldwide continue to experience various forms of violence and abuse ranging from sexual violence to intimate partner abuse. "Violence against women (VAW) over the years has been recognized as a global and complex problem that challenges justice systems, policymakers, service providers, community leaders, activists, families, and individuals concerned with both preventing and responding to it" (Gardsbane et. al, 2020, pp.2). Intimate partner violence (IPV), a form of violence against women, has been labeled one of the most pervasive human rights issues and public health concerns. About thirty percent of women worldwide have been victims of IPV (WHO, 2013). IPV is defined as a pattern of behavior by a current or former intimate partner encompassing a number of forms of abuse or violence including, but not limited to, physical, emotional, and sexual abuse as well as stalking (Centers for Disease Control and Prevention, 2014). The WHO (2010) also defines it as any form of behavior that occurs within an intimate relationship and which causes sexual, psychological, or physical trauma or harm. These acts may include physical aggression, psychological abuse, controlling behaviors as well as sexual violence.

Studies suggests that IPV continues to prevail worldwide despite attempts by governments, policymakers, organizations, among others to end or ameliorate the issue. As highlighted by Ler, Sivakami, and Monárrez-Espino (2020), IPV is a pressing public health issue that has become pervasive. According to the United Nations, a woman's home is the most dangerous place for her to be (UNDOC, 2018). In the year of 2018, an estimated fifty-eight percent out of the eight hundred and seven thousand women killed were murdered by their intimate partners or family members (UNDOC, 2018). Furthermore, before the COVID-19 pandemic, about two hundred and fortythree million women and girls between the ages of fifteen and forty-nine years around the globe 
were victims of sexual and physical abuse perpetrated by their intimate partners. An estimated seven hundred and thirty-six million women, that is one in three women globally, are abused sexually and physically by an intimate partner or sexually abused by a non-partner. (UN Women, 2020; World Health Organization, 2021). Reports emanating from various Asian countries shows that about twenty-one to fifty-one percent of Asian women have suffered IPV (Facts \& Stats Report, 2015). Approximately, thirty percent of married women in China have been subjected to abuse by their intimate partners (Wang, 2014). A study conducted in Ghana revealed that between the period of 2010-2012, an estimated forty-six out of the fifty-two reported cases of spousal murders were perpetrated against women (Human Rights and Advocacy Center, 2012). Additionally, eighty-one percent of women in Canada were reported to be victims of spousal abuse (Zhang et al., 2012).

The situation is no different in the United States of America (USA). Data from the National Intimate Partner and Violence Survey (NISVS) suggests that an estimated thirty-six percent of women and ten percent of men have suffered abuse by an intimate partner (Black et al., 2011; Burton \& Carlyle, 2020). Tjaden \& Thoenness (2000) revealed that an estimated one in four women have been victims of IPV during a point in their lifetime. National Intimate Partner and Sexual Violence Survey also showed that three out of ten women living in the USA experience some form of IPV at a point during their lifetime (NISVS, 2011). The Center for Disease Control and Prevention (CDC) has reported that one in three women in the country, that is an estimated thirty-six percent/forty-six million women suffered physical abuse, sexual abuse, and/or stalking from an intimate partner in their lifetime. Again, $36.4 \%$ or 43.5 million women reported having experienced psychological aggression from an intimate partner over their lifetime (CDC, 2017; 
2015). These numbers show how pervasive and serious IPV is all over the world and the need for drastic measures to be implemented to address it.

Indeed, IPV is a phenomenon that affects all persons regardless of age, race, religion, ethnicity, culture, economic background or immigration status. As highlighted by Johnson \& Leone (2005) and Johnson (2006), IPV affects all persons irrespective of their educational background, race, gender, sexuality, or immigration status. This form of violence can be seen in all types of relationships be it heterosexual, homosexual, committed, casual, current, or ended and may occur between adolescents or adults. And although the phenomenon affects both men and women, women are more likely to be victims and men more likely to be perpetrators. Research on IPV suggests that acts of IPV that are reported at domestic violence shelters, within the criminal justice system and in emergency departments, including others are mainly directed towards women and are usually harsh and marked by coercive control (Kelly, 2011).

\section{Effects of the Corona Virus Pandemic on IPV}

The start of the Corona Virus pandemic also known as COVID-19, has caused a spike in the number of cases involving domestic violence. The onset of the pandemic coupled with lockdown and stay-at-home orders, although advantageous from a public health point of view, also led to other negative outcomes such as an increase in IPV and child-abuse globally (Boserup et al., 2020; Piquero et al., 2021). Local police in China's Hubei province reported that IPV cases tripled in February of 2020 when compared to February of the previous year (Fraser, 2020). Additionally, the United Nations Women's entity reported that IPV cases increased in France by thirty percent after initiating lockdown in March of 2020. Argentina also recorded an increase in calls relating to IPV by twenty-five percent since their lockdown on the twentieth of March 2020. Data also 
revealed that IPV helplines in Singapore and Cyprus received about thirty-three percent and thirty percent increase in calls for help respectively (UN Women, 2020).

The USA also saw an increase in IPV related cases during the COVID-19 pandemic. Numerous studies conducted in the USA revealed an $8.10 \%$ increase rate in the country (Piquero et.al., 2021). For example, Police Bureau in Portland Oregon reported an increase in IPV-related arrests (twenty-two percent) after lockdown measures were implemented. This percentage was higher than that of prior weeks. The San Antonio Police Department also recorded an eighteen percent increase in calls related to family violence in March of 2020 which was much higher than that of March of 2019 (Portland Police Bureau, 2020; Management CoSAOoE, 2020). Again, the Jefferson County Sheriff in Alabama communicated that they county had seen a twenty-seven percent increase in IPV cases in March of 2020, which contrasted the numbers recorded for March of 2019. In the same month, the New York City Police Department also recorded a ten percent increase in calls for help with IPV cases as compared to the previous year (Money, 2020; New York City Police Department, 2020).

From March through to July of 2020, McClean County, in which Illinois State University and Bloomington-Normal are situated, saw a spike in the number of IPV cases reported. The county recorded an estimated six hundred and ninety-seven cases following the COVID-19 pandemic and implementation of lockdown measures, indicating a tripled increase in IPV related cases. Cases of severe injuries, for instance, strangulation, lacerations, and brain injuries resulting from IPV also increased (Denham, 2020). Bilyeau (2020) also highlighted that, IPV calls to the police increased at a seven-point five percent rate during the months of March, April, and May. This result was obtained from an investigation into the matter by the Council on Criminal Justice. The study compared IPV data set before the start of the COVID-19 pandemic to that of after the 
pandemic and found that the pandemic had led to a three-point five percent increase in IPV calls for help within the five weeks following social distancing orders. This numbers clearly suggests how the pandemic has increased abuse and violence perpetrated against women worldwide.

\section{Risk Factors and Negative Impacts Associated With Intimate Partner Violence}

IPV has been attributed to many risk factors by scholars and non-scholars alike. These factors include poor economic background, exposure of victims or perpetrators to abuse in childhood, stress, including other factors and can be seen at the family, individual and society level. Again, differences in power, educational background, employment/income have been identified as factors that fuel violence against women (Hatcher et al., 2013; World Health Organization, 2013). Other factors include antisocial personality disorder of the perpetrator, harmful use of alcohol, a history of child maltreatment, witnessing family violence, attitudes that create violent behavior patterns, controlling behaviors of men towards their partners, inability of partners to communicate well, societies that uphold men in higher esteem than women, including others (WHO, 2017). Women who earn low wages, have little to no education, pregnant and indigenous are reported to have a higher risk of suffering IPV (Sinha, 2015; Wathen, 2014; George, 2012).

A study conducted in India by Ler et al., (2020) showed that women who believed that men had the right to beat their wives were more likely to express IPV at a twenty-nine percent rate. Results also indicated that, women who lived in towns were one point four times more prone to IPV than those who lived in the Capital. Additionally, the researchers found that women who historically had parents who suffered or engaged from/in IPV were 2.3 times more likely to experience IPV, and women who did not have any form of education also had a higher chance of experiencing IPV. Another study conducted by Reese et.al (2021) in Tanzania indicated that power 
deferential played a role in women's experiences with IPV. For instance, women who earned income independently were less likely to experience IPV than those who did not. Again, women whose partners were the major decision-makers in the family had a higher chance of experiencing IPV than those whose partners were not.

The effects of IPV are numerous and devasting not only for the woman but the family and society as a whole. According to the World Health Organization, the negative effects of IPV includes depression, post-traumatic stress disorder, anxiety, still birth, eating disorders, miscarriages and suicide attempts (WHO, 2017). Studies have revealed that children who are exposed to IPV directly and indirectly suffer its effects. Chung and her colleagues (2021) highlight that, numerous studies have found a correlation between physical and psychological IPV and a decrease in the quality of parenting among individuals with younger children. One such study found that mothers of younger children who earned low income and experienced physical violence or abuse in the past year were harsher and more hostile towards their toddlers (Gustafsson \&Cox, 2012). Postmus and her colleagues (2012) also found an increase in the use of spanking by mothers with five years old children due to the psychological abuse they suffered. A meta-analysis of studies involving young children who were eleven years old or younger found that there was a significant association between IPV and ineffective parenting that were usually characterized by a reduction in parental-warmth, child maltreatment and a lack of interaction between parent and child (Chiesa et al., 2018).

Literature also shows that contrary to the popular belief and notion that the effects of IPV end when the victim/survivor leaves the abuser, the effects are long-lasting. Survivors have reported having a heightened level of negative consequences even long after they have left abusive relationships. These include increased risk and fear of getting killed by their abusers, harassment, 
stalking, suicidal thoughts, post-traumatic stress disorder, self-medication and depression leading to their need for social support and services (Rapp et. al, 2013; Tjaden \& Thoennes, 2000; Westbrook \& Gonzalez, 2011). Again, women who suffer IPV according to an analysis conducted by WHO in 2013 were two times more likely to develop depression and drinking problems.

\section{Intimate Partner Violence Among Women of Color in Heterosexual Relationships}

Women of color despite numerous attempts to deal with IPV and its negative consequences continue to experience increased rates of the phenomenon although their fellow white women continue to see a reduction in their rates of IPV. As highlighted by Tutty and her colleagues (2008a; 2010, p.1), "racial minority women from developing countries were reported to have a higher prevalence of violence as compared to Canadian women." Despite the decreasing rates of IPV among White women in the USA in recent years, women of color still report skyrocketing numbers of abuse and violence perpetrated by their intimate partners. Potter (2008) states that in the year 2008, data from the National Violence Against Women Survey and the NCVS disclosed that women of color, especially Black women and Native American women, continue to report the largest percentages in IPV. Caetano (2009) also disclosed that national data on male perpetrated violence against women revealed a higher percentage of the phenomena among Black and Hispanic women when compared to the rates for White women. The intimate partner violence suvery-2010 reported that forty-four percent of Black Non-Hispanic women and fifty-four percent of multiracial non-Hispanic women were more likely than not to have experienced rape, physical violence and stalking from an intimate partner during their lifetime as compared to White nonHispanic women (thirty-five percent) (Breiding et al., 2014).

On the other hand, Asian or Pacific-Highlander non-Hispanic women (twenty-five percent) were reported to be less likely to experience any of the forms of IPV when compared to white 
Non-Hispanic women (Breiding et al., 2014). Smith and colleagues (2018) have reported that a recent survey on IPV showed that non-Hispanic Black women residing in the USA go through lifetime and past years IPV at a much higher rate than their fellow white, Hispanic and Asian Pacific Highlander women. Additionally, Petrosky and his colleagues (2017) also reported that minority women of color, especially, Black non-Hispanic women and Alaska/American Indian women were victims of homicides at a higher rate than White women. These women of color made up about 4.3 and 4.4 percent out of every hundred thousand of the population who were victims of homicides with almost 55.3\% resulting from IPV. Moreover, the Bureau of Justice (2006) stated that despite the fact that IPV affects all people from all walks of life regardless of their race, age, sexual orientation, gender, and immigration status, being a woman of color increased one's chances of exposure to victimization. Truman \& Morgan (2014) also divulged that African American women are usually victims of IPV at a higher rate than that of White women.

The continual increase in the rates of IPV among women of color has been attributed to several factors, one of which is culture. Some centuries ago, IPV was treated as a phenomenon that was similar for all women irrespective of their race, educational background, financial background, and other individual-level characteristics. The traditional feminist ideology attributes the persistent abuse of women to gender inequalities and cultures that have been socially constructed and accepted respectively (Mooney, 2000; Johnson \& Dawson, 2011). It was believed that gender and cultural norms which relegated women to subordinate positions and men to superior positions, were to blame for the constant abuse of women. This is supported by Sokoloff (2008) who highlighted that feminism in the late 1960s and early 1970s explained IPV and rape as resulting from the gender inequalities and culture that had been instituted and accepted within the society. Latina women's constant exposure to IPV has been tied to their cultural norms that are 
considered as accepting of violent behavior towards women due to their subordinate position (Pearce \& Sokoloff, 2013).

On the contrary, there have been debates as to whether gender and culture are the only factors that shape women's experiences with violence. Scholars have called for an intersectional approach toward the explanation and understanding of IPV that occurs among women of color. These scholars argue that an intersectional approach to IPV will provide a multi-level analysis to the problem as it occurs among racialized minority communities (Cho et al., 2013; Sokoloff \& Dupont, 2005). Traditional factors of oppression and marginalization such as race, gender, class, and sexual orientation will not be viewed as independent, but rather as a multiplexity of factors that converge to shape and create the unique experiences of women of color. Thus, intersectionality provides the framework by which IPV is not attributed to a single factor but rather as resulting from the intersection between multiple factors such as gender inequalities and other systems of domination and oppression (Cho et al, 2013). Thus, when IPV is examined through the lens of intersectionality, it allows for the plight of women of color to be better and more deeply understood.

The experiences of women of color with IPV has been shaped by their interlocking identities within the society. The intersections of race, gender, class, and so on continue to affect women of color negatively. Prior studies have unveiled the fact that Black and minority women who find themselves at the intersections of multiple structural inequalities also face extra problems and stress that increase their risks of IPV (Patel, 2003; Thiara \& Gill; 2010). West and Johnson (2013) also state that Black women have a higher risk of violent victimization not only in an intimate relationship but also outside of it. According to Isom Scott (2018), Black women are at a higher risk for violent victimization due to structural inequalities and socialization. For example, 
women of color since centuries ago have found themselves at the bottom of the economic class and usually lack any form of class or economic privilege. As a result, women of color, most especially Black women, are reported to be the poorest in society as they lack the needed finances to cater for their needs and those of their families. Black women and other women of color face higher unemployment rates, lack of job skills, lack of permanent support from both family and friends, among other things (Crenshaw, 1991) which unfortunately exacerbates their chances of experiencing victimization whilst also forcing them to continue staying with abusive partners. This is also reiterated by Richie (2005) and Petrosky and his colleagues (2017) who postulate that poor women of color are more likely to live below the poverty line, more prone to IPV as well as social positions that are dangerous, more likely to be murdered by an intimate partner and more like to face criminalization in the society.

\section{Intimate Partner Violence Among Immigrant Women of Color}

Globalization and international trading have led to the opening of borders and economies of countries worldwide. This has led to high incidences of migration as people from all walks of life continue to seek greener pastures and protection, safety. For example, many people especially those from African countries, usually migrate to the western world in search of job opportunities. Yet, migration yields both positive and negative outcomes. One such negative outcome is IPV. Literature has disclosed that migration is one of the most prominent factors of IPV among women. Guruge and colleagues (2010) highlight that despite the challenges associated with estimating the correct prevalent rates of abuse among immigrants, studies have showed that immigrant women may experience a heightened level of violence or abuse from their partners after migration.

Research conducted in Spain found that about twenty-three percent of immigrant women in the country had suffered IPV in the previous twelve months (Vives-Cases et al., 2010). Prosman 
et.al. (2011) also divulged a high prevalence rate of IPV among some immigrant groups found in the Netherlands (37.9\%). Data from Norway also revealed that sixty-six percent of women staying in shelters are immigrants and about half of them stay with their children and may stay longer at the shelters on average than those with Norwegian background (The Norwegian Directorate for Children, Youth and Family Affairs, 2016). Park and her colleagues (2021) found a forty-one percent IPV rate among immigrant women in Canada.

Immigrants in the United States also face a higher risk of experiencing violence with its negative consequences (Murshid \& Bowen, 2018). Additional studies have revealed that IPV rates are high among Sri Lankan and Iranian immigrants at sixty-three percent and forty-three percent rates respectively (Guruge et al., 2012). Kalunta-Crumpton (2013) published that between the years two thousand and five and two thousand and eight, nine Nigerians who were immigrants were killed by their intimate partners in the USA. Three others were killed by their intimate partners between the years two thousand and ten and two thousand and fourteen (KaluntaCrumpton, 2017). Numerous researchers found that among Latina immigrants, poverty and immigration status exacerbated their chances of IPV (Gonzalez-Guarda, et al., 2011; Moreno, 2007). Also, Du Mont \& Forte (2012) found that immigrants who had spent twenty years and more in Canada are more likely than those who have spent less years in the country or those born in the country to report having experienced violence. Similar reports have been given by Miszkurka et al. (2012) who stated that long term immigrants had a higher probability of getting abused by their intimate partners. On the contrary however, statistics from Canada's self-report survey suggested that immigrants in highly industrialized nations may have lower IPV rates than Canadian-born citizens and women from developing countries (Brownridge, 2009). 
Indeed, migration has been identified as a gender phenomenon. Although both men and women equally engage in migration, men are usually the initiators of it. Women usually migrate to other countries because of their husbands or fathers (Erez, 2000). It is worth noting that the context in which migration often converge with gender ideologies where women are subordinates to further complicate their experiences with violence. Many women from Southeastern Asian and Eastern European countries for instance, usually migrate to the USA to marry men they have not met before (Erez, \& Harper, 2018). Although immigrant women may experience abuse equally as those born in the country, the added effects of being a person in a new country further compounds their suffering. Their immigrant status coupled with the interaction of other structural oppression resulting from their race, gender, culture, and ethnicity heightens their experiences with IPV ((Barberet, 2014; Erez \&Harper, 2018).

Scholars have cautioned against the simplistic examination of immigrant women's encounters with abuse. Rather, they have called for an intersectional approach to the matter as it provides a framework for an extensive analysis of the problem. According to Crenshaw (1991), intersectionality theory helps in the understanding that various social and structural factors coupled with power relations such as gender, race, immigration status and ethnicity produces oppression that affects women of color. An immigrant woman from Ghana may not only suffer structural violence as a result of her gender, race, and status, but also suffer abuse from her intimate partner. These multiple and interlocking components of the immigrant woman worsens their risks of experiencing abuse in their intimate relationships (Barberet, 2014; Erez et al., 2009; Sokoloff \& Dupont, 2005). As stated by Chiu (2017), immigration generates barriers that are social, legal, and institutional and which hinder immigrant women from accessing materials, support and the 
network needed to leave abusive relationships. It is therefore imperative that IPV among immigrant communities be explained through the lens of intersectionality.

\section{Intimate Partner Violence Among Women of Color in Same-Sex Relationships}

The scholarly research surrounding IPV has focused mainly on heterosexual relationships with less focus on same-sex relationships (Langenderfer-Magruder et al., 2015). Yet, a growing number of investigations have revealed that the phenomena is not unique to heterosexual couples and relationships. There has been an increase in the rates at which IPV occurs in same-sex relationships including bi-sexual relationships (Finneran and Stephenson 2013; Messinger 2011). Although a number of studies have reported similar rates of IPV among both heterosexual and homosexual relationships, other studies have reported that IPV rates are higher among same-sex relationships (Jones \& Raghaven 2012; Martin-Storey 2015). Investigations of IPV occurrence among sexual minorities by Martin-Storey (2015) showed that youth who identified as gay, lesbian, bi-sexual or unsure of their sexuality experienced a higher prevalence of dating violence victimization than those in heterosexual relationships.

In addition, Goldberg and Meyer (2013) found that women who identified as heterosexual has a lesser risk of experiencing abuse than those who did not. An estimated thirty-two to thirtynine percent of lesbian women reported having suffered from IPV (Goldberg \& Meyer, 2013; West, 2012). Again, Messinger (2011) disclosed that lesbian women reported physical, sexual and verbal assault at higher rates. Despite the high occurring rates of violence found in homosexual relationships, it seems that the rates for women of color in this category are much higher. A study conducted by Pittman (2020) indicated that Black queer women have a hundred and forty-eight percent higher chance of experiencing emotional abuse from an intimate partner when compared to other races. They also have a hundred and sixty-three percent chance of suffering physical abuse 
and sexual violence in an intimate relationship, a rate higher than that of other races. This was also the case for Latinx queer women in intimate relationships. The prevalent rates for physical IPV among Latinx queer women were three hundred and fifty percent more than that of their fellow heterosexual couples and almost two hundred percent more than that of Black queer women. Emotional IPV rates were also higher than that of White and Black queer women (Pittman, 2020)

The high rates of IPV among women of color in same-sex relationships has been explained as stemming from the multiplicative and interlocking identities that they face in societies. These factors include hetro-gendered norms, racism, sexual orientation, and others that intersect to create their unique experiences with violence (Furman, et al., 2017). The feelings of stigmatizing and disparagement faced by homosexual women of color provides the way for heightened risks of experiencing unsafe behaviors from their partners as they overly rely on them for support and love (Melendez \& Pinto 2007). Women of color in same-sex partnerships, particularly Black women may resort to abuse and violence as a result of the need to feel powerful. This stems from the intersecting effects of internalized heterosexism and racism that they frequently encounter in the society (Balsam, 2001, 2003; Hardesty et al. 2008; McKenry et al., 2006; Tigert, 2001). Now that the various intersectional facets of IPV have been considered, the next section will explore the topic of victim services.

\section{Online Social Support for Victims of Intimate Partner Violence}

Battered women seek helps and support from numerous avenues. Usually, support for IPV victims, either informal or formal, are delivered face to face mostly by friends, family members, and other support groups or by specialized organizations or institutions (Constantino et al., 2005; Evans \& Feder, 2015; Sullivan, 2012), yet a lack of knowledge on being a victim may prevent battered women from accessing these services. Moreover, the demand on them unfortunately out 
numbers the available resources (Council of Australian Governments, 2010; Evans \& Feder, 2015; Zink et al., 2004). Other studies have also revealed that the use of IPV screening and other safety initiatives such as distribution of paraphernalia and phone numbers for support have yielded little to no positive outcomes on the consistent occurrence of IPV (Jahanfar, 2013; Wathen \& McMillian, 2014; Houry et al, 2008). Moreover, the stigma, shame and discrimination labeled against women with abusive partners may prevent them from seeking face-to-face support (Constantino et al., 2015; Palanisamy et al., 2014). In fact, victims/survivors of violence encounter numerous obstacles in their search and access of health-related information on IPV. Their search for information is made nearly impossible as it is complicated with geographical locations, stalking by partners, safety concerns, and so on (MacGregor et al, 2014; Mason \& Magnet, 2012; Westbrook, 2012).

It is imperative that we acknowledge that the experiences of IPV and demand for support among battered women varies significantly from one individual to another. Obtaining and utilizing health information by victims and survivors of violence is highly individualized and may require a need for different information and service provision that compliment with the various phases of IPV that abused women go through (Wathen, 2012). Battered women require services and help that provide support and safety for them at every stage during their encounter with abuse (Chang et al., 2005; Wuest \& Merritt-Gray, 2001). Results from a variety of investigations on victims of abuse indicates that victims prefer services and interventions that are tailored to suit their unique needs (Merritt-Gray \& Wuest, 1995; Wuest \& Merritt-Gray, 1999).

Scholarship examining the various kinds of social support utilized by victims/survivors of IPV has reported that battered women also resort to the use of the internet and other social media outlets in seeking for help and support. Chu and colleagues (2020) highlighted that victims of IPV 
utilize different technologies in looking for help and support as well as avenues for escaping abusive relationships. These vary and includes mobile phone applications that provide information on IPV and other forms of resources that are helpful in dealing with IPV (Stortz, 2016). Other analysis of IPV by scholars has also disclosed that women between the ages of fifteen and twentyfour are high risk groups for experiencing IPV (Fairbairn, 2015; Fass et al, 2008; Sinha, 2015) and are also high user of the internet and social media among which includes web-based services via which people connect and interact with other people. The interactions may be health based and health terms such as Medicine 2.0 shows how people discusses and contribute to health-related concerns online (Perrin, 2015; Pew Research Center, 2015; Scanfeld et al, 2010). A survey distributed to professionals who work with abused women in shelters divulged that they made use of technology and the internet in helping abused women. They also ascertained that technology and the internet were valuable in helping battered women deal with IPV. They however raised concerns about its safety as the abusers may be able to use the same platform to harass their victims (Murray et al., 2015). Another study by Westbrook (2015) demonstrated that question and answer forums online were used to seek for information on IPV (legal, financial and health).

Evaluations of targeted online intervention provided to IPV victims showed they were positive alternatives of support and had the potential to overcome some of the barriers that present with accessing face-to-face interventions (Eden et al., 2015; Koziol-McLain et al., 2015, 2018; Tarzia et al., 2015; 2016; 2017a). As a matter of fact, previous studies of online support for abused women have established that the virtual space affords each person a chance to seek support from others like themselves affected by similar situations and problems most especially discrimination, stigmatization and difficulties in accessing help via face-face intervention (Rains et al., 2015; Shi \& Chen, 2014). Rempel and her colleagues (2019) also found that a majority of online 
interventions provided to IPV victims are effective in providing safety measures for those who were planning to leave, or at the critical stages of leaving an abusive relationship. On the other hand, battered women usually require support after leaving their partners as the long term of effects of abuse is usually inevitable (Wuest \& Merritt-Gray, 2001). A qualitative content analysis of thousand two hundred and twenty-nine twitter messages revealed that social media could be an appropriate alternative place for abused women to gain social support. Another qualitative content analysis of three hundred and six tweets with the hashtag \#NotOkay showed that more than half of the messages were positive in nature and provided some form of emotional and informal social support to victims (Bogen et al., 2018; McCauley et al., 2018). Chu et al, (2021), explored messages in a Chinese online support group for IPV victims found that messages provided some form of support in terms of personal experience, explanations, strategies for dealing with abuse and emotional support.

Despite the disadvantages that may arise from the use of technology on battered women such as stalking and harassment, a lot of positives outcomes also exist. For, example, when safety measures are put in place, it provides anonymity and is accessible at any point in time. This is crucial for women whose physical whereabouts are always controlled by their partners or those who feel uneasy with disclosing their abuse (Dimond et al., 2011; Mathews et al., 2017; Tarzia et al., 2017a; Woodlock, 2017). Women who are restricted as a result of their location or some form of physical disability can also benefit from the internet. Other studies have also disclosed that online interventions can provide positive support (Barrera et al., 2002; Eysenbach et al., 2004). A study examining young Australian women's view on use of technology in addressing IPV disclosed that they had positive views on it but were concerned if a website had the capacity to 
provide support with a form of human touch (Tarzia et al., 2017a). The next section will discuss the theoretical framework that will be used for this study.

\section{Theoretical Framework}

\section{Intersectionality Theory}

Intersectionality theory emerged as an attempt to show the ways in which women, especially women of color, experience situations differently as a result of the many systems that intersect or combine to shape their experiences. The theory is believed to have been propounded first by Kimberle Crenshaw (1991) who stated that the theory gives an explanation to the many ways that social identities that exist at the micro and macro levels converge to great the unique experiences that women go through. Simply put, this theory implies that we are products of different social identities and when these multiple identifies overlap at the micro and macro level,

they produce different experiences for different individuals or groups within society which may put them at an advantage or disadvantage. A poor Latina queer woman may experience IPV differently from a White Middle-Class woman as a result of her race, sexual orientation, and class.

This is also highlighted by Bowleg (2012), who points out that the theory of intersectionality suggests that the social identities of each individual (race, gender, class, etc.) are not mutually exclusive but rather dependent on each other; these social identities are complicated and combine together rather than stand alone. Collins (2000) also postulates that intersectionality recognizes the combined effects of specific forms of oppressions such as race and sexuality, immigration status and gender, that overlap with each other to produce injustices and oppression in the society. This is also highlighted by Kelly (2011) who revealed that feminist intersectionality is built on the beliefs that every social group has distinct qualities; that each person is placed in social structures that determines power relationships and that there are interplays between the 
different social identities, for instance, race sexuality and gender that sometimes produces negative effects on the wellbeing and health of an individual. Hence, to fully understand the abuse that women encounter or are subjected to, it is necessary to explore the different things that overlap to form the multiple identities of women, and which ultimately affects their experiences with IPV.

Moreover, the theory helps in better understanding of the idea that examining just an aspect of an individual's identity in an attempt to understand and solve their negative experiences such as IPV, will only lead to solutions that are half-baked and does not fully address the issue at hand. As stated by Kelly (2011: 43) on the role played by intersectionality, "the theory is a body of knowledge," with an objective of ensuring the prevalence of social justice and provides an explanation to the ways in which groups and individuals who find themselves in various oppressive positions in society such as class, immigration status, disability, among others are unable to gain equitable access to resources in the society, thereby leading to social injustices. This is also reiterated by Sokoloff (2008: 234), "looking at both the intersecting and interlocking systems of oppression heightens our awareness to the ways in which the dominant society constructs racialized communities which has implications for the gendered dynamics within those communities".

Following the globalization that the world has experienced and continues to experience, it is essential that we begin to examine the experiences of women in the larger world context. It will be worth noting to consider in this age of globalization, how the different types and levels of oppression suffered by women are influenced by the global structures and systems of political and economic forces, nationality, migrant status, and colonialism (Mohanty, 2003, 2013; Barberet, 2014). Viewing the experiences of women through a global or international lens, provides more accurate depictions on how nationality overlaps with other identities such as gender, culture, race 
and socioeconomic background, to influence women's encounters with IPV. As hinted by Beichner and Hagemann $(2016 ; 87)$, the use of the intersectionality theory to compare the experiences of women from diverse ethnic, racial, or economic backgrounds in a larger context, helps in allowing us to expand our scope outside the range of "race, class and socioeconomic status" whilst also helping in the better understanding of how some groups of women in the society are marginalized.

Despite the praise given by most scholars to intersectionality theory as providing a framework that incorporates the multiple dynamics that shape the occurrences of oppression and marginalization of some groups of people, some scholars have also levelled criticism against it. Potter (2013) elucidated that, despite the importance given by Crenshaw on the intersection of race and gender, she failed to explicitly show how nationality, sexuality, class including other identities, also add to one's experiences and thereby reducing the oppression and other experiences of Black women to only being influenced by gender and race. Critics have also revealed that Crenshaw failed to include other factors beyond race and gender that intersect to create the unique experiences of women, most especially Black women. Additionally, others have criticized Crenshaw's concept of intersectionality as failing to recognize that gender and race affects Black women's experiences differently in different time context and that what one Black woman encounters at one time will be experienced differently by one Black woman at a different time and not in the same ways. Critics have lambasted the theory again as only concentrating heavily on Black women instead of all women of color (Nash, 2008).

In response to critics, Crenshaw (2011) has elucidated that due to the fact that we all exist "within some form of "power matrix", the theory applies to us all and that intersectionality is a representation of a structure and unique arrangements such that power influences the relationship 
among and between the categories of experiences that makes it different. Swedish feminist, Nina Lykke (2011) has also indicated that there is no definite or one single definition of intersectionality but rather, it is a broad, inclusive, and open-ended theoretical tool that is useful for analysis in feminism. It is worth noting however that other scholars have adapted and expanded the theory to be applicable to other populations beyond African American women whom Crenshaw developed the theory about.

\section{Summary And Present Study}

IPV is indeed a global pandemic with dire consequences which are suffered by all, especially women of color. As this chapter details, there are many issues to consider regarding the gendered crime of IPV. This form of abuse is prevalent among women of color and is heightened by a number of things including race, gender, ethnicity, sexual orientation and class. An intersectional approach allows for researchers and scholars to better examine the numerous intersecting factors that shape the identities of women and influences their different experiences with IPV. Although multiple sources of help and support exist for victims and survivors of color, studies have revealed that the internet and social media are among the most used platforms by women suffering from abuse to look for support and resources. It may be the first point of contact for victims and survivors of IPV and hence plays an important role.

Despite the knowledge that victimization is intersectional and those intersectionalities may impact access to services, there is a dearth of literature in this area. For this reason, this study seeks to examine the online content of victim service provider websites to explore how representative they are of victims and survivors of color. The next chapter (Chapter 3) will provide a detailed overview of the methodology that will be employed in the study. 


\section{CHAPTER III: METHODOLOGY}

\section{Purpose Of The Study}

The purpose of this qualitative content analysis of victim support services websites is to examine website contents to determine how representative they are of women of color who are survivors of intimate partner violence. Precisely, the contents that were examined on the websites includes but not limited to photographs/images, language, and text/words.

\section{Research Questions}

The aim of this study is to determine how representative intimate partner violence victim support services websites are for victims/survivors of color. Specifically, the study seeks to answer the questions:

1. Is the language content indicative of inclusivity of women of color?

2. Is the visual content, such as images used on the websites of victim support services, consistent with inclusivity?

3. How deeply embedded on the website is the information on survivors of color?

\section{Hypotheses}

Hypothesis 1 (H1): The languages used on most websites will not be indicative of inclusivity women of color.

Hypothesis 2 (H2): Visual contents such as images will not be consistent with inclusivity. Hypothesis 3 (H3): Most websites will not depict diversity and inclusivity images and text on the main landing page.

\section{Study Design}

The research methodology in this study was a content analysis. This method enabled the researcher to fully understand the hidden messages behind contents that was analyzed. Content 
analysis, according to Krippendorff (1989), is one of the research methodologies that has been originally attributed to research in communications. It is also considered a methodology that is important to social science. This method is multipurpose in nature and has been used in various criminological and criminal justice studies. As a methodology applied in various research studies, content analysis lies between purely qualitative and quantitative (Kort-Butler, 2016). Moreover, its aim is to critically assess and explain data within a specific context and usually focuses on the meanings that different cultures or groups attribute to them (Krippendorff, 1989). Worth noting is the idea that communications, messages, and symbols that make up numerous webpages, books, newspapers, including others differ from observable things and events in that they provide other information aside what is seen or read; they also expose other characteristics of their producers and have different conceptual effects on their senders, receivers, and organizations for which it is intended (Krippendorff,1989).

Content analysis as a methodology is more than merely watching movies or reading stories, comic books or newspapers and reporting on it. Rather, it involves a systematic method of reading or watching stories or movies with a critical and analytical eye, moving beyond what is merely presented or seen and searching for the deeper meanings and messages conveyed to media consumers (Kort-Butler, 2016). Using a qualitative content analysis provided an opportunity and framework within which the researcher was able to determine how symbolic the websites of victim support services are of victims/survivors of colors. Usually, a qualitative content analysis is used to interpret content made up of text data through categorization, coding and identifying of themes and patterns from a subjective point of view (Hsieh and Shannon, 2005). According to Schreier (2012), qualitative content analysis is a suitable method that can be used to anatomize and explain 
short response data sets. The researcher employed an inductive approach in analyzing data set to allow categories and subcategories to be created from the data sets (Kondracki et al. 2002).

\section{Sampling Of Data}

According to Krippendorff (1989), the unitizing stage of content analysis involves definition and identification of units of analysis within the available data. The researcher defined and identified specific unites relevant to the study. This allowed for a more quality data set which was used to answer each research question. A non-probability sampling method, specifically the availability/convenience sampling method was used in collecting data. A non-probability sampling method was appropriate for this study because it is usually used for preliminary and/or exploratory studies (Bachman et.al., 2017). The researcher first randomly selected two states from each of the four geographic regions identified by the United States Census. These regions include the Midwest, Northeast, South and West. The rationale for including states from each of the geographical regions is to seek representativeness of the nation. From each of the eight selected states, two counties were randomly selected to ensure representativeness.

\section{Data Sampled}

Two states were randomly selected from the Northeast, Midwest, South and West regions in other to have a more representative sample. The states of South Dakota and Nebraska were chosen from Midwest, Maryland and Kentucky from the South, New York and Rhode Island from the Northeast and finally Colorado and Connecticut from the West regions respectively bringing the total number of sampled states to eight. Five victim support services websites were then randomly selected from each of the selected states and contents such as images, language and services provided were critically analyzed using a qualitative content analysis. In all, a total of forty victim services websites were sampled and analyzed for the study. 


\section{Pilot Study and Procedure}

The researcher conducted a pilot study to determine the best approach for finding relevant websites for inclusion in the study. As a first step, the researcher assessed two county maps of the state of Iowa which were randomly selected. This convenience sample approach generated the city of Des Moines in Polk County and the city of Davenport in Scott. Google and Microsoft Edge search engines were then used to search for victim support services located within the selected cities. Search terms such as "victim support services" and "domestic violence support services" were input into the two search engines which yielded some results. The search was done until all the terms led to no new services. Searches involving counties and cities did not yield many results. However, searches involving the whole state provided considerable results as many of the web addresses and/or names of the various victims' support services included the state. Three victim support services were randomly selected from those found using the state. Photographs, language, words, number of clicks/scrolls before one can assess an image of a person of color as well as number of clicks needed before accessing page for services for victims/survivors of IPV, and other content were scrutinized and examined.

Based on the pilot test yielding results suggesting that city- and county-wide resource websites are not likely, the researcher randomly sampled five victim support services websites from each of the randomly selected states. This resulted in approximately forty victim support services websites in total. Keywords such as "domestic abuse shelters," "victim support services," and "intimate partner abuse resource centers" was used to find victim support services located in the selected states on the internet. Next, the content on the page was thoroughly and efficiently analyzed as the researcher evaluated images, texts, language contents and information provided. Websites that provide some form of help to victims/survivors of abuse was included in the study 
and those that do not provide any form of service to victims/survivors of abuse was excluded from the study. To ensure that the data is usable and of good quality, the researcher investigated the various websites of the selected victims support services and programs for its provision of authenticity and inclusion of service provision for survivors and victims of abuse.

\section{Measures/Coding}

Coding has been described by Krippendorff(1989) as a stage within content analysis where the researcher gives a description of the units of analysis or categorizes them into themes or construct selected for the purpose of the study. Variables that were collected from the various websites were coded into different categories.

The following measures were gathered from the data:

- States: States selected were categorized under the four regions named by the US Census Bureau.

- General Content: This variable refers to all the information provided on the websites. Information provided on the selected websites was analyzed.

- Language content: This variable refers to the language in which the websites content or information provided are published and indicates a capability for interaction and participation among website users with diverse background. Language used was analyzed to determine how inclusive it is of women of color.

- Images/Photographs: This variable refers to any portraits that are shown on the websites. The sizes of the various images shown on the websites were compared and number of images shown were recorded as well.

- Words/Texts: Word/text on the website was examined to determine how inclusive they are. 
- Clicks: This focused on the number of clicks/scrolls it took to see an image of a woman of color as well as service provision targeted towards victims/survivors of IPV.

- Location of Victim Support Services: Victim support services were categorized according to where they are found within the state.

\section{Measurement Of Hypotheses}

Hypothesis 1 (H1): The languages used on most websites will not be indicative of inclusivity women of color.

The data that was used to examine hypothesis (1) was based on the type of language recorded from the webpages. The type of language used on the websites was recorded to capture whether they depicted inclusivity of women of color. For instance, each of the respective webpage directories were coded to capture whether the English language was the only language represented on the site. Other information that instructed the client to language or interpretation services, was coded and the specific language(s) was recorded.

Hypothesis 2 (H2): Visual contents such as images will not be consistent with inclusivity. This hypothesis was tested with data recorded for all the pages found within the websites. All images presented on the website were noted in a way that showed whether it was consistent with inclusivity. Number of portraits depicting a survivor of color were noted and later compared with those of white women to see how frequently they appeared on each page of the website. Additional information was documented if present.

Hypothesis 3 (H3a): Most websites will not depict diversity and inclusivity images and text on the main landing page.

H3b: If there are images of people of color, they will be less prominent and appear smaller than the images of other people. 
The data used to examine hypothesis 2 was based on the content recorded for the main landing page of the website. All of the images and language content displayed on the website were recorded in a way to capture how embedded they were. For example, in the table of content for each website, an image on the main landing page of the content was labeled as a zero location (since it required no additional mouse clicks to view it). A description of the image was also recorded, as well as the approximate size of the image. The same procedure was used for text/word content on landing pages. The main content was given a location number, description, and any other important notes were documented.

\section{Reliability}

According to Cravens and her colleagues (2015), no specific criteria exist for assessing the trustworthiness of qualitative content analysis. However, Cho and Lee (2014) recommend that studies involving qualitative analysis make use of the general guidelines suggested for qualitative studies which will help to enhance the reliability of content analysis. Reliability is obtained by choosing a well-established methodological approach and ensuring that all the procedures within that methodology are followed precisely. To ensure the creditably and reliability of this study, the researcher followed Mayring's (2000) procedures for qualitative content analysis accurately by making sure that each of the steps were carried out during each stage (organization, coding, reporting, preparation, and others) with specificity and to its fullest potential. Multiple sources were included in the study to improve trustworthiness and richness of data set and results. Categories that emerged during the development of codes were analyzed and those that needed modification were refined to guarantee that the data sets related to the study objectives thereby reducing the likelihood of misrepresentation (Cho \& Lee, 2014). 


\section{CHAPTER IV: RESULTS}

This study sought to examine how representative websites of victim service organizations are of women of color. The three objectives of the study were to (1) To examine whether the language used on the various websites will be indicative of inclusivity of women of color. (2) To examine whether visual contents on the websites were consistent with inclusivity. (3) To see whether the websites depicted inclusivity and diversity through images and texts on the main landing page. This chapter covers findings resulting from the analysis conducted on the data collected from forty victim support services websites and eight states across the four geographic regions in the United States.

\section{Census Data on Sampled States}

This study used census data collected by the US Census Bureau in 2019 to determine the percentage number of citizens found in each of the sampled states (see Table 1). South Dakota according to the census data, has an estimated population of 884,659 citizens living in the state. Out of this, $84.6 \%$ identify as White, $2.3 \%$ identify as Black/African American, $4.2 \%$ identify as Hispanic/Latino, 9.0\% identify as American Indian/Alaska Native, $0.1 \%$ identify as Native Hawaiian/Pacific Islander and $4.1 \%$ of the total population are immigrants. The state of Nebraska has an estimated total population of $1,934,408$ out of which $88.1 \%$ are White, $5.2 \%$ are Black/African American, 11.4\% are Hispanic/Latino, 1.5\% are American Indian/Alaska Native, 0.1 are Native Hawaiian/Pacific Islander and 7.2\% are immigrants. An estimated 19,453,561 people live in the state of New York. Out of the total population, Whites make up 69.6\%, Blacks/African Americans make up 17.6\%, Hispanics/Latinos make up 19.3\%, American Indians/Alaska Natives make up 1.0\%, Native Hawaiians/Pacific Islanders make up 0.1\% with immigrants making up $22.6 \%$ of the entire population. Rhode Island has an estimated population 
of $1,059,361$ with $83.6 \%$ identifying as White, $8.5 \%$ identifying as Black/African American, $16.3 \%$ identifying as Hispanic/Latino, $1.1 \%$ identifying as American Indians/Alaska Natives, $0.2 \%$ identifying as Native Hawaiians/Pacific Islanders with $13.6 \%$ being immigrants (United States Census Bureau, 2019).

In addition, Maryland has an estimated population of 6,045,680. Out of this, Whites make up 58.5\%, Blacks/African Americans make up 31.1\%, Hispanics/Latinos make up 10.6\%, American Indians/Alaska Natives make up 0.6\%, Native Hawaiians/Pacific Islanders make up $0.1 \%$ with immigrants making up $15.2 \%$ of the population. The estimated population living in Kentucky is $4,467,673.87 .5 \%$ of the population are Whites, $8.5 \%$ are Black/African Americans, $3.9 \%$ are Hispanics/Latinos, $0.3 \%$ are American Indians/Alaska Natives, $0.1 \%$ are Native Hawaiians/Pacific Islanders and $3.9 \%$ are immigrants. The estimated population for Colorado according to the census data is $5,758,736$ with Whites making up $86.9 \%$, Blacks/African Americans making up 4.6\%, Hispanics/Latinos making up 21.8\%, American Indians/Alaska Natives making up $1.6 \%$, Native Hawaiians/Pacific Islanders making up $0.2 \%$ and immigrants making up $9.7 \%$ of the estimated total population. Connecticut has an estimated population rate of $3,565,287$. Out of this $79.7 \%$ identify as White, $12.2 \%$ identify as Black/African American, $16.9 \%$ identify as Hispanic/Latino, $0.6 \%$ identify as American Indians/Alaska Natives, $0.1 \%$ identify as Native Hawaiians/Pacific Islanders and 14.6\% are immigrants (see Table 1) (United States Census Bureau, 2019).

The census data shows how diverse the populations are in the eight sampled states although a majority of the population identify as White. This shows how important it is for service provisions to be inclusive and diverse to better serve the people living in the state or the country as a whole. 
Table 1: Census Data (2019)

\begin{tabular}{|c|c|c|c|c|c|c|c|}
\hline State & $\begin{array}{l}\text { Total } \\
\text { Estimat } \\
\text { ed } \\
\text { Populat } \\
\text { ion. }\end{array}$ & $\begin{array}{l}\text { Whi } \\
\text { te } \\
(\%)\end{array}$ & $\begin{array}{l}\text { Blac/Afri } \\
\text { can } \\
\text { America } \\
\text { n }(\%)\end{array}$ & $\begin{array}{l}\text { Hispanic/L } \\
\text { atino }(\%)\end{array}$ & $\begin{array}{l}\text { American } \\
\text { Indian/Al } \\
\text { aska } \\
\text { Native } \\
(\%)\end{array}$ & $\begin{array}{l}\text { Native } \\
\text { Hawaiian/P } \\
\text { acific } \\
\text { Islander } \\
(\%)\end{array}$ & $\begin{array}{l}\text { Immigr } \\
\text { ants }(\%)\end{array}$ \\
\hline $\begin{array}{l}\text { South } \\
\text { Dakota }\end{array}$ & 884,659 & 84.6 & 2.3 & 4.2 & 9.0 & 0.1 & 4.1 \\
\hline $\begin{array}{l}\text { Nebrask } \\
\text { a }\end{array}$ & $\begin{array}{l}1,934,40 \\
8\end{array}$ & 88.1 & 5.2 & 11.4 & 1.5 & 0.1 & 7.2 \\
\hline $\begin{array}{l}\text { New } \\
\text { York }\end{array}$ & $\begin{array}{l}19,453,5 \\
61\end{array}$ & 69.6 & 17.6 & 19.3 & 1.0 & 0.1 & 22.6 \\
\hline $\begin{array}{l}\text { Rhode } \\
\text { Island }\end{array}$ & $\begin{array}{l}1,059,36 \\
1\end{array}$ & 83.6 & 8.5 & 16.3 & 1.1 & 0.2 & 13.6 \\
\hline $\begin{array}{l}\text { Marylan } \\
\text { d }\end{array}$ & $\begin{array}{l}6,045,68 \\
0\end{array}$ & 58.5 & 31.1 & 10.6 & 0.6 & 0.1 & 15.2 \\
\hline $\begin{array}{l}\text { Kentuck } \\
\mathbf{y}\end{array}$ & $\begin{array}{l}4,467,67 \\
3\end{array}$ & 87.5 & 8.5 & 3.9 & 0.3 & 0.1 & 3.9 \\
\hline $\begin{array}{l}\text { Colorad } \\
\text { o }\end{array}$ & $\begin{array}{l}5,758,73 \\
6\end{array}$ & 86.9 & 4.6 & 21.8 & 1.6 & 0.2 & 9.7 \\
\hline $\begin{array}{l}\text { Connect } \\
\text { icut }\end{array}$ & $\begin{array}{l}3,565,28 \\
7\end{array}$ & 79.7 & 12.2 & 16.9 & 0.6 & 0.1 & 14.6 \\
\hline
\end{tabular}

\section{Description Of Websites}

The eight states used in the study had varying numbers of websites out of which five were randomly sampled to be analyzed using qualitative content analysis. This yielded a total of forty websites $(n=40)$ that were included in the study (see Table 2). In terms of the total number of websites found for each state, North Dakota had 65 websites, Nebraska had 104 websites, New York had 164 websites, Rhode Island had 29 websites, Maryland had 133 websites, Kentucky had 107 websites, Colorado had 137 websites and Connecticut had 141 websites. This indicates that 
various victim service organizations that offer help to victims of abuse have websites that they use to advertise services provided at the organization to potential clientele and hence must show inclusivity of all persons regardless of race, sexual orientation, immigration status and ethnicity.

Table 2: Total Number of Websites

\begin{tabular}{lcc}
\hline State & Total No. of websites Found & $\begin{array}{c}\text { Total no. Sampled in } \\
\text { study }\end{array}$ \\
\hline South Dakota & 65 & 5 \\
\hline Nebraska & 104 & 5 \\
\hline New York & 164 & 5 \\
\hline Rhode Island & 29 & 5 \\
\hline Maryland & 133 & 5 \\
\hline Kentucky & 107 & 5 \\
\hline Colorado & 137 & 5 \\
\hline Connecticut & 141 & 5 \\
\hline
\end{tabular}

Total no. $=40$

\section{General Contents on Websites/Main Landing Pages}

General content that was found on all of the websites included information on domestic violence, types of services provided, contact information, images, exist/escape button and hotlines. The websites also had colorful background themes and words of hope, intended to motivate victims of abuse to seek help or leave their abusive situations. Testimonials also appeared on more than half of the websites. These serve as a source of inspiration for women, who may be going through abusive relationships. The main landing page of most of the websites had images, background, words of hope, statistics on domestic and sexual abuse, mission and contact information of the organizations such as email address, mailing address and location as well as emergency escape/exist buttons that allows for potential clients to safely leave the website with no traces of 
their web activities. Although the main landing page is of importance, each site also contained various tabs that opened new pages with detailed information on domestic violence, programs and services provided, how to get involved, and/or instructions for making financial donate donations to the organization. In addition, more than half of the websites provided warning information to potential clients as to how they can ensure their safety from their abusers who may be monitoring their technological usage by using the escape button or clearing their search history after visiting the website or in the event of an emergency. The next paragraphs cover hypotheses and findings that arose out of the study.

\section{Hypotheses}

Hypothesis 1 (H1): The languages used on most websites will not be indicative of inclusivity of women of color.

This hypothesis was analyzed by recording the type of language used to provide information on the website. Additional details such as information directing clients to translate into other languages other than English was also recorded. A mixture of results was obtained for this hypothesis. Findings revealed that out of the forty victim support services sampled, twentytwo of them, representing (55\%) of the websites, used English language only for providing information whereas only fifteen of the forty websites representing (37.5\%) of the total provided an option for clients to translate the respective website content into other languages. Additionally,

only three out of the forty websites, that is $(7.5 \%)$, provided information in both English and Spanish (see Table 3 for results). These findings support the hypothesis that the languages used to provide information to clients on a majority of victim service organizations' websites will not be indicative of inclusivity. 
In addition, results showed that a majority of the victim service organizations' websites only provided translation to Spanish, without the option to translate to other languages (See Table 3). There were fourteen (35\%) websites out of the forty that provided this English to Spanish option only. Only five out of the forty, that is (12.5\%) allowed for clients to translate information from English language to languages other than Spanish (e.g., Afrikaans, Yoruba, Mongolian, etc.). When available, the translation tool on the websites were located at the top of the main landing page or other pages of the website. This tab/icon was usually labelled as "select language" or "Español."

Hypothesis 2 (H2): Visual contents such as images will not be consistent with inclusivity.

This hypothesis was tested by analyzing the images on the main landing page and all subpages found within the websites. The number of images depicting survivors were coded to indicate whether the image included a survivor of color or a white survivor. The comparison of website images revealed that the majority of images were of White women and men; fewer images existed for people of color (see Table 3). Of the forty websites analyzed, twenty-three (57.5\%) had more images of white people than people of color. Ten websites (25\%) had more images of people of color than White people. Only seven of the sites (17.5\%) had equal numbers of images that contained both people of color and white persons (see Table 3 for results). Thus, it can be deduced that many victim support services websites have visual content that are not consistent with inclusivity.

Hypothesis 3 (H3a): Most websites will not depict diversity and inclusivity images and text on the main landing page.

H3b: If there are images of people of color, they will be less prominent and appear smaller than the images of other people. 
Also, of interest to this project was how deeply embedded were the images of people of color versus their white counterparts. The data used to examine hypothesis 3 was based on the content recorded for the main landing page of the website. All of the images and language content displayed on the website was recorded in a way to capture how embedded they are. For example, in the table of content for each website, an image on the main landing page of the content was labeled as a zero location (since it requires no additional mouse clicks to view it). A description of the image was also recorded, as well as the approximate size of the image. The same procedure was used for text/word content on landing pages. The main content was given a location number, description, and any other important notes was documented.

Results for the first hypothesis revealed that more than half of the websites did not depict diversity and inclusivity images and text on the main landing page. Rather than appearing on the main landing page, many of the images of people of color were one to three clicks away from the landing page. Whereas the main landing pages were usually filled with images of individuals with white skin color, images of people of color usually appeared on subpages for "how to support," "contact information," or "volunteer and internships," among others.

The main landing pages of eighteen websites, that is $(45 \%)$ had words/texts such as LGBTQ+, "race", "immigrant women", and other language denoting diversity and inclusion on the main landing page. On the other hand, a total of twenty-two (55\%) victim service organizations' websites did not have words/texts that depicted inclusivity (see Table 3). Potential clients would not observe diverse content or images on about half of the websites, as such materials are embedded and require multiple clicks (between 1 and 3) from the main landing site. Furthermore, the major language that is used to provide details on the main landing pages to potential clients of victim service organizations' websites was English language. Only a few 
provided statements in both Spanish and English language on the main landing pages or directed potential clients to translation services. The statements that were most often provided in both Spanish and English included anti-discrimination statements and information directing clients to call emergency hotlines/crises lines.

Hypothesis 3B was tested by analyzing the sizes of the images that appeared on the main landing pages of the sampled websites. Images were noted with detailed descriptions (See Codebook) and the number and perceived race/ethnicity of the people in each image was noted, where possible. Mixed results were found with regards to the sizes of the images of people depicted on the websites. Using pixels as the indicator, images were either large, miniature or medium in size and the sizes were inclusive for all persons depicted. Some photos included mixed groups of people, depicting both people of color and white people. Other photos were images that included a lone person. In addition, a few websites had blurry images of people of color that are difficult to see but a majority of the websites had clear pictures of women of color. As such, the hypothesis that the images people of color would be depicted in smaller (fewer pixel) images did not find support from the data collected.

Findings of the study revealed that more than half of victim service organizations' websites provided information in only English language with a few providing information in both English and Spanish languages and hence the hypothesis; "The languages used on most websites will not be indicative of inclusivity of women of color" was supported. In addition, results supported the hypothesis "Visual contents such as images will not be consistent with inclusivity". Visual contents found on a majority of the websites were not consistent with inclusivity; images that were found on almost half of the websites showed more white women than women of color. Furthermore, the results obtained from the study supported the hypothesis "Most websites will not 
depict diversity and inclusivity images and text on the main landing page." The languages used and the images found on the main landing page of a majority of the websites did not depict inclusivity. On the other hand, hypothesis $3 \mathrm{~b}$ did not find support from the findings. Sizes of photographs found on the various websites were either large, medium or miniature in nature and were similar for all persons depicted. Based on the overall results, it can be said that the websites of victim service organizations are not inclusive of women of color. Chapter five provides detailed discussions of findings, conclusion, limitations and recommendations.

Table 3: Content on Websites

\begin{tabular}{lll}
\hline Variables & Total No. & Percentage \\
\hline Language Used & 22 & 55 \\
English Only & 3 & 7.5 \\
English and Spanish only & 15 & 37.5 \\
English to other languages & 14 & 35 \\
English to Spanish only & 5 & 12.5 \\
$\begin{array}{l}\text { English to other languages } \\
\text { other than Spanish }\end{array}$ & \\
\hline $\begin{array}{l}\text { Visual content (images) } \\
\text { Greater no. of White people }\end{array}$ & 23 & 57.5 \\
$\begin{array}{l}\text { Greater no. of people of color } \\
\text { Equal no. of White and }\end{array}$ & 7 & 25 \\
people of color & 70 & 17.5 \\
\hline $\begin{array}{l}\text { Main Landing page } \\
\begin{array}{l}\text { Inclusivity and diversity } \\
\text { texts/words }\end{array}\end{array}$ & 18 & 55 \\
$\begin{array}{l}\text { Lack of inclusivity and } \\
\text { diversity texts/words }\end{array}$ & 22 & 45 \\
\hline
\end{tabular}




\section{CHAPTER V: DISCUSSION AND CONCLUSION}

\section{Discussion Of Findings}

Multiple sources of help and support exist for victims/survivors of abuse, yet a great number of studies (for e.g. Chu et al., 2020) have indicated that most victims/ survivors of intimate partner violence use the internet to find resources. Accordingly, victim services websites are the first point of contact for victims/survivors. These technological resources vary and includes applications on mobile phones which provide victims with various information on IPV (Stortz, 2016). Additional research on IPV also showed that online forums were used to seek details on the phenomenon (Westbrook, 2015). Moreover assessment of targeted online intervention directed towards survivors/victims of abuse by some scholars revealed that they were beneficial and provided other positive options that may overcome barriers associated with face-to-face interventions (Eden et al., 2015; Koziol-McLain et al., 2015, 2018). As shown by numerous studies, the internet may be a beneficial tool in providing resources and support to victims/survivors of abuse. It is only right that websites of victim service organizations show inclusivity and diversity.

This study provides a detailed view of victim support services websites and whether it is inclusive of women of color through a qualitative content analysis. Findings of the current study uncovered the lack of inclusivity on websites of victim service organizations in terms of language used. The major language used in the provision of details on the websites was the English language. Fewer than half of the websites provided translation from English to other languages. Moreover a few of the websites provided some statements in both English and Spanish and a few allowed for potential clientele to translate information on the website from English to other languages such as French, Arabic and Afrikaans. As suggested by prior research, IPV also affects immigrants at a 
higher rate and their experiences may be heightened by numerous factors such as their immigration status and gender (Guruge et al., 2010; Crenshaw, 1991; Barberet, 2014). Immigrants migrate to the USA from different regions and countries and hence may speak languages other than English/Spanish. As such, when information on websites is only provided in English/Spanish only, it may be an obstacle for clients that are not very familiar with the English and Spanish language and may deter them from seeking the help and support that they may desperately need.

More than half of the forty victim services websites had visual content that was not very inclusive of women of color. A large number of the websites depicted survivor/victims with white skin. Only a few had more images with women and/or men of color and just seven of the sites that is $(17.5 \%)$ had an equal number of images that contained both women of color and White women. Some of the websites also had no photographs that showed women of color; rather the images found were of White women only. This may pose a problem for prospective clientele who may be victims/survivors of color as they may feel unwelcomed to the organization. As literature has revealed, survivors/victims of color usually are unwilling in seeking help from non-religious services that have been created for their needs due to their belief that racially diverse staff are most of the time unable to understand the challenges that they encounter (Gillum, 2008b, 2009; Laughon, 2007).

Hence, a lack of representativeness of women of color on victim service organizations' websites may prevent or discourage potential clientele of color from further assessing services and programs that are beneficial and may help in dealing or preventing abuse. As studies have shown, many victims/survivors of color are reluctant to seek help and support from organizations because they believe that the service providers available in these organizations do not understand their needs due to the cultural/racial differences (Taylor, 2005; Few, 2005). Seeing fewer visual contents 
on victim service websites may cause prospective clients to feel their needs may not be catered for should they seek assistance from those organizations.

The various websites also did not have inclusive content such as words/texts and images on their main landing pages. Contents that were both visual and words/texts were mostly centered around White victims, citizens of the country and cisgender victims. The bulk of websites did not have images or words that depicted inclusivity on their main landing pages; only a few provided such contents on their main landing pages. Additionally, most of the diverse contents/images were embedded on the websites and required prospective clients to acquire such information by leaving the main landing page and moving through one, two, or three additional subpages of the website. A majority of the websites that depicted diversity and inclusivity usually did so through antidiscrimination statements and information directing clients to call emergency hotlines/crises lines.

A few of the websites included images and portraits depicting the LGBTQIA community (i.e., the rainbow flag, pride symbols) on their main landing pages. Less than half of the website also provided content on their main landing pages that indicated support of immigrant victims/survivors of abuse. As the data collected for the study indicated, a considerable number of immigrants reside in the country (for e.g., $22.6 \%$ in New York, $15.2 \%$ in Maryland and $9.7 \%$ in Colorado) (United States Census Bureau, 2019) and may require services and support as victims/survivors of abuse. Moreover, IPV equally affects women of color who are in homosexual relationships and at a higher rate than their fellow heterosexual and White counterparts (Finneran \& Stephenson 2013; Messinger 2011; Pittman, 2020) and they may also require victim support services in dealing with their abuse. This lack of inclusivity of women of color on the main landing pages of victim service organizations' websites may produce situations in which victims/survivors 
of colors may be discouraged from searching through the other pages for additional information which may be beneficial to them.

Findings of the study also overlap with prior studies (e.g. Kulkarni, 2019; Potter, 2008) which have shown that although programs and services have been established to help deal with IPV, gaps and limitations continue to be found in services and programs that are directed towards the most marginalized of the female population in this case, victims/survivors of color. As revealed by the current study, a majority of victim service organizations' websites are not very representative of women of color. This only goes to show the continual marginalization and exclusion of women of color in the society. Results from the current study seem to confirm the arguments of the theory of intersectionality which was used as a framework for the study. The theory posits that women of color, especially Black women experience IPV differently from White women as a result of multiple factors such as their race, gender and immigration status (Crenshaw, 1991) yet their experiences are not really seen and paid attention to due to their victim statuses, gender, race and class (Potter, 2008).

Kelly (2011) also reports that the theory of intersectionality provides a framework that allows for better understanding of how individuals or groups who find themselves in various oppressive positions are prevented from acquiring equitable services thereby producing social injustices in the society. To better provide services and support to victims/survivors of abuse and to avoid social injustices, there is a need for the platforms that advertise services to potential clients to ensure that their websites are representative of women of color through images, words and language used. This may help to send a message to victims/survivors of color that they are welcomed to the organization and their needs will be met. 


\section{Conclusions and Limitations}

The current study examined how representative victim service organizations' websites are of survivors of color. It was revealed that many of the websites were not very inclusive of women of color as portrayed by their visual contents. Language used in delivering information on the websites, images used on the main landing pages, as well as other subpages on the websites and the words/texts used were not consistent with inclusivity.

Despite the valuable information provided from the findings of the study on victim service organizations' websites and how inclusive they are of women of color; some limitations are noted. One such limitations is the inability to record images found on some of the websites. Some of the photographs were black and white and others were blurry in nature. This prevented the accurate description and inclusion of such images in the data as the skin color of those shown in the images could not be determined. This may have influenced the results obtained however, to prevent bias in the findings, the researcher ensured that all the images that were clear and colored were included and vividly described. Another limitation was the non-probability sampling method used in collecting the data. This may have influenced the data as some websites that may have diverse contents may have been overlooked. Further research using a probability sampling method can be conducted to measure other diverse contents that may be available on websites.

\section{Recommendations}

Victim service organizations' websites may be one of the most important tools via which victims/survivors of abuse can obtain information, help and support. The websites may also be the first point of contact for many victims/survivors of abuse. It is therefore of importance that they be designed in a way that reflects the inclusion of all victims/survivors of abuse. The language used in providing details on the websites can be more inclusive rather than not. For example, more 
languages can be made available or as an option to provide a wide array or variety of language options to survivors/victims of abuse. For example, the website for enCourage Advocacy Center (https://www.encouragecenter.org/) located in Nebraska and Urban Resource Institute (https://urinyc.org/\#) situated in New York provide an option for potential clientele to translate content on its website into numerous languages other than Spanish. The languages made available include Afrikaans, Yoruba, Latin, French and Arabic. Inclusion of multiple languages may provide a sense of belonging most especially for victims/survivors who may be immigrants or may not be familiar with the English and Spanish language. This way, they well be motivated to seek for the help and support that they need.

Furthermore, the websites of victim support services can show more inclusivity through their visual contents. Many victims/survivors may be drawn to an organization or be encouraged to seek assistance from an organization located within their location if they feel more represented on the website. They may feel that their needs may be meet and understood at the organization as the visual contents provided on the website portrays some form of acceptance regardless of their skin color, national origin and race. For instance, Lucy's Hearth (https://www.lucyshearth.org) found in Rhode Island provided equal number of images that portrayed White women and women of color. Such representation may provide a sense of comfort for victims/survivors of abuse and may stimulate them to contact the organization for assistance.

It may also be helpful if the main landing pages of websites show more inclusivity of women of color. The main landing pages of websites acts as a first point of contact for victims/survivors and may motivate or discourage them from going through the rest of the pages on the website. Victim service organizations can include more diverse content such as images, words and/or illustrations that are representative of women of color. Victims/survivors of color 
may be immigrants or members of the LGBTQIA and hence including such diverse contents that speaks to them may go a long way of motivating them to seek help or to contact the organization for the intervention they need. 


\section{REFERENCES}

Barnett, O., Miller-Perrin, C. L., \& Perrin, R. D. (2005). Family violence across the lifespan: An introduction. Sage Publications, Inc.

Barrera, M., Glasgow, R. E., McKay, H. G., Boles, S. M., \& Feil, E. G. (2002). Do internet-based support interventions change perceptions of social support? An experimental trial of approaches for supporting diabetes self-management. American Journal of Community Psychology, 30(5), 637-654. https://doi.org/10.1023/A:1016369114780

Bachman, R. D., Schutt, R. K., \& Plass, P. S. (2015). Fundamentals of research in criminology and criminal justice: With selected readings. Sage Publications.

Balsam, K. F. (2001). Nowhere to hide: Lesbian battering, homophobia, and minority stress. Women \& Therapy, 23(3), 25-37. https://doi.org/10.1300/J015v23n03_03

Barberet, R. (2014). Women, crime and criminal justice: A global enquiry. Routledge.

Beichner, D. \& Hagemann, O. (2016). Incarcerated Women - Their Situation, Their Needs, and Measures for Sustainable Reintegration. In Women and Children as Victims and Offenders: BackgrounPrevention-Reintegration: Suggestions for Succeeding Generations (Pp. 85-116). Edited by Helmut Kury, Slawomir Redo, and Evelyn Shea (Editors). Switzerland: Springer International Publishing.

Bent-Goodley, T. B. (2004). Perceptions of domestic violence: A dialogue with African American women. Health \& Social Work, 29(4), 307-316.

Bilyeau, Nancy. (August 26, 2020). 'Sheltering in Place' Fueled Domestic Violence: Study. The Crime Report. 'Sheltering in Place' Fueled Domestic Violence: Study | The Crime Report 
Black, M. C. (2011). Intimate Partner Violence and Adverse Health Consequences: Implications for Clinicians. American Journal of Lifestyle Medicine, 5(5), 428439. https://doi.org/10.1177/1559827611410265

Bogen, K. W., Bleiweiss, K. K., Leach, N. R., \& Orchowski, L. M. (2019). \#MeToo: Disclosure and Response to Sexual Victimization on Twitter. Journal of Interpersonal Violence. https://doi.org/10.1177/0886260519851211

Boserup, B., McKenney, M., \& Elkbuli, A. (2020). Alarming trends in US domestic violence during the COVID-19 pandemic. The American Journal of Emergency Medicine, 38(12), 2753-2755. https://doi.org/10.1016/j.ajem.2020.04.077

Bowleg, L. (2012). The problem with the phrase women and minorities: intersectionality—an important theoretical framework for public health. American Journal of Public Health, 102(7), 1267-1273. https://doi.org/10.2105/AJPH.2012.300750

Breiding, M.J., Chen J., \& Black, M.C. (2014). Intimate Partner Violence in the United States 2010. Atlanta, GA: National Center for Injury Prevention and Control, Centers for Disease Control and Prevention.

Breiding MJ, Basile KC, Smith SG, Black MC, Mahendra RR. (2015). Intimate Partner Violence Surveillance: Uniform Definitions and Recommended Data Elements, Version 2.0. Atlanta (GA): National Center for Injury Prevention and Control, Centers for Disease Control and Prevention

Brownridge, D. A. (2009). Violence against women: Vulnerable populations. Routledge.

Burton, C. W., \& Carlyle, K. E. (2020). Increasing Screening for Intimate Partner Violence and Reproductive Coercion: Understanding Provider Motivations. Violence Against Women. https://doi.org/10.1177/1077801220969875 
Bureau of Justice Statistics. (2006). Intimate partner violence in the U.S. May 11, 2016. http://www.bjs.gov/content/intimate/victims.cfm.

Centers for Disease Control and Prevention. (2014). Intimate partner violence: Definitions. https://www.cdc.gov/violenceprevention/intimatepartnerviolence/index.html\#: :text=Intim ate\%20partner\%20violence\%20(IPV)\%20is,or\%20former\%20partner\%20or\%20spouse

Center for Disease Control and Prevention. (2015). National Intimate Partner and Sexual Violence Survey: 2015 Data Brief - $\quad$ Updated Release. https://www.cdc.gov/violenceprevention/pdf/2015data-brief508.pdf

Center for Disease Control and Prevention. (2017). Findings from the National Intimate Partner and Sexual Violence Survey. 2010-2012 State Report. https://www.cdc.gov/violenceprevention/pdf/NISVS-StateReportFactsheet.pdf

Chang JC, Cluss P a. A, Ranieri L, Hawker L, Buranosky R, Dado D, McNeil M, Scholle SH. (2005). Health care interventions for intimate partner violence: what women want. Women's Heal Issues, 15(1):21-30. doi: 10.1016/j.whi.2004.08.007.

Chiesa, A. E., Kallechey, L., Harlaar, N., Rashaan Ford, C., Garrido, E. F., Betts, W. R., \& Maguire, S. (2018). Intimate partner violence victimization and parenting: A systematic review. Child Abuse \& Neglect, 80, 285-300. https://doi.org/10.1016/j.chiabu.2018.03.028

Chiu, T. Y. (2017). Marriage migration as a multifaceted system: The Intersectionality of Intimate Partner Violence In Cross-Border Marriages. Violence Against Women, 23(11), 1293-1313 https://doi.org/10.1177\%2F1077801216659940

Cho, S., Crenshaw, K. W., \& McCall, L. (2013). Toward a field of intersectionality studies: Theory, applications, and praxis. Signs, 38(4), 785-810. https://doi.org/10.1086/669608 
Cho, J. Y., \& Lee, E. (2014). Reducing Confusion about Grounded Theory and Qualitative Content Analysis: Similarities and Differences. The Qualitative Report, 19(32), 1-20. https://doi.org/10.46743/2160-3715/2014.1028

Chung, G., Jensen, T. M., Parisi, A., Macy, R. J., \& Lanier, P. (2021). Impact of Intimate Partner Violence on Parenting and Children's Externalizing Behaviors: Transactional Processes Over Time. Violence Against Women. https://doi.org/10.1177\%2F1077801220985125

Chu, T. H., Su, Y., Kong, H., Shi, J., \& Wang, X. (2021). Online social support for intimate partner violence victims in China: quantitative and automatic content analysis. Violence Against Women, 27(3-4), 339-358. https://doi.org/10.1177\%2F1077801220911452

Hill Collins, P. (2000). Black Feminist Thought: Knowledge, Consciousness, and the Politics of Empowerment (2nd ed.). Routledge. https://doi.org/10.4324/9780203900055

Council of Australian Governments. (2010) National plan to reduce violence against women and their children 2010-2022. https://www.dss.gov.au/women/programs-services/reducingviolence/the-national-plan-to-reduce-violence-against-women-and-their-children-20102022

Constantino, R., Kim, Y. and Crane, P.A. (2005) Effects of a social support intervention on health outcomes in residents of a domestic violence shelter: a pilot study. Issues in Mental Health Nursing, 26, 575-590. https://doi.org/10.1080/01612840590959416

Crenshaw, K. (1991) Mapping the Margins: Intersectionality, Identity Politics, and Violence against Women of Color. Stanford Law Review, 43, 1241-1299. http://dx.doi.org/10.2307/1229039 
Denham, Ryan. (2020, September 14). Pandemic brings More Domestic Violence to B-N- And More Serious Cases Too. WGLT.org. https://www.wglt.org/show/wglts-sound-ideas/202009-14/pandemic-brings-more-domestic-violence-to-b-n-and-more-serious-cases-too

Dimond, J. P., Fiesler, C., \& Bruckman, A. S. (2011). Domestic violence and information communication technologies. Interacting With Computers, 23(5), 413-421. https://doi.org/10.1016/j.intcom.2011.04.006

Du Mont, J., \& Forte, T. (2012). An exploratory study on the consequences and contextual factors of intimate partner violence among immigrant and Canadian-born women. BMJ Open, 2(6). http://dx.doi.org/10.1136/bmjopen-2012-001728

Eden, K.B., Perrin, N.A., Hanson, G.C., Messing, J.T., Bloom, T.L., Campbell, J.C. and Glass, N. (2015) Use of online safety decision aid by abused women. American Journal of Preventive Medicine, 48, 372-383. https://doi.org/10.1016/j.amepre.2014.09.027

Erez, E. (2000). Immigration, culture conflict and domestic violence/woman battering. Crime $\begin{array}{llll}\text { Prevention and } \quad \text { Community 27-36. } & \text { 2(1), }\end{array}$ https://doi.org/10.1057/palgrave.cpcs.8140043

Erez, E., Adelman, M., \& Gregory, C. (2009). Intersections of immigration and domestic violence: Voices of battered immigrant women. Feminist Criminology, 4(1), 32-56. https://doi.org/10.1177\%2F1557085108325413

Evans, M. and Feder, G. (2015) Help-seeking amongst women survivors of domestic violence: a qualitative study of pathways towards formal and informal support. Health Expect., https://doi.org/10.1111/hex.12330 
Eysenbach, G., Powell, J., Englesakis, M., Rizo, C., \& Stern, A. (2004). Health related virtual communities and electronic support groups: systematic review of the effects of online peer to peer interactions. $B M J, 328(7449), 1166$. https://doi.org/10.1136/bmj.328.7449.1166

Facts \& Stats Report. (2015, July 5). Domestic violence in Asian \& Pacific Islander homes. https://s3.amazonaws.com/gbv-wp-uploads/wp-content/uploads/2018/12/05001647/FactsStats-Report-DV-API-Communities-2015.pdf

Fairbairn, J. (2015). Ecologies of Change: Violence Against Women Prevention, Feminist Public Sociology, and Social Media (Doctoral dissertation, Carleton University).

Finneran, C., \& Stephenson, R. (2013). Intimate partner violence among men who have sex with men: A systematic review. Trauma, Violence, \& Abuse, 14(2), 168-185. https://dx.doi.org/10.1177\%2F1524838012470034

Fass, D. F., Benson, R. I., \& Leggett, D. G. (2008). Assessing prevalence and awareness of violent behaviors in the intimate partner relationships of college students using internet sampling. Journal of College Student Psychotherapy, 22(4), 66-75. https://doi.org/10.1080/87568220801952248

Fraser, E. (2020). Impact of COVID-19 pandemic on violence against women and girls. UKAid VAWG Helpdesk Research Report, 284.

Furman, E., Barata, P., Wilson, C., \& Fante-Coleman, T. (2017). "It's a gap in awareness": Exploring service provision for LGBTQ2S survivors of intimate partner violence in Ontario, Canada. Journal of Gay \& Lesbian Social Services, 29(4), 362-377. https://doi.org/10.1080/10538720.2017.1365672 
Gardsbane, D., Bukuluki, P., \& Musuya, T. (2021). Help-seeking within the context of patriarchy for domestic violence in urban Uganda. Violence Against Women, https://doi.org/10.1177\%2F1077801220985943

George, J. A. (2012). Intimate partner violence (IPV) and the social determinants of Aboriginal peoples' health: a case study of First Nations women's resilience, resistance, and renewal. Electronic Thesis and Dissertation Repository.794. https://ir.lib.uwo.ca/etd/794

Gelles, R. J. (1997). Intimate violence in families (3rd ed.). Sage. https://doi.org/10.1002/cbm.274

Goldberg, N. G., \& Meyer, I. H. (2013). Sexual orientation disparities in history of intimate partner violence: Results from the California Health Interview Survey. Journal of Interpersonal Violence, 28(5), 1109-1118. https://doi.org/10.1177\%2F0886260512459384

Gonzalez-Guarda, R. M., Vasquez, E. P., Urrutia, M. T., Villarruel, A. M., \& Peragallo, N. (2011). Hispanic women's experiences with substance abuse, intimate partner violence, and risk for HIV. Journal of Transcultural Nursing, 22(1), 46-54. https://doi.org/10.1177/1043659610387079

Gosselin, D. K. (2000). Heavy hands: An introduction to the crimes of domestic violence. PrenticeHall.

Gillum, T. (2008b). Community response and needs of African American female survivors of domestic violence. Journal of Interpersonal Violence, 23, 39-57. https://doi.org/10.1177\%2F0886260507307650

Guruge, S., Khanlou, N., \& Gastaldo, D. (2010). Intimate male partner violence in the migration process: Intersections of gender, race and class. Journal of Advanced Nursing, 66(1), 103113. https://doi.org/10.1111/j.1365-2648.2009.05184.x 
Guruge, S., Roche, B., \& Catallo, C. (2012). Violence against women: an exploration of the physical and mental health trends among immigrant and refugee women in Canada. Nursing Research and Practice, https://doi.org/10.1155/2012/434592

Gustafsson, H. C., \& Cox, M. J. (2012). Relations among intimate partner violence, maternal depressive symptoms, and maternal parenting behaviors. Journal of Marriage and Family, 74(5), 1005-1020. https://doi.org/10.1111/j.1741-3737.2012.01010.x

Hardesty, J. L., Oswald, R. F., Khaw, L., Fonseca, C., \& Chung, G. H. (2008). Lesbian mothering in the context of intimate partner violence. Journal of Lesbian Studies, 12(2-3), 191-210. https://doi.org/10.1080/10894160802161364

Hsieh, H. F., \& Shannon, S. E. (2005). Three approaches to qualitative content analysis. Qualitative Health Research, 15, 1277-1288. https://doi.org/10.1177\%2F1049732305276687

Hill, S. A. (2005). Black intimacies : a gender perspective on families and relationships. AltaMira Press.

Houry, D., Kaslow, N. J., Kemball, R. S., McNutt, L. A., Cerulli, C., Straus, H., ... \& Rhodes, K. V. (2008). Does screening in the emergency department hurt or help victims of intimate partner violence? Annals of Emergency Medicine, 51(4), 433442.http://dx.doi.org/10.1016/j.annemergmed.2007.11.019

Human Rights and Advocacy Center. (2012). Deadly relationships and toxic bonds: Spousal murders and rival killings in Ghana. http://www.hracghana.org/wpcontent/uploads/2012/11/Deadly-Relationships-and-Toxic-Bonds-With-Cover.pdf 
Isom Scott, D. A. (2018). Disentangling the impact of female victimization across racial and ethnic $\begin{array}{lllll}\text { lines. } & \text { Victims }\end{array}$ https://doi.org/10.1080/15564886.2018.1468369

Jahanfar S, Janssen PA, Howard LM, Dowswell T. (2013). Interventions for preventing or reducing domestic violence against pregnant women. Cochrane Database Syst Rev, (2):CD009414. doi:10.1002/14651858.CD009414.

Johnson, Michael. (2006). Conflict and Control: Gender Symmetry and Asymmetry in Domestic $\begin{array}{llll}\text { Violence. } & \text { Violence } & \text { Against }\end{array}$ https://doi.org/10.1177/1077801206293328

Johnson, MP, Leone, JM. (2005). The differential effects of intimate terrorism and situational couple violence: findings from the National Violence Against Women Survey. J Fam Issues, 26, (3):322-349. https://doi.org/10.1177\%2F0192513X04270345

Jones, C. A., \& Raghavan, C. (2012). Sexual orientation, social support networks, and dating violence in an ethnically diverse group of college students. Journal of Gay \& Lesbian Social Services: The Quarterly Journal of Community \& Clinical Practice, 24(1), 1-22. https://doi.org/10.1080/10538720.2011.611107

Kalunta-Crumpton, A. (2013). Intimate partner violence among immigrant Nigerian women in the United States: An analysis of internet commentaries on the murders of nine Nigerian women by their male spouses. International Journal of Law, Crime and Justice. 41. 213-232. https://doi.org/10.1016/j.ijlcj.2013.06.002

Kalunta-Crumpton, A. (2016). Attitudes and solutions toward intimate partner violence: Immigrant Nigerian women speak. Criminology and Criminal Justice. 17. https://doi.org/10.1177\%2F1748895816655842 
Kelly, U. (2011). Theories of Intimate Partner Violence: From Blaming the Victim to Acting Against Injustice Intersectionality as an Analytic Framework. ANS. Advances in Nursing Science. (34). E29-51. http://dx.doi.org/10.1097/ANS.0b013e3182272388

Kort-Butler, L. (2016). Content Analysis in the Study of Crime, Media, and Popular Culture. Oxford Research Encyclopedia of Criminology. https://doi.org/10.1093/acrefore/9780190264079.013.23

Kondracki, N. L., Wellman, N. S., \& Amundson, D. R. (2002). Content analysis: Review of methods and their applications in nutrition education. Journal of Nutrition Education and Behavior, 34(4), 224-230. https://doi.org/10.1016/S1499-4046(06)60097-3

Koziol-McLain, J., Vandal, A. C., Nada-Raja, S., Wilson, D., Glass, N. E., Eden, K. B., ... \& Case, J. (2015). A web-based intervention for abused women: the New Zealand isafe randomised controlled trial protocol. BMC Public Health, 15(1), 1-8. http://dx.doi.org/10.1186/s12889015-1395-0

Koziol-McLain, J., Vandal, A. C., Wilson, D., Nada-Raja, S., Dobbs, T., McLean, C., Sisk, R., Eden, K. B., \& Glass, N. E. (2018). Efficacy of a web-based safety decision aid for women experiencing intimate partner violence: Randomized controlled trial. Journal of Medical Internet Research, 20(1), [e8]. https://doi.org/10.2196/jmir.8617

Krippendorff, K. (1989). Content analysis. In E. Barnouw, G. Gerbner, W. Schramm, T. L. Worth, \& L. Gross (Eds.), International Encyclopedia of Communication, (1): 403-407. Oxford University Press. http://repository.upenn.edu/asc_papers/226

Kulkarni, S. (2019). Intersectional trauma-informed intimate partner violence (IPV) services: Narrowing the gap between IPV service delivery and survivor needs. Journal of Family Violence, 34(1), 55-64. https://doi.org/10.1007/s10896-018-0001-5 
Langenderfer-Magruder, L., Walls, N. E., Whitfield, D. L., Brown, S. M., \& Barrett, C. M. (2016).

Partner violence victimization among lesbian, gay, bisexual, transgender, and queer youth: Associations among risk factors. Child and Adolescent Social Work Journal, 33(1), 55-68. https://doi.org/10.1007/s10560-015-0402-8

Laughon, K. (2007). Abused African American women's processes of staying healthy. Western Journal of Nursing Research, 29, 365-384. https://doi.org/10.1177\%2F0193945906296558

Ler, P., Sivakami, M. \& Monárrez-Espino, J. (2020). Prevalence and Factors Associated With Intimate Partner Violence Among Young Women Aged 15 to 24 Years in India: A SocialEcological Approach. Journal of Interpersonal Violence, 35(19-20): 4083-4116 https://doi.org/10.1177\%2F0886260517710484

Lichtenstein, B., \& Johnson, I. M. (2009). Older African American women and barriers to reporting domestic violence to law enforcement in the rural deep south. Women \& Criminal Justice, 19, 286-305. http://dx.doi.org/10.1080/08974450903224329

Lindsay, M., Messing, J. T., Thaller, J., Baldwin, A., Clough, A., Bloom, T., ... \& Glass, N. (2013). Survivor feedback on a safety decision aid smartphone application for college-age women in abusive relationships. Journal of Technology in Human Services, 31(4), 368-388. https://doi.org/10.1080/15228835.2013.861784

Management CoSAOoE. (2020). City of San Antonio and Bexar County announce stay home, work safe orders. Department of Government and Public Affairs. https://www.sanantonio.gov/gpa/News/ArtMID/24373/ArticleID/18651/City-ofSanAntonio-and-Bexar-County-announce-Stay-Home-Work-Safe-Orders [Accessed 2020]. 
Management CoSAOoE. (2020). Social distancing doesn't mean safety distancing. Department of $\begin{array}{llll}\text { Government and } & \text { Public } & \text { Affairs. }\end{array}$ gov/gpa/News/ArtMID/24373/ArticleID/18724/Social-distancing-doesn

Mayring, P. (2000). Qualitative content analysis. Forum: Qualitative Social Research, I(2). http://217.160.35.246/fqstexte/2-00/2-00mayring-e.pdf

MacGregor, J. C., Wathen, N., Kothari, A., Hundal, P. K. \& Naimi, A. (2014). Strategies to promote uptake and use of intimate partner violence and child maltreatment knowledge: An integrative review. BMC Public Health, 14, 862. https://doi.org/10.1186/1471-2458-14-862

McKenry, P. C., Serovich, J. M., Mason, T. L., \& Mosack, K. (2006). Perpetration of gay and lesbian partner violence: A disempowerment perspective. Journal of Family Violence, 21(4), 233-243. https://doi.org/10.1007/s10896-006-9020-8

Mason, C. \& Magnet, S. (2012). Surveillance Studies and Violence Against Women. Surveillance and Society, http://dx.doi.org/10.24908/ss.v10i2.4094

Matthews, T., O'Leary, K., Turner, A., Sleeper, M., Woelfer, J. P., Shelton, M., ... \& Consolvo, S. (2017). Stories from survivors: Privacy \& security practices when coping with intimate partner abuse. In Proceedings of the 2017 CHI Conference on Human Factors in Computing Systems (2189-2201).85.

Martin-Storey, A. (2015). Prevalence of dating violence among sexual minority youth: Variation across gender, sexual minority identity and gender of sexual partners. Journal of Youth and Adolescence, 44(1), 211-224. https://doi.org/10.1007/s10964-013-0089-0

Messinger, A. M. (2011). Invisible victims: Same-sex IPV in the National Violence Against Women Survey. Journal of Interpersonal Violence, 26, 2228-2243. https://doi.org/10.1177\%2F0886260510383023 
Melendez, R. M., \& Pinto, R. (2007). 'It's really a hard life': Love, gender and HIV risk among male $\square$ to $\square$ female transgender persons. Culture, Health \& Sexuality, 9(3), 233-245. https://doi.org/10.1080/13691050601065909

Merritt-Gray M, \& Wuest J. (1995). Counteracting abuse and breaking free: the process of leaving revealed through women's voices. Health Care Women Int, 16:399-412. https://doi.org/10.1080/07399339509516194

Miszkurka, M., Zunzunegui, M.V. \& Goulet, L. (2012). Immigrant status, antenatal depressive symptoms, and frequency and source of violence: What's the relationship? Archives of Women's Mental Health, 15. 387-96. http://dx.doi.org/10.1007/s00737-012-0298-7

Money, J. J. (2020). County experiencing increase in domestic violence crimes during Covid-19 pandemic. Jefferson County Sheriff's Office. https://jeffcosheriffal.com

Moreno, C. L. (2007). The relationship between culture, gender, structural factors, abuse, trauma, and HIV/AIDS for Latinas. Qualitative Health Research, 17, 340-352. https://doi.org/10.1177/1049732306297387

Mooney, J. C. (2000). Gender, violence, and the social order. MacMillan Press.

Mohanty, C. T. (2013). Transnational feminist crossings: On neoliberalism and radical critique. Signs. Journal of Women in Culture and Society, 38(4), 967-991. http://dx.doi.org/10.1086/669576

Murshid, S.N. \& Bowen, A. E. (2018). A Trauma-Informed Analysis of the Violence Against Women Act's Provisions for Undocumented Immigrant Women. Violence Against Women, 24(13): 1540-1556. https://doi.org/10.1177\%2F1077801217741991 
Murray, C. E., Chow, A. S., Pow, A. M., Croxton, R. \& Poteat, L. (2015) Domestic Violence Service Providers' Technology Readiness and Information Needs, Journal of Aggression, Maltreatment \& Trauma, 24:3, 257-278. https://doi.org/10.1080/10926771.2015.997908

National intimate partner and sexual violence survey: 2010 summary report. Retrieved from http://www.cdc.gov/ViolencePrevention/pdf/NISVS_Executive_Summary-a.pdf.

Nash, S. T. (2005). Through black eyes: African American women's constructions of their experiences with intimate male partner violence. Violence Against Women, 11, 1420-1440. https://doi.org/10.1177\%2F1077801205280272

New York City Police Department (2020). Domestic violence reports. New York City Police Department. $\quad$ https://www1.nyc.gov/site/nypd/stats/reports-analysis/ domesticviolence.page

Pew Research Center (2015). Social networking fact sheet [Internet]. Washington, DC: Pew Research Center. http://www.pewinternet.org/fact-sheets/social-networking-fact-sheet/.

Park, T., Mullins, A., Zahir, N., Salami, B., Lasiuk, G., \& Hegadoren, K. (2021). Domestic violence and immigrant women: a glimpse behind a veiled door. Violence Against Women, https://doi.org/10.1177\%2F1077801220984174

Patel, P. (2003). The tricky blue line: black women and policing. From Home Breakers to Jailbreakers: Southall Black Sisters, Zed Books, 160-87.102.

Palanisamy, B., Sensenig, S., Joshi, J., \& Constantino, R. (2014). LEAF: A privacy-conscious social network-based intervention tool for IPV survivors. In Proceedings of the 2014 IEEE 15th International Conference on Information Reuse and Integration (IEEE IRI 2014) (138146). IEEE. 
Pearce, S. C., \& Sokoloff, N. J. (2013). "This Should Not Be Happening in This Country": Private $\square$ Life Violence and Immigration Intersections in a US Gateway City. In Sociological Forum, 28, (4), 784-810.

Petrosky, E., Blair, J. M., Betz, C. J., Fowler, K. A., Jack, S. P., \& Lyons, B. H. (2017). Racial and ethnic differences in homicides of adult women and the role of intimate partner violenceUnited States, 2003-2014. MMWR. Morbidity and Mortality Weekly Report, 66(28), 741.

Perrin A. (October 8, 2015) Social Media Usage (2005-2015): 65\% of adults now use social networking sites - a nearly tenfold jump in the past decade. Pew Research Center. https://www.pewresearch.org/internet/2015/10/08/social-networking-usage-2005-2015/

Piquero, A. R., Jennings, W. G., Jemison, E., Kaukinen, C., \& Knaul, F. M. (2021). Evidence from a systematic review and meta-analysis: Domestic Violence during the COVID-19 Pandemic. Journal of Criminal Justice, 101806. https://doi.org/10.1016/j.jcrimjus.2021.101806

Pittman, D. M., Riedy Rush, C., Hurley, K. B., \& Minges, M. L. (2020). Double jeopardy: Intimate partner violence vulnerability among emerging adult women through lenses of race and sexual orientation. Journal of American College Health, 1-9. https://doi.org/10.1080/07448481.2020.1740710

Portland Police Bureau. (2020). Trends analysis: pre and post school closures. Portland Police Bureau, Strategic Services Division. https://www.portlandoregon.gov/police/article/760238

Postmus, J. L., Huang, C., \& Mathisen-Stylianou, A. (2012). The impact of physical and economic abuse on maternal mental health and parenting. Children and Youth Services Review, 34(9), 1922-1928. https://doi.org/10.1016/j.childyouth.2012.06.005

Potter, H. (2008). Battle Cries: Black Women and Intimate Partner Abuse. New York University Press. https://doi.org/10.1111/j.1741-3737.2010.00747.x 
Prosman, G. J., Jansen, S. J., Lo Fo Wong, S. H., \& Lagro-Janssen, A. L. (2011). Prevalence of intimate partner violence among migrant and native women attending general practice and the association between intimate partner violence and depression. Family Practice, 28(3), 267-271. https://doi.org/10.1093/fampra/cmq117

Rains, S. A., Peterson, E. B., \& Wright, K. B. (2015). Communicating social support in computermediated contexts: A meta-analytic review of content analyses examining support messages shared online among individuals coping with illness. Communication Monographs, 82(4), 403-430. https://doi.org/10.1080/03637751.2015.1019530

Rapp, L., Button, D. M., Fleury-Steiner, B., \& Fleury-Steiner, R. (2010). The internet as a tool for black feminist activism: Lessons from an online antirape protest. Feminist Criminology, 5(3), 244-262. https://doi.org/10.1177\%2F1557085110371634

Reese, B. M., Chen, M. S., Nekkanti, M., \& Mulawa, M. I. (2021). Prevalence and risk factors of women's past-year physical IPV perpetration and victimization in Tanzania. Journal of Interpersonal $\quad$ Violence, $\quad 36(3-4), \quad 1141-1167$. https://doi.org/10.1177\%2F0886260517738775

Rempel, E., Donelle, L., Hall, J., \& Rodger, S. (2019). Intimate partner violence: A review of online interventions. Informatics for Health and Social Care, 44(2), 204-219. https://doi.org/10.1080/17538157.2018.1433675

Richie, Beth (2005). A Black Feminist Reflection on the Antiviolence Movement. In Natalie J. Sokoloff (Ed.) (with Christina Pratt). Domestic Violence at the Margins: Readings in Race, Class, Gender \& Culture (pp. 50-55). Rutgers University. 
Scanfeld D, Scanfeld V, Larson EL. (2010). Dissemination of health information through social networks: twitter and antibiotics. Am J Infect Control, 38(3):182-88. https://doi.org/10.1016/j.ajic.2009.11.004

Saltzman, L.E., Fanslow, J.L., McMahon, P.M. and Shelley, G.A. (2002) Intimate Partner Violence Surveillance: Uniform Definitions and Recommended Data Elements (Version 1.0). Centers for Disease Control and Prevention, National Center for Injury Prevention and Control, Atlanta.

Schreier, M. (2012). Qualitative content analysis in practice. Sage publications.

Sokoloff, N. J., \& Dupont, I. (2005). Domestic violence at the intersections of race, class, and gender. $\quad$ Violence Against Women, 11(1), 38-64. https://doi.org/10.1177\%2F1077801204271476

Sokoloff, J. Natalie. (2008). Expanding the Intersectional Paradigm to Better Understand Domestic Violence in Immigrant Communities. Critical Criminology, 16: 229-255. http://dx.doi.org/10.1007/s10612-008-9059-3

Sokoloff, Natalie J. and Ida Dupont. (2013). "Domestic Violence: Examining the Intersections of Race, Class, and Gender-An Introduction.” In Natalie J. Sokoloff (ed.), Domestic Violence at the Margins: Readings on Race, Class, Gender, and Culture: (pp. 1-13). Rutgers University Press.

Shi, Jingyuan Jolie \& Chen, Liang. (2014). Social support on Weibo for people living with HIV/AIDS in China: A quantitative content analysis. Chinese Journal of Communication, 7. 285-298. http://dx.doi.org/10.1080/17544750.2014.926954

Sinha, M. (2013). Measuring violence against women: Statistical trends. Juristat: Canadian Centre for Justice Statistics, 1. 
Strauss, A. L., \& Corbin, J. (1990). Basics of Qualitative Research: Grounded Theory Procedures and Techniques. Sage.

Stortz, M. (2016, May 3). Can an app stop domestic violence? Daily Beast. https://www.thedailybeast.com/articles/2016/05/03/can-an-app-stop-domestic-violence

Sullivan, C. M. (2012). Support groups for women with abusive partners: A review of the empirical evidence. Harrisburg, PA: National Resource Center on Domestic Violence.

The Norwegian Directorate for Children, Youth and Family Affairs. (2016). Rapportering fra krisesentertilbudene 2016 [Reporting from theWomen's Shelters 2016]. Report 11/2016.

Taylor, J. Y. (2005). No resting place: African American women at the crossroads of violence. Violence Against Women, 11, 1473-1489. http://dx.doi.org/10.1177/1077801205280275

Tarzia, L., Murray, E., Humphreys, C., Glass, N., Taft, A., Valpied, J. and Hegarty, K. (2015) IDECIDE: An online intervention drawing on the Psychosocial Readiness Model for women experiencing domestic violence. Women's Health Issues, 26, 206-218. https://doi.org/10.1016/j.whi.2015.07.011

Tarzia, L., May, C. and Hegarty, K. (2016) Assessing the feasibility of a web-based domestic violence intervention using chronic disease frameworks: reducing the burden of 'treatment' and promoting capacity for action in women abused by a partner. BMC Women's Health, 16, 1-9. https://bmcwomenshealth.biomedcentral.com/articles/10.1186/s12905-016-0352-0

Tarzia, L., Iyer, D., Thrower, E. and Hegarty, K. (2017a). ‘Technology doesn’t judge you': young Australian women's views on using the internet and smartphones to address intimate partner violence. Journal of Technology in Human Services. http://dx.doi.org/10.1080/15228835.2017.1350616 
Tigert, L. M. (2001). The power of shame: Lesbian battering as a manifestation of homophobia. Women \& Therapy, 23(3), 73-85. https://doi.org/10.1300/J015v23n03_06

Thiara, R. K. and Gill, A.K. (2010), Violence Against South Asian Women: Issues for Policy and Practice. Jessica Kingsley Publishers.

Tjaden, P., \& Thoennes, N. (2000). Full report of the prevalence, incidence and consequences of violence against women. Findings from the national violence against women's survey. National Institute of Justice.

Thomas, M. Dawna. (2020). A Scholar's Reflection on Intimate Partner Violence in the Cape Verdean Community. Violence Against Women, 26, (14) :1790-1811 https://doi.org/10.1177/1077801220942845

Tutty, L. M., Giurgiu, B., Traya, N., Weaver-Dunlop, J., \& Christensen, J. (2010). Promising practices to engage ethno-cultural communities in ending domestic violence. RESOLVE, University of Calgary.

UN Women, United Nations Entity for Gender Equality and the Empowerment of Women. (2013). Ending violence against women: Passing and implementing effective law and policies.http://www.unwomen.org/en/what-we-do/ending-violence-against-women/factsandfigures

United Nations Office on Drugs and Crime. (November 25, 2018). Home, the most dangerous place for women, with majority of female homicide victims worldwide killed by partners or family, UNODC study says. https://www.unodc.org/unodc/en/press/releases/2018/November/home--the-mostdangerous-place-for-women--with-majority-of-female-homicide-victims-worldwide-killedby-partners-or-family--unodc-stud 
United Nations Women. (Monday, April 6, 2020). Violence against women and girls: the shadow pandemic. $\quad$ https://www.unwomen.org/en/news/stories/2020/4/statement-ed-phumzileviolence-against-women-during-pandemic

Vives-Cases, C., Gil-González, D., Ruiz-Pérez, I., Escribà-Agüir, V., Plazaola-Castaño, J., Montero-Piñar, M. I., \& Torrubiano-Domínguez, J. (2010). Identifying sociodemographic differences in intimate partner violence among immigrant and native women in Spain: a cross-sectional study. Preventive $\quad$ Medicine, 51(1), https://doi.org/10.1016/j.ypmed.2010.03.017

Wang, Q. (2014, November 26). Domestic violence “a social problem," not a private one. China Daily. http://www.chinadaily.com.cn/china/2014-11/26/content_18980189.htm

Wathen N. (2012). Health impacts of violent victimization on women and their children. Research and Statistics Division Department of Justice Canada.

Wathen N, MacMillan HL. (2014). Research brief: identifying and responding to intimate partner violence against women. PreVAil: Preventing Violence Across the Lifespan Research Network.

West, C. M. (2012). Partner abuse in ethnic minority and gay, lesbian, bisexual, and transgender populations. Partner Abuse, 3(3), 336-357. https://doi.org/10.1891/1946-6560.3.3.336

Westbrook, L., \& Gonzalez, M. E. (2011). Information support for survivors of intimate partner violence: Public librarianship's role. Public Library Quarterly, 30(2), 132-157. https://doi.org/10.1080/01616846.2011.575709

Westbrook L. (2012). Internet access and use in domestic violence shelters: policy, capacity, and management barriers. S. Soc Work, 13(1):30-53. https://doi.org/10.1177\%2F1468017311435184 
Westbrook, L. (2015). Intimate partner violence online: Expectations and agency in question and answer websites. Journal of the Association for Information Science and Technology, 66, 599-615. https://doi.org/10.1002/asi.23195

West, C., \& Johnson, K. (2013). Sexual violence in the lives of African American women. VAWnet.org. A project of the National Resource Center on Domestic Violence http://dx.doi.org/10.13140/2.1.3850.9444

Woodlock, D. (2017). The abuse of technology in domestic violence and stalking. Violence against Women, 23(5), 584-602. https://doi.org/10.1177\%2F1077801216646277

Truman, J. L., \& Morgan, R. E. (2014). Nonfatal Domestic Violence. US Department of Justice, Bureau of Justice Statistics. http://archive.mnadv.org/_mnadvWeb/wpcontent/uploads/2011/07/BJS-Nonfatal-DV-2003-2012.pdf

Tutty, L. M., George, D., Nixon, K., \& Gill, C. (2008a). Women's views of programs to assist them with the justice system. In J. Ursel, L. Tutty, \& J. LeMaistre (Eds.), What's law got to do with it? The law, specialized courts and domestic violence in Canada (pp. 21-45). Cormorant Press.

World Health Organization. (2010). Preventing intimate partner and sexual violence against women: Taking action generating evidence. http://www.who.int/violence_injury_prevention/publications/violence/9789241564007_eng .$p d f$

World Health Organization. (2013). Global and regional estimates of violence against women: Prevalence and health effects of intimate partner violence and non-partner sexual violence. https://apps.who.int/iris/bitstream/handle/10665/85239/9789241564625_eng.pdf. 
World Health Organization. (September 29, 2017). Violence against women. https://www.who.int/news-room/fact-sheets/detail/violence-against-women

World Health Organization. (March 9, 2021). Devastatingly pervasive: 1 in 3 women globally experience violence: Younger women among those most at risk. https://www.who.int/news/item/09-03-2021-devastatingly-pervasive-1-in-3-womenglobally-experience-violence

Wuest J, Merritt-Gray M. (2001). Beyond survival: reclaiming self after leaving an abusive male partner. Can J Nurs Res, 32(4):79-94.

Zhang, T., Hoddenbagh, J., McDonald, S., \& Scrim, K. (2012). An estimation of the economic impact of spousal violence in Canada, 2009. Department of Justice Canada.

Zink, T., Elder, N., Jacobson, J., \& Klostermann, B. (2004). Medical Management of Intimate Partner Violence Considering the Stages of Change: Precontemplation and Contemplation. Annals of Family Medicine, 2(3), 231-239. https://doi.org/10.1370/afm.74 
APPENDIX A: RAW DATA

RAW DATA (A)

\begin{tabular}{|l|l|l|l|l|l|l|}
\hline STATE & $\begin{array}{l}\text { VICTIM } \\
\text { SUPPORT } \\
\text { ORG. }\end{array}$ & LOCATION & $\begin{array}{l}\text { GENERAL CONTENT/MAIN } \\
\text { LANDING PAGE }\end{array}$ & $\begin{array}{l}\text { LANGUAGE } \\
\text { CONTENT }\end{array}$ & $\begin{array}{l}\text { DIVERSITY IN } \\
\text { WORDS/TEXTS }\end{array}$ & $\begin{array}{l}\text { NO OF CLICKS TO SEE } \\
\text { DIVERSE } \\
\text { CONTENT/INFO ON DV }\end{array}$ \\
\hline
\end{tabular}




\begin{tabular}{|c|c|c|c|c|c|c|}
\hline $\begin{array}{l}\text { South } \\
\text { Dakota }\end{array}$ & $\begin{array}{l}\text { a. } \begin{array}{l}\text { Working } \\
\text { against } \\
\text { violence } \\
\text { inc. }\end{array} \\
\text { https://Www.W } \\
\text { avi.org/ }\end{array}$ & $\begin{array}{lr}527 & \text { Quincy } \\
\text { Street, } & \text { Rapid } \\
\text { City, } & \text { SD } \\
57701 & \\
\end{array}$ & $\begin{array}{l}\text { - Information is provided on } \\
\text { hotlines to call for } \\
\text { assistance and domestic } \\
\text { abuse as well as } \\
\text { information on COVID-19 } \\
\text { are provided on the main } \\
\text { landing page. } \\
\text { - Types of services provided } \\
\text { are recorded on the main } \\
\text { landing page and a } \\
\text { welcome message and } \\
\text { details about the } \\
\text { organization is also } \\
\text { provided. } \\
\text { - A total of eight images are } \\
\text { seen on the websites. }\end{array}$ & $\begin{array}{l}\text { Information on the } \\
\text { website is provided } \\
\text { in only English } \\
\text { language with no } \\
\text { option for translating } \\
\text { into different } \\
\text { language(s). }\end{array}$ & \begin{tabular}{|lr} 
No text/words \\
exist on the page to \\
indicate inclusivity \\
of rammigrant \\
women r and \\
LGBTQ+ persons.
\end{tabular} & $\begin{array}{l}\text { For specific information } \\
\text { on domestic violence, an } \\
\text { individual first needs to } \\
\text { click on a tab labelled } \\
\text { "Are you in danger?" } \\
\text { located on the upper part } \\
\text { of the main landing page. } \\
\text { No clicks are needed to } \\
\text { see diverse images as } \\
\text { images showing women } \\
\text { of color are only on the } \\
\text { main landing page. }\end{array}$ \\
\hline
\end{tabular}




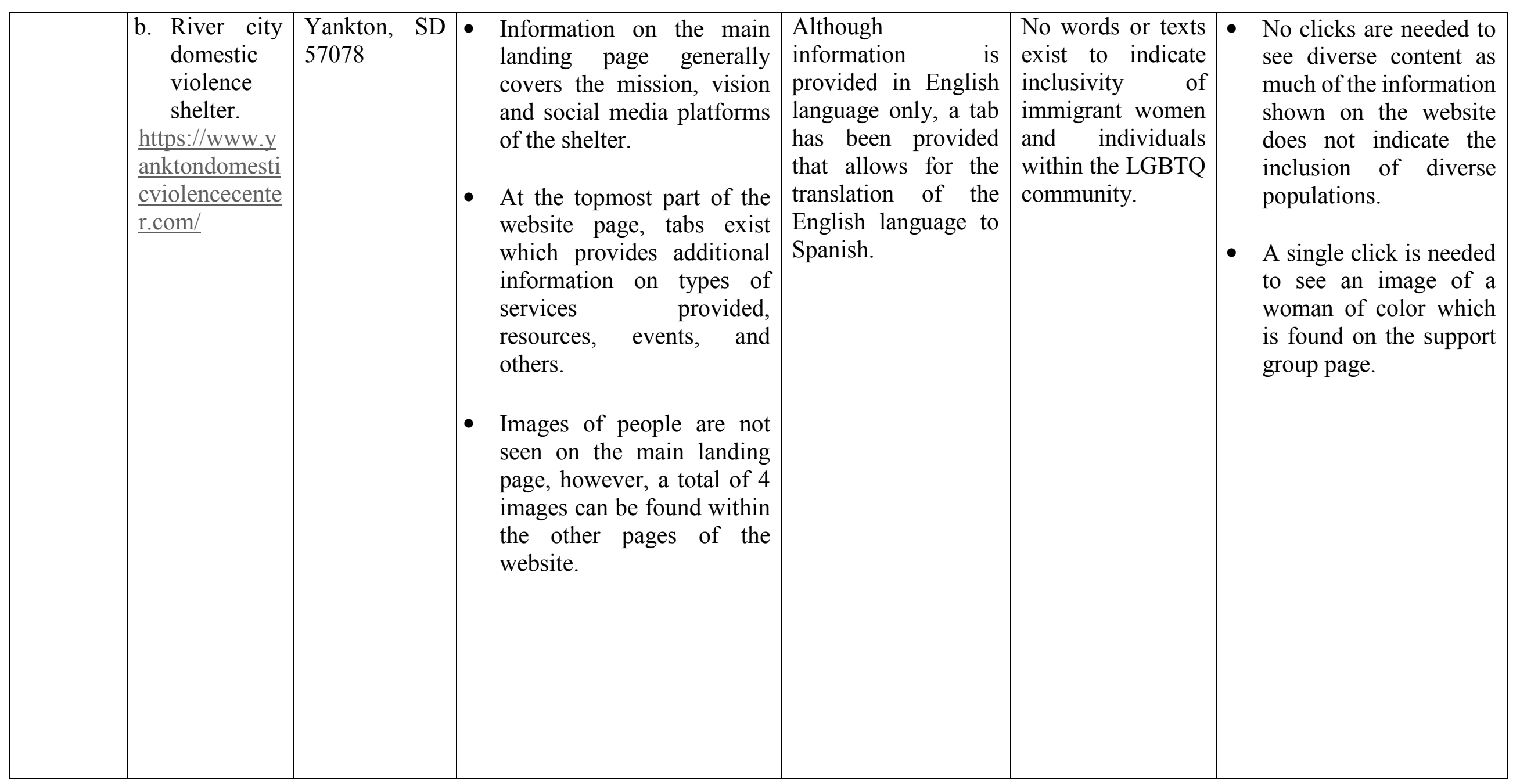




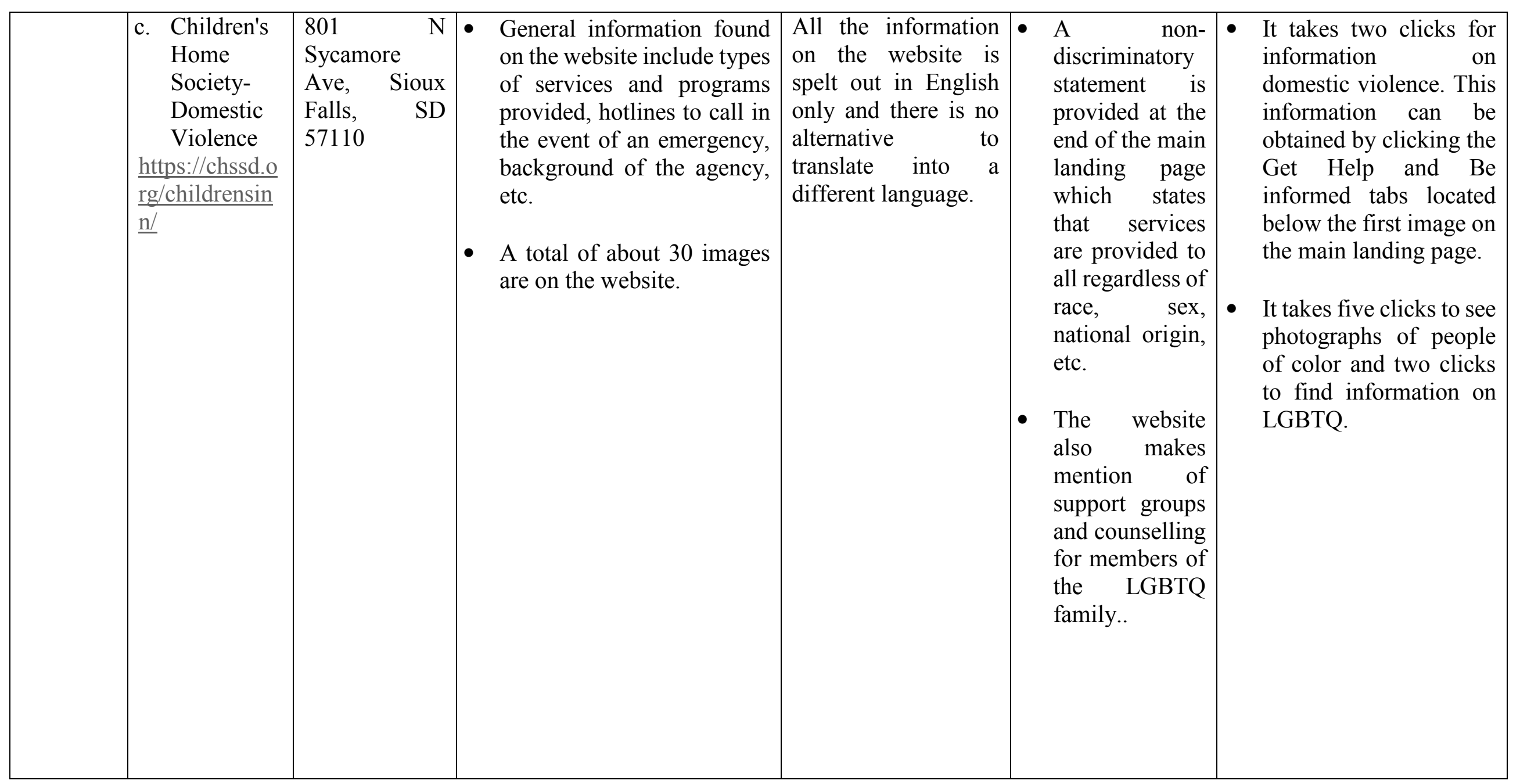




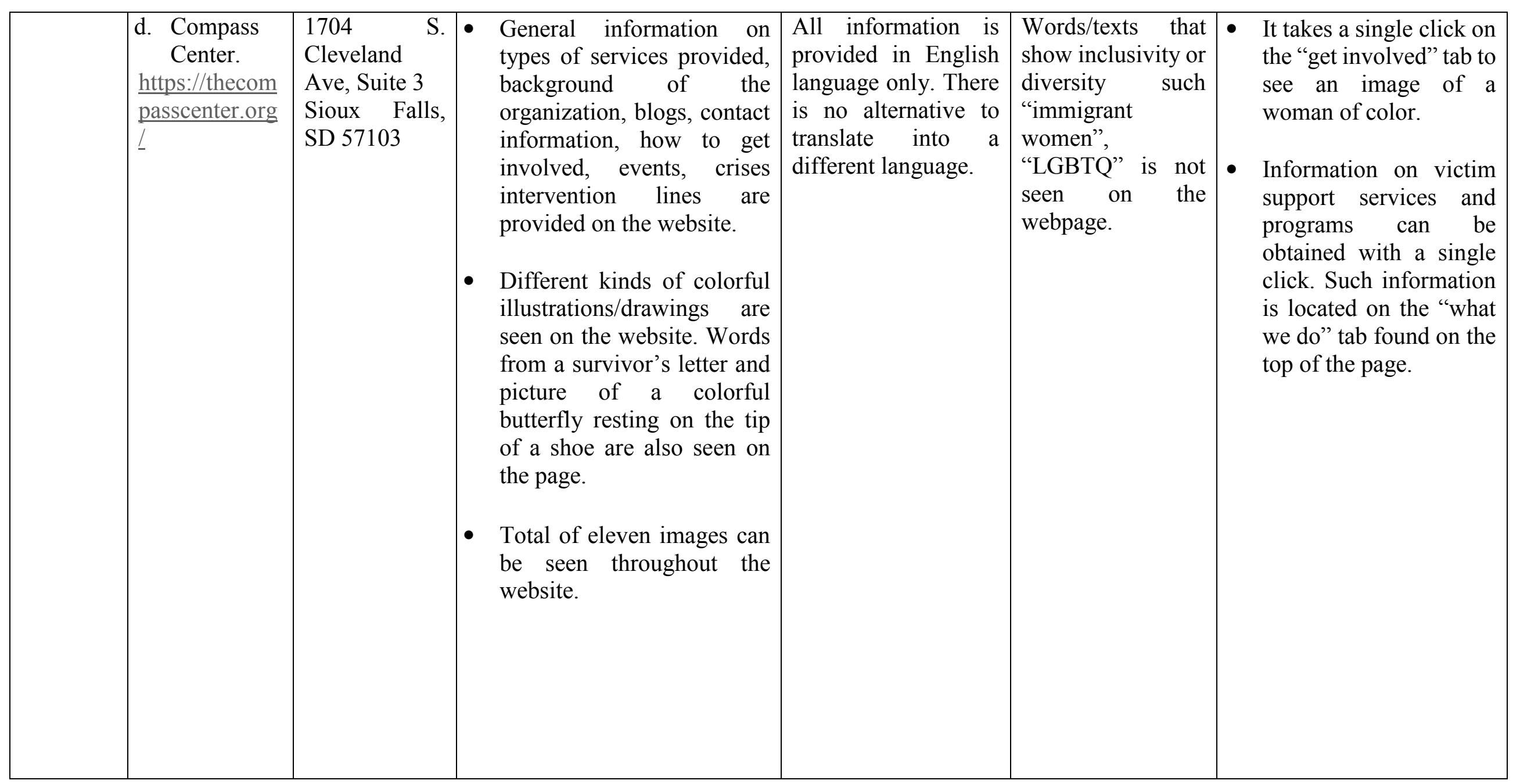




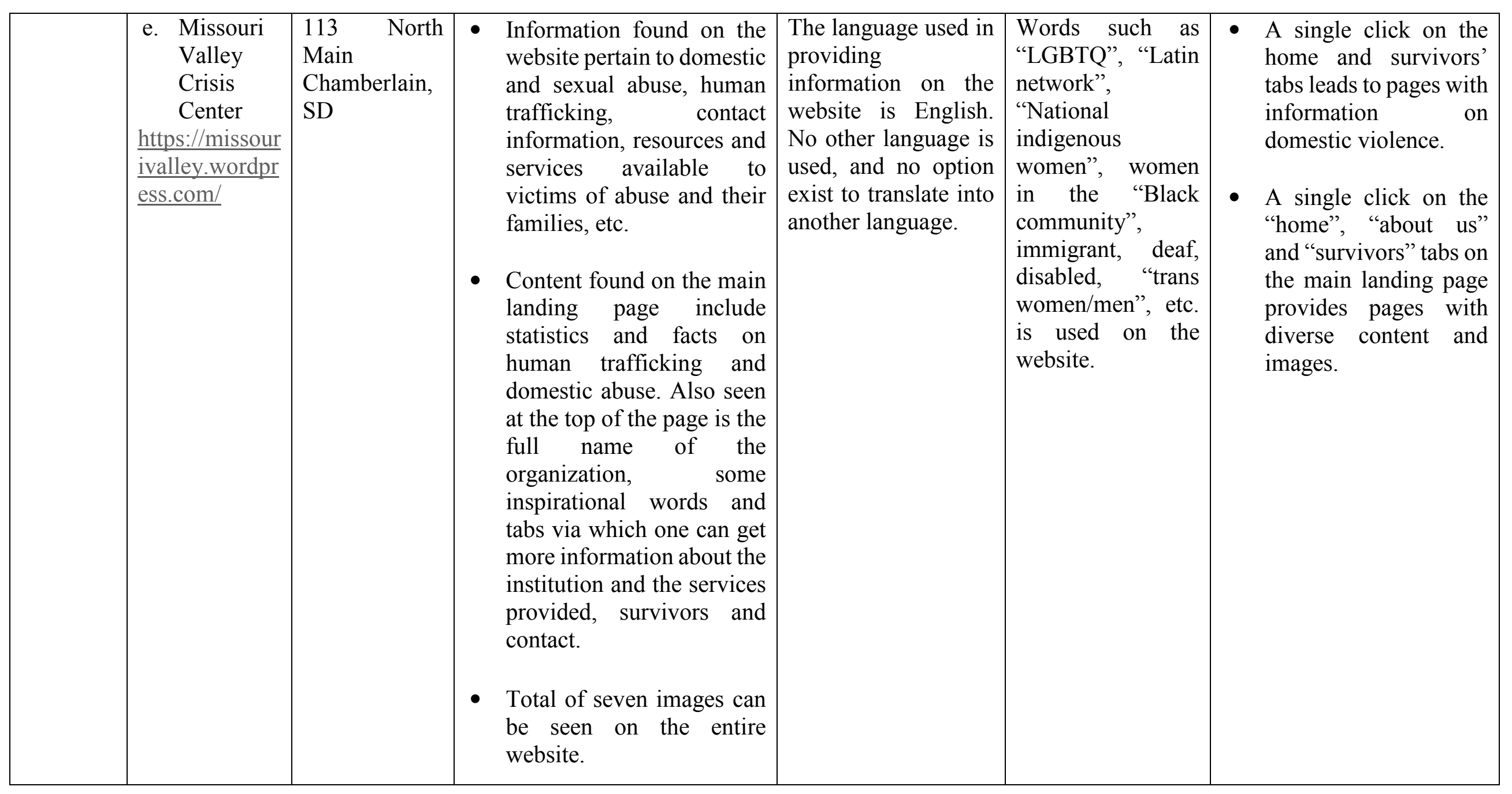




\begin{tabular}{|c|c|c|c|c|c|c|}
\hline Nebraska & $\begin{array}{l}\text { a. S.A.F.E. } \\
\text { Center. } \\
\text { https://safecen } \\
\text { ter.org/ }\end{array}$ & $\begin{array}{lr}620 \quad \text { E. } & 25 \text { th } \\
\text { Suite } & 14 \\
\text { Kearney } & \text { NE, } \\
68847 & \end{array}$ & $\begin{array}{l}\text { - Information pertaining to } \\
\text { domestic and sexual abuse, } \\
\text { human trafficking, services } \\
\text { and programs available to } \\
\text { victims of abuse, mission } \\
\text { and vison of the } \\
\text { organization, and counties } \\
\text { served are provided on the } \\
\text { website. } \\
\text { - Content on the main } \\
\text { landing page include } \\
\text { contact information, } \\
\text { domestic and sexual } \\
\text { assault information, } \\
\text { hotlines, social media and } \\
\text { partners of the } \\
\text { organization. } \\
\text { Total of eleven } \\
\text { photographs is shown on } \\
\text { the website. }\end{array}$ & $\begin{array}{l}\text { - General details } \\
\text { on the website are } \\
\text { written out in } \\
\text { English. } \\
\text { - Only the } \\
\text { statement on } \\
\text { discrimination is } \\
\text { provided in a } \\
\text { different } \\
\text { language } \\
\text { (Spanish) at the } \\
\text { bottom of each } \\
\text { page. }\end{array}$ & $\begin{array}{l}\text { No words or text } \\
\text { exist on the } \\
\text { website to indicate } \\
\text { inclusivity. }\end{array}$ & $\begin{array}{l}\text { - A single click on the } \\
\text { services tab found on } \\
\text { the top of the main } \\
\text { landing page leads to } \\
\text { information on } \\
\text { domestic and sexual } \\
\text { violence. } \\
\text { - Zero clicks are needed } \\
\text { to see diverse content } \\
\text { or images as the can be } \\
\text { seen on the main } \\
\text { landing pages. } \\
\text { A flag representing the } \\
\text { colors of LGBTQ is } \\
\text { seen at the bottom of } \\
\text { each of the pages on } \\
\text { the website. }\end{array}$ \\
\hline
\end{tabular}




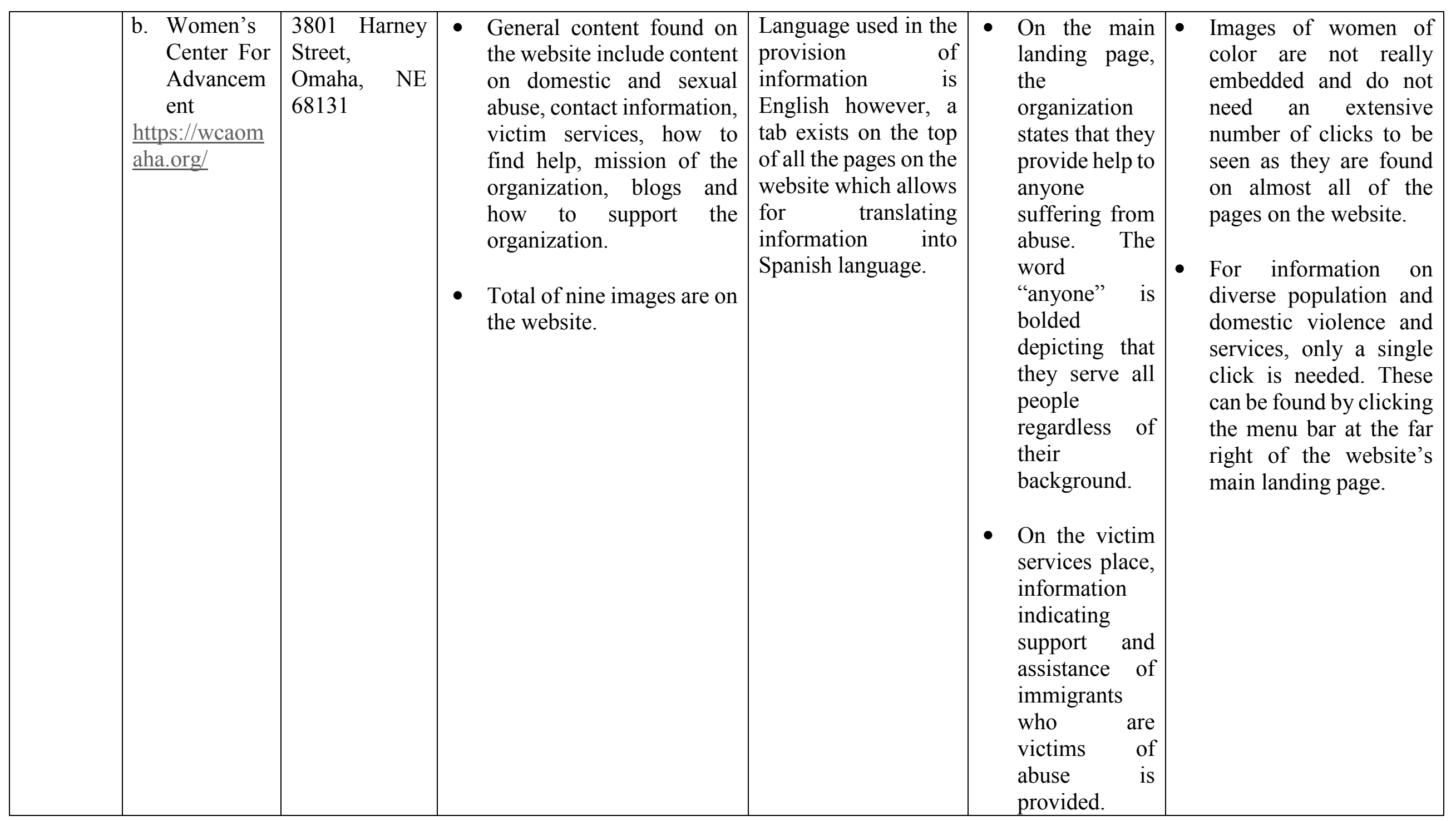




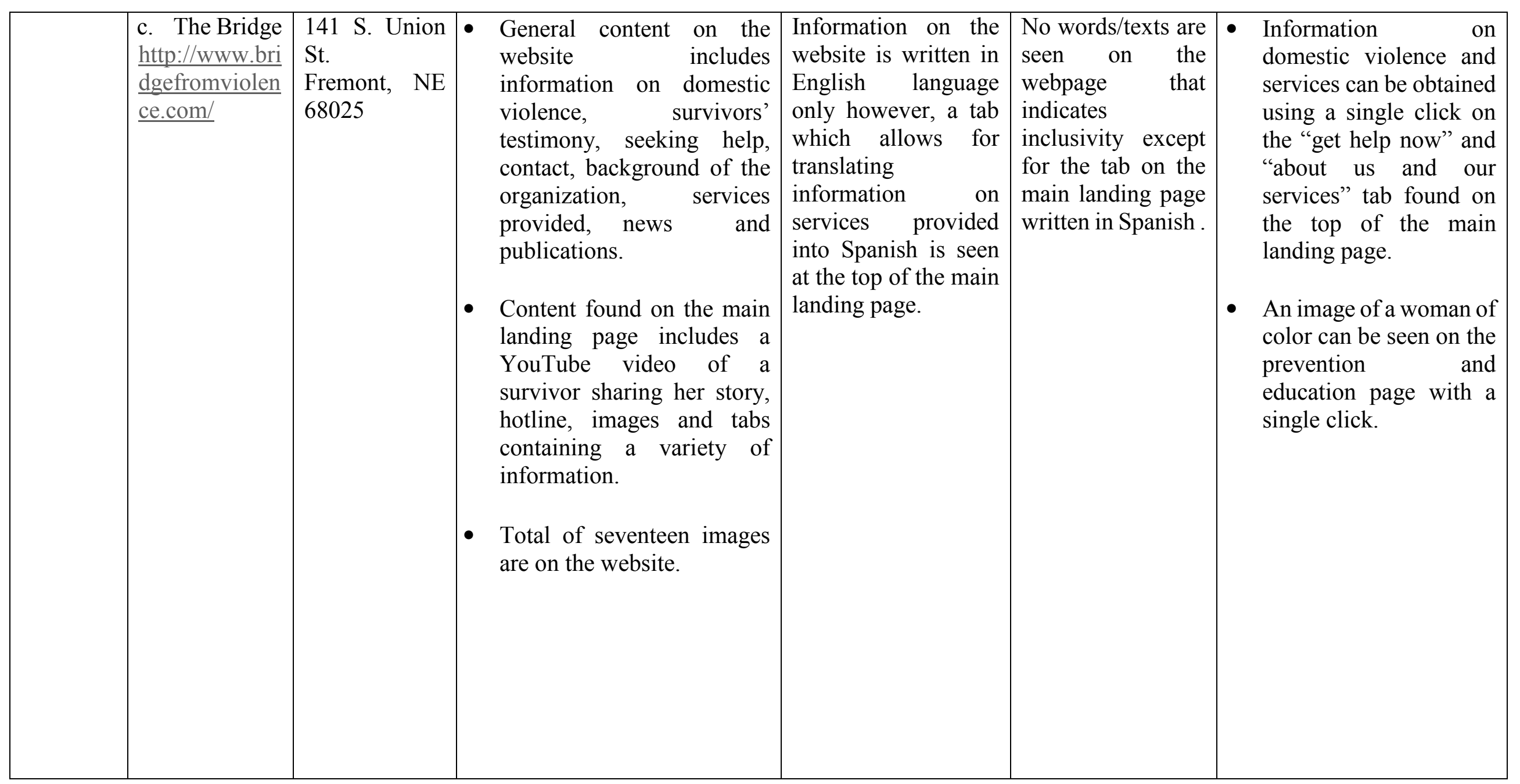




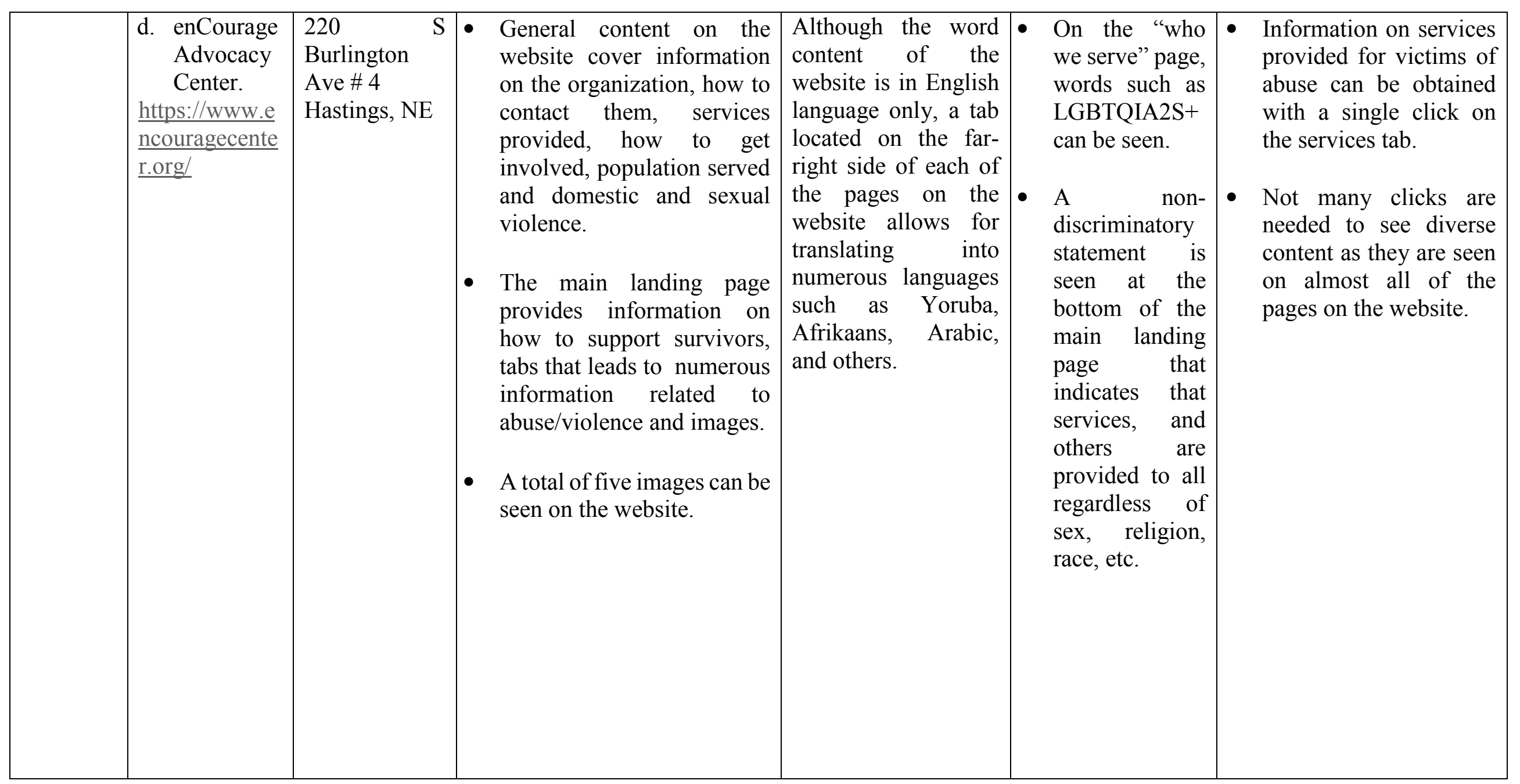




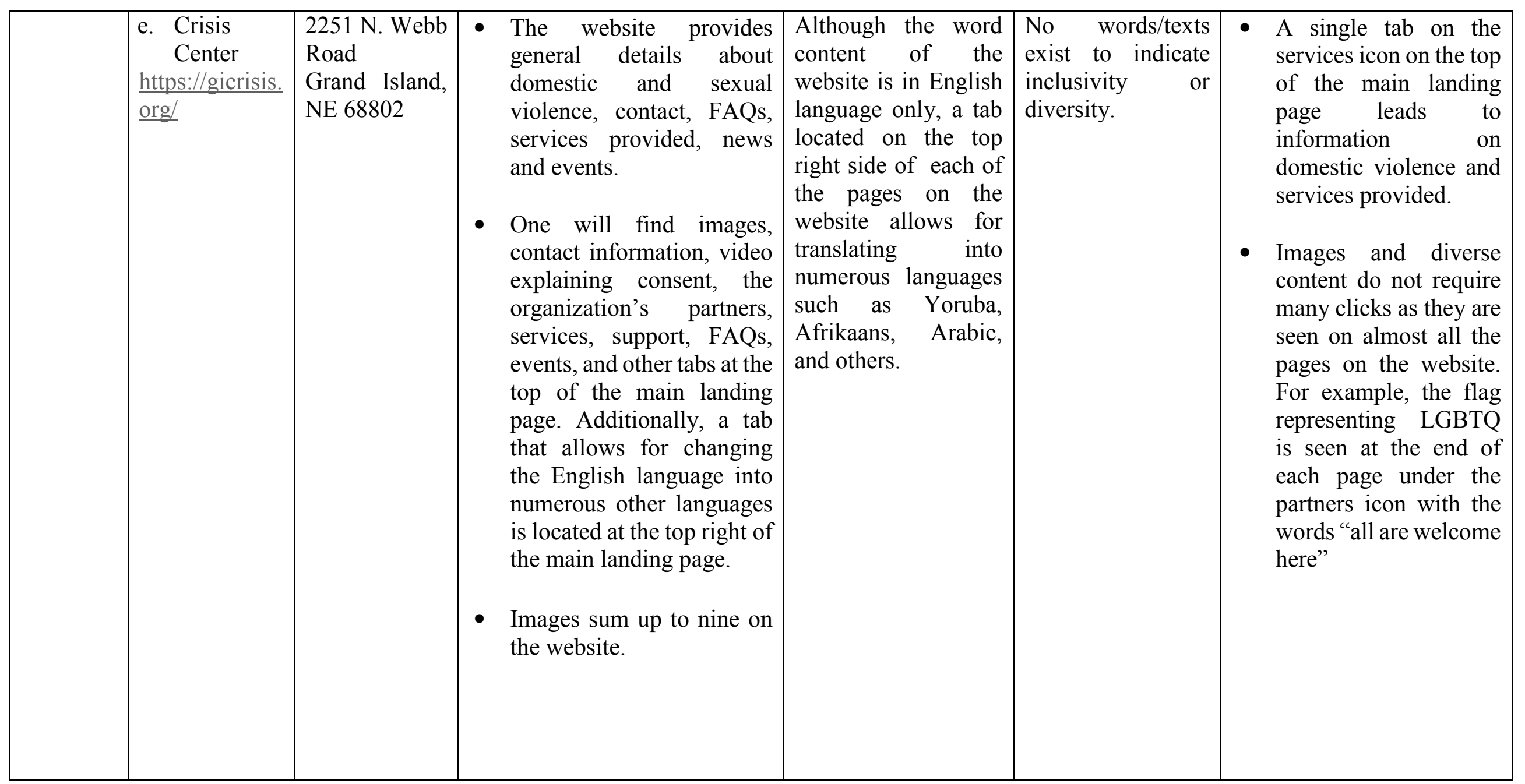




\begin{tabular}{|c|c|c|c|c|c|c|}
\hline Maryland & 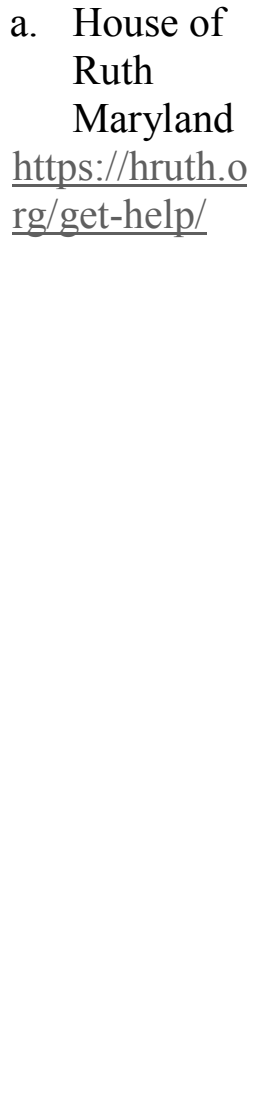 & $\begin{array}{l}2201 \text { Argonne } \\
\text { Drive. } \\
\text { Baltimore, } \\
\text { MD } 21218\end{array}$ & $\begin{array}{l}\text { - General content found on } \\
\text { this website encompass } \\
\text { information on the } \\
\text { organization, domestic and } \\
\text { sexual abuse, intervention } \\
\text { and counselling } \\
\text { programs/groups, hotlines } \\
\text { to contact in the event of an } \\
\text { emergency, contact } \\
\text { information, social media } \\
\text { handles, news, how to get } \\
\text { help, etc. } \\
\text { On the main landing page, } \\
\text { one will find images, tabs to } \\
\text { click for more information, } \\
\text { hide page button, some } \\
\text { information on violence and } \\
\text { a menu bar. } \\
\text { Eight images and eight } \\
\text { illustrations are seen on the } \\
\text { website. }\end{array}$ & $\begin{array}{l}\text { A majority of the } \\
\text { information on the } \\
\text { website is in English } \\
\text { but a statement is } \\
\text { also given in Spanish } \\
\text { on the main landing } \\
\text { page. }\end{array}$ & $\begin{array}{l}\text { No texts/words are } \\
\text { seen on the website } \\
\text { to indicate } \\
\text { inclusivity. }\end{array}$ & $\begin{array}{l}\text { - Information on } \\
\text { domestic violence can } \\
\text { be seen with a single } \\
\text { click on the menu bar } \\
\text { which provides a drop } \\
\text { box with additional } \\
\text { information on specific } \\
\text { areas of abuse and } \\
\text { programs. } \\
\text { - Diverse images run } \\
\text { through the different } \\
\text { pages on the website } \\
\text { and does not require } \\
\text { many clicks to be } \\
\text { located. }\end{array}$ \\
\hline
\end{tabular}




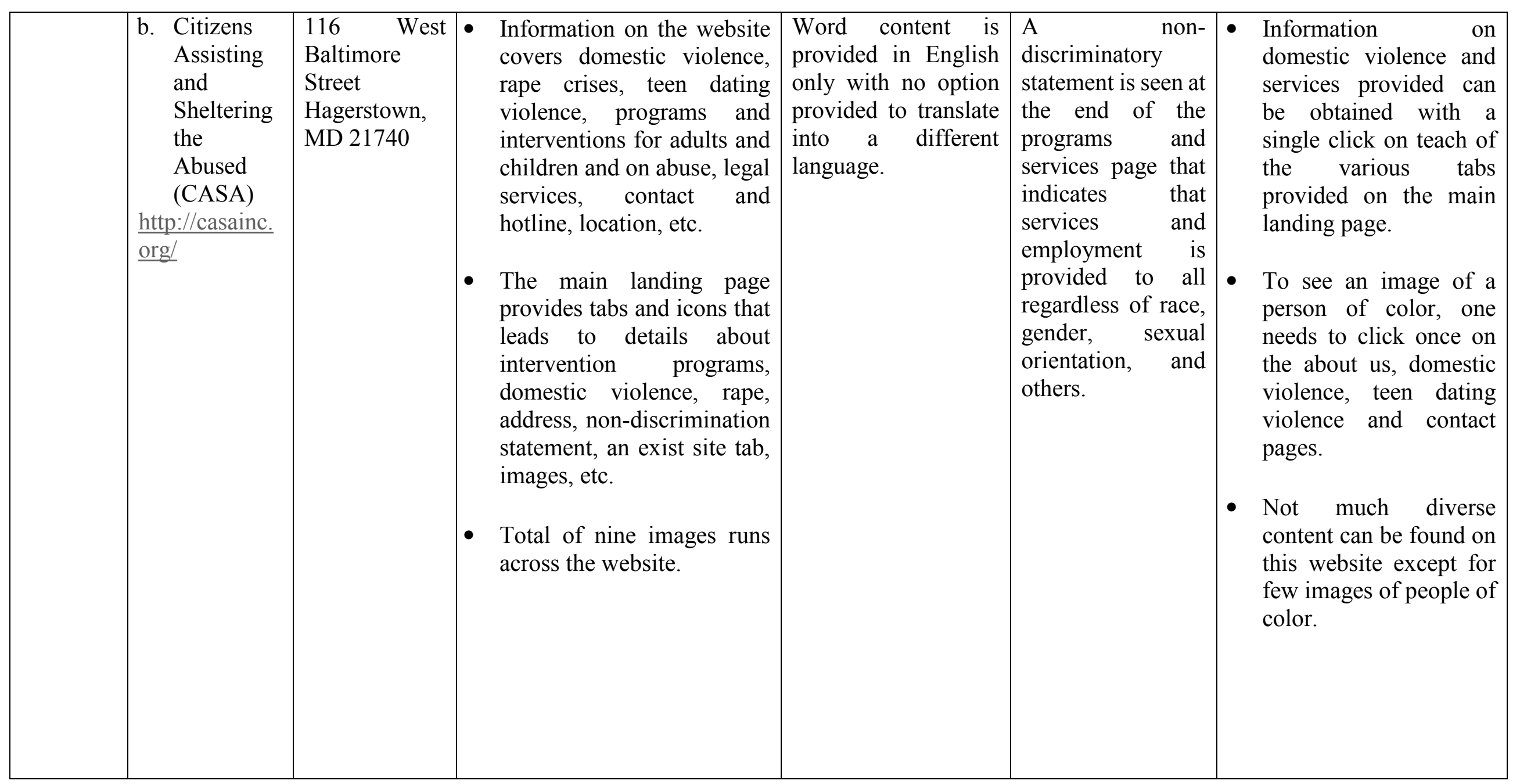




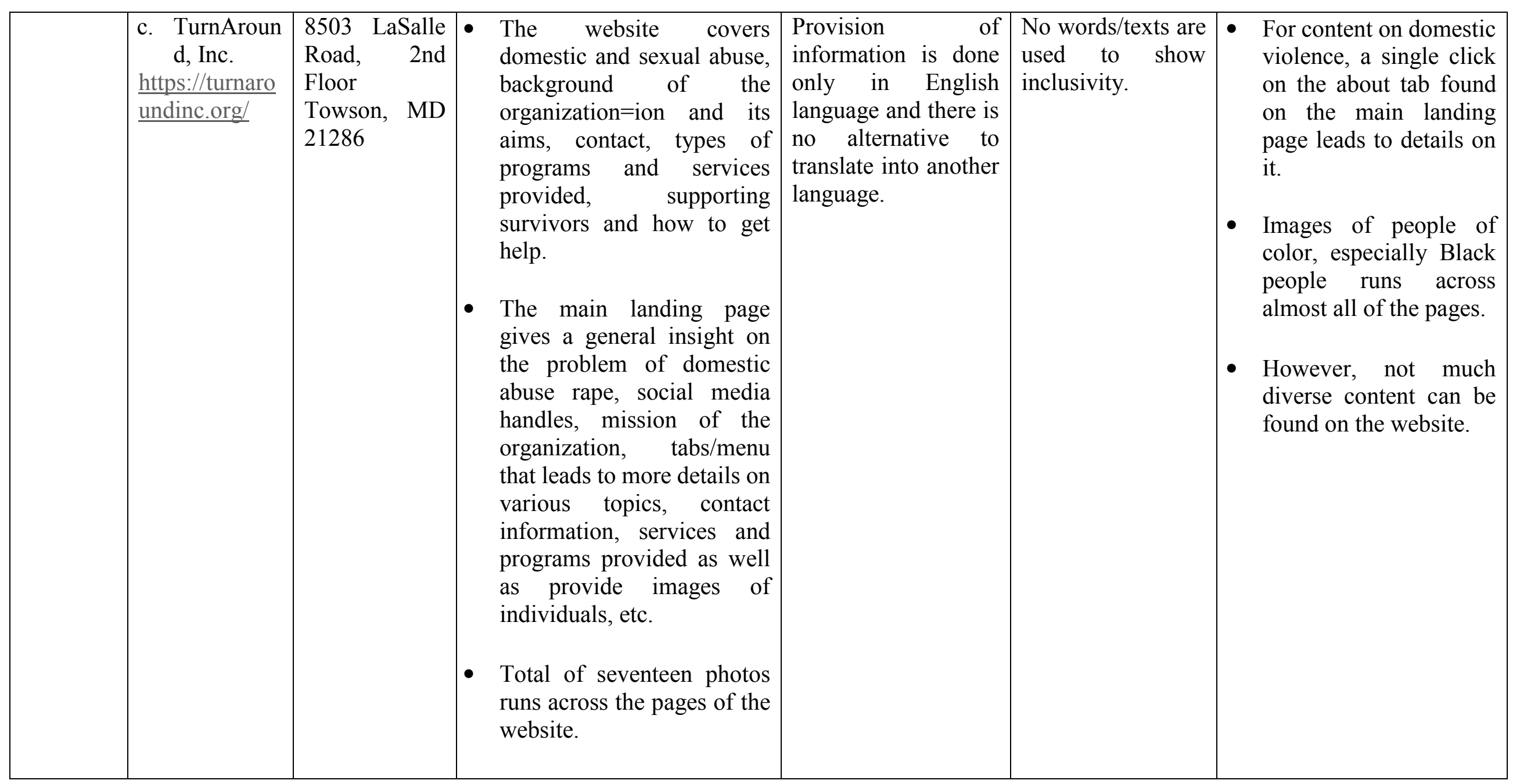




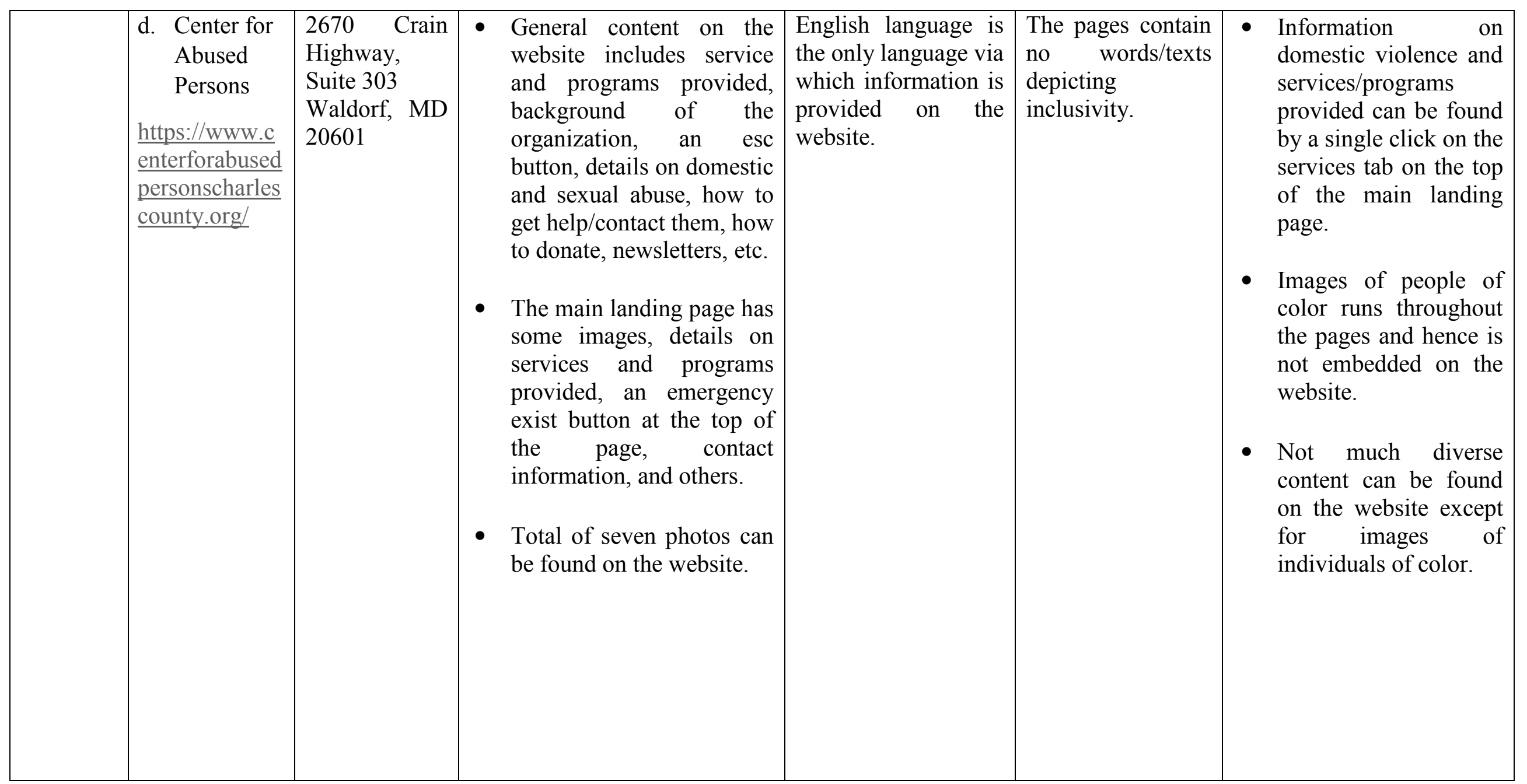




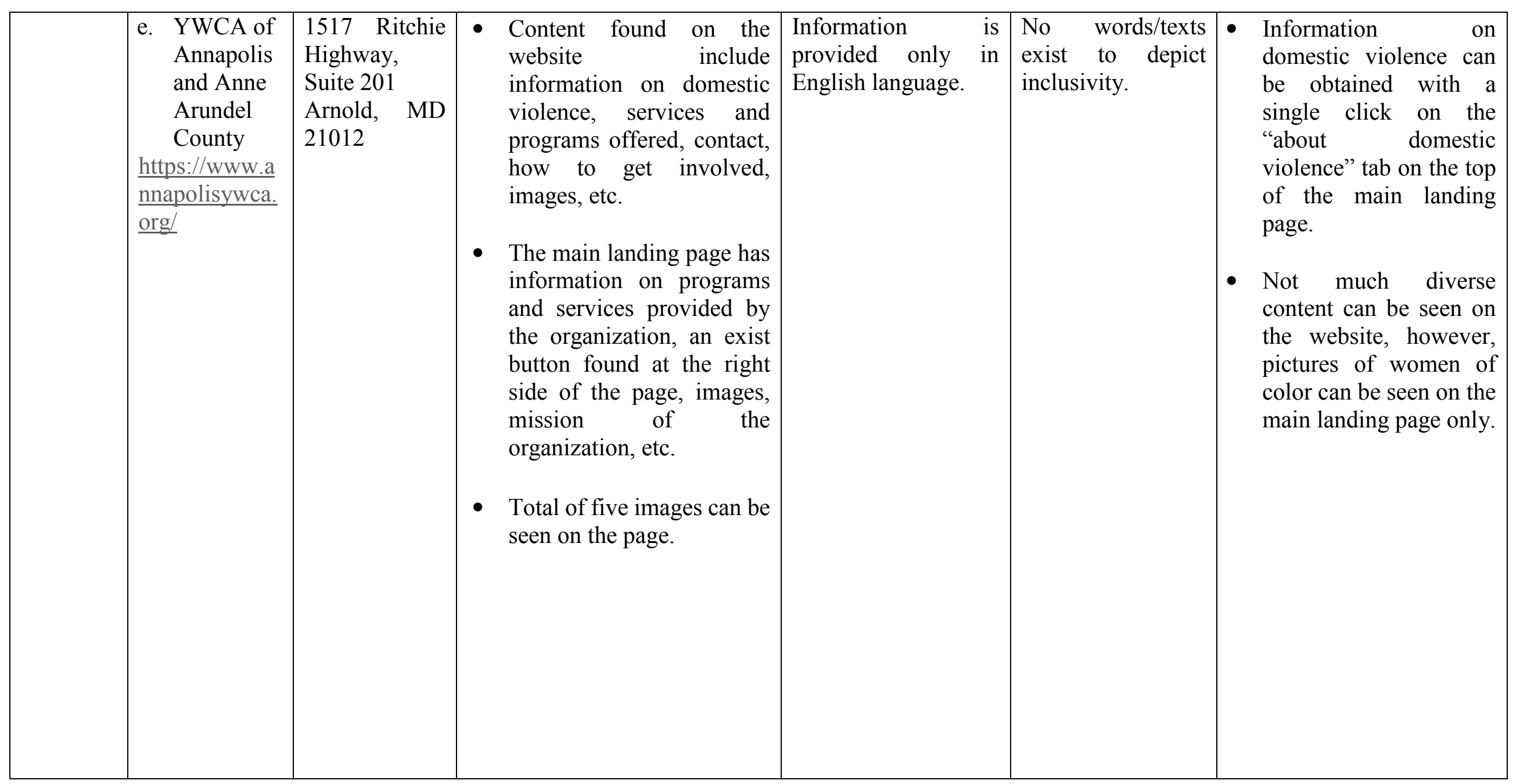




\begin{tabular}{|c|c|c|c|c|c|c|}
\hline Kentucky & $\begin{array}{l}\text { a. Bethany } \\
\text { House } \\
\text { Abuse } \\
\text { Shelter, } \\
\text { Inc. } \\
\text { https://bethany } \\
\text { houseinc.org/ }\end{array}$ & $\begin{array}{l}\text { Somerset, } \\
\text { Kentucky } \\
42502\end{array}$ & $\begin{array}{l}\text { - General information on } \\
\text { domestic violence, services } \\
\text { provided, background and } \\
\text { mission of the organization, } \\
\text { how to get involved/contact } \\
\text { them, how to support them, } \\
\text { etc. can be found on the } \\
\text { website. } \\
\text { - Content found on the main } \\
\text { landing page include some } \\
\text { images, an esc button in the } \\
\text { event of an emergency, } \\
\text { words of hope, mission of } \\
\text { the organization, contact } \\
\text { information, tabs on the top } \\
\text { of the page that leads to } \\
\text { additional information on } \\
\text { various topics, etc. } \\
\text { Six images are on the } \\
\text { website. }\end{array}$ & $\begin{array}{l}\text { English is the only } \\
\text { medium through } \\
\text { which information } \\
\text { has been provided on } \\
\text { the website. }\end{array}$ & $\begin{array}{l}\text { No texts or words } \\
\text { exist to show } \\
\text { inclusivity } r \text { or } \\
\text { diversity on the } \\
\text { website. }\end{array}$ & $\begin{array}{l}\text { - Content on domestic } \\
\text { violence and victim } \\
\text { services can be found } \\
\text { via a single click on the } \\
\text { services tab located on } \\
\text { the top of the main } \\
\text { landing page. } \\
\text { - Not enough diverse } \\
\text { content can be seen on } \\
\text { the website. A single } \\
\text { picture of the arm of a } \\
\text { Black person can be } \\
\text { found on the services } \\
\text { page. }\end{array}$ \\
\hline
\end{tabular}




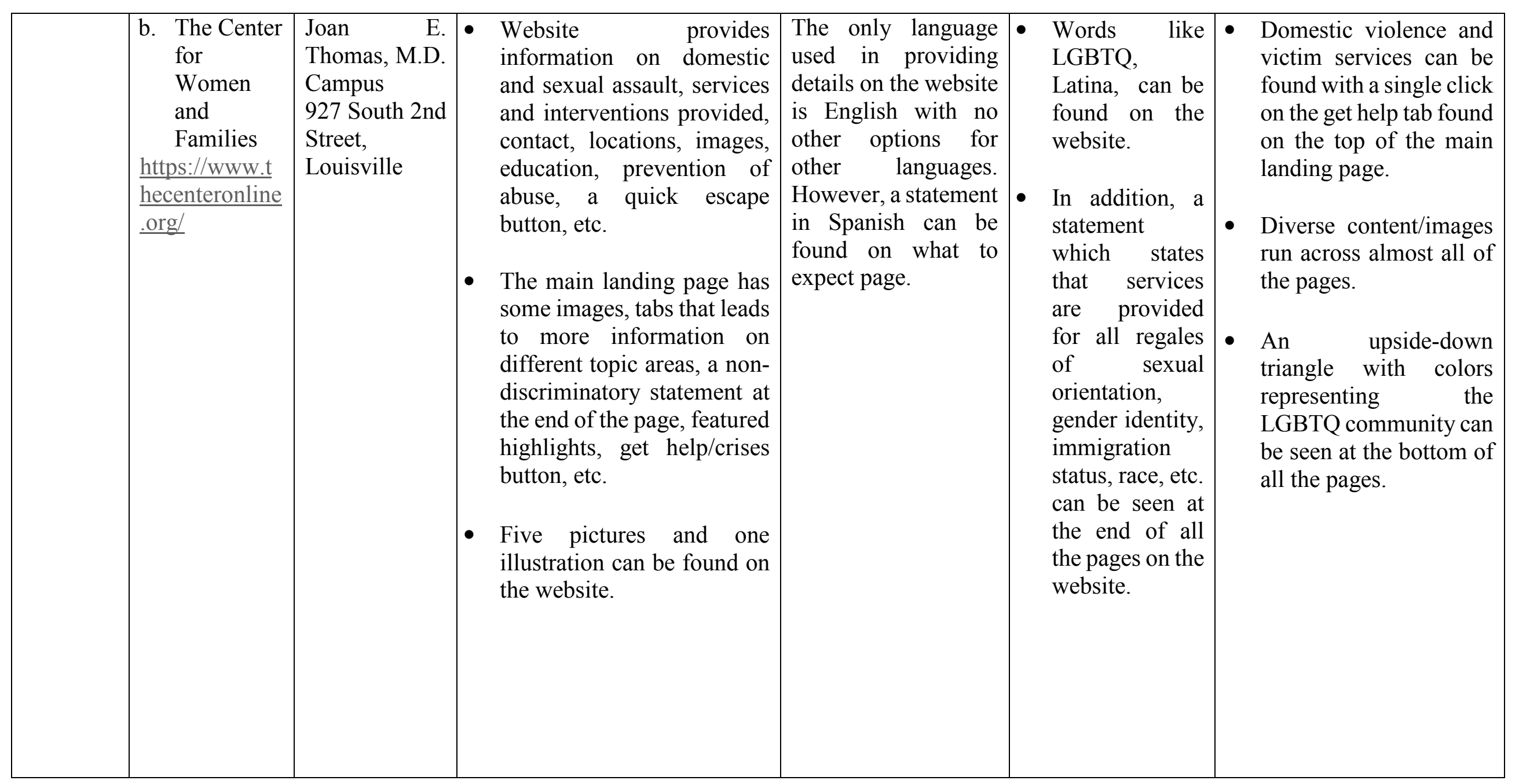




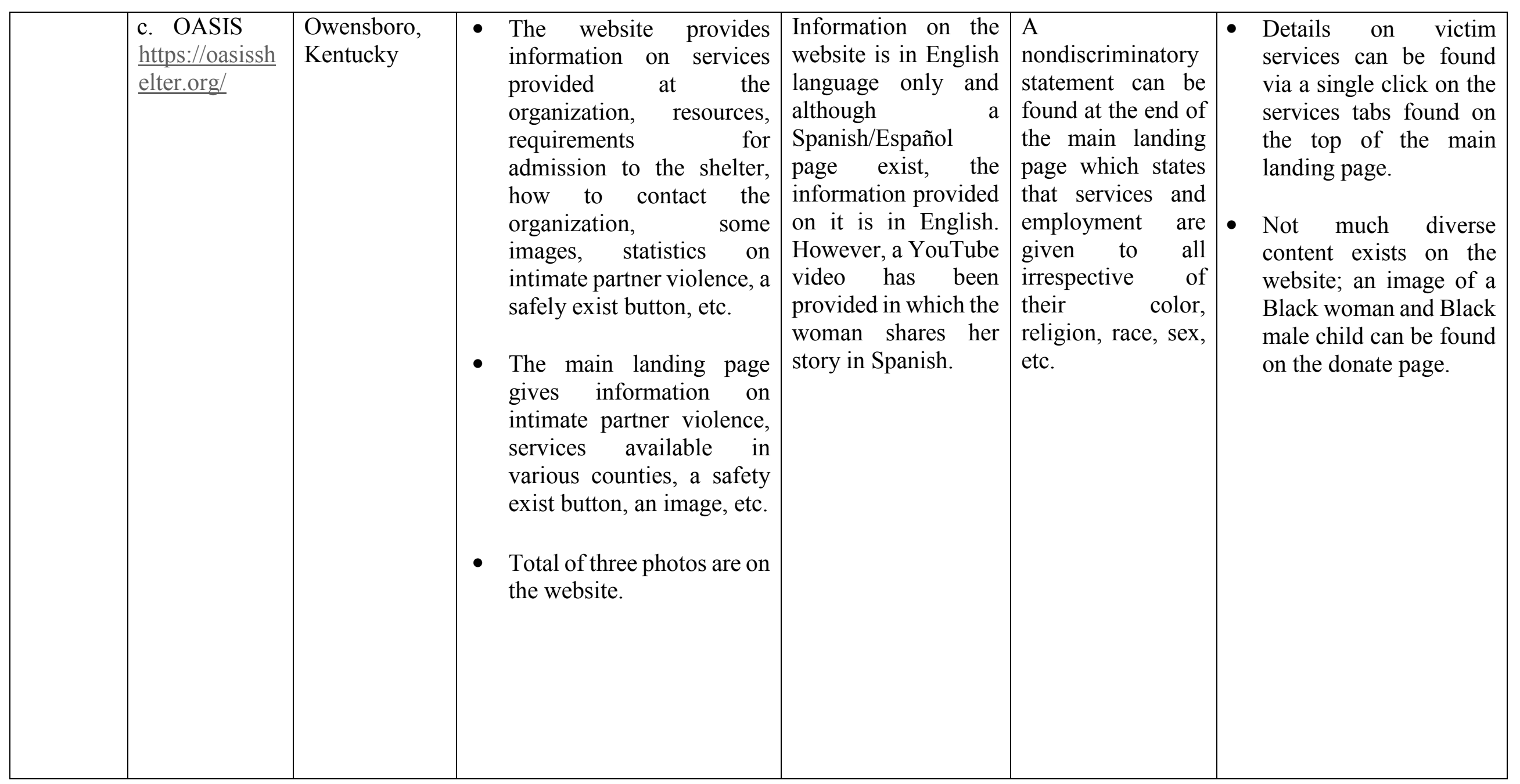




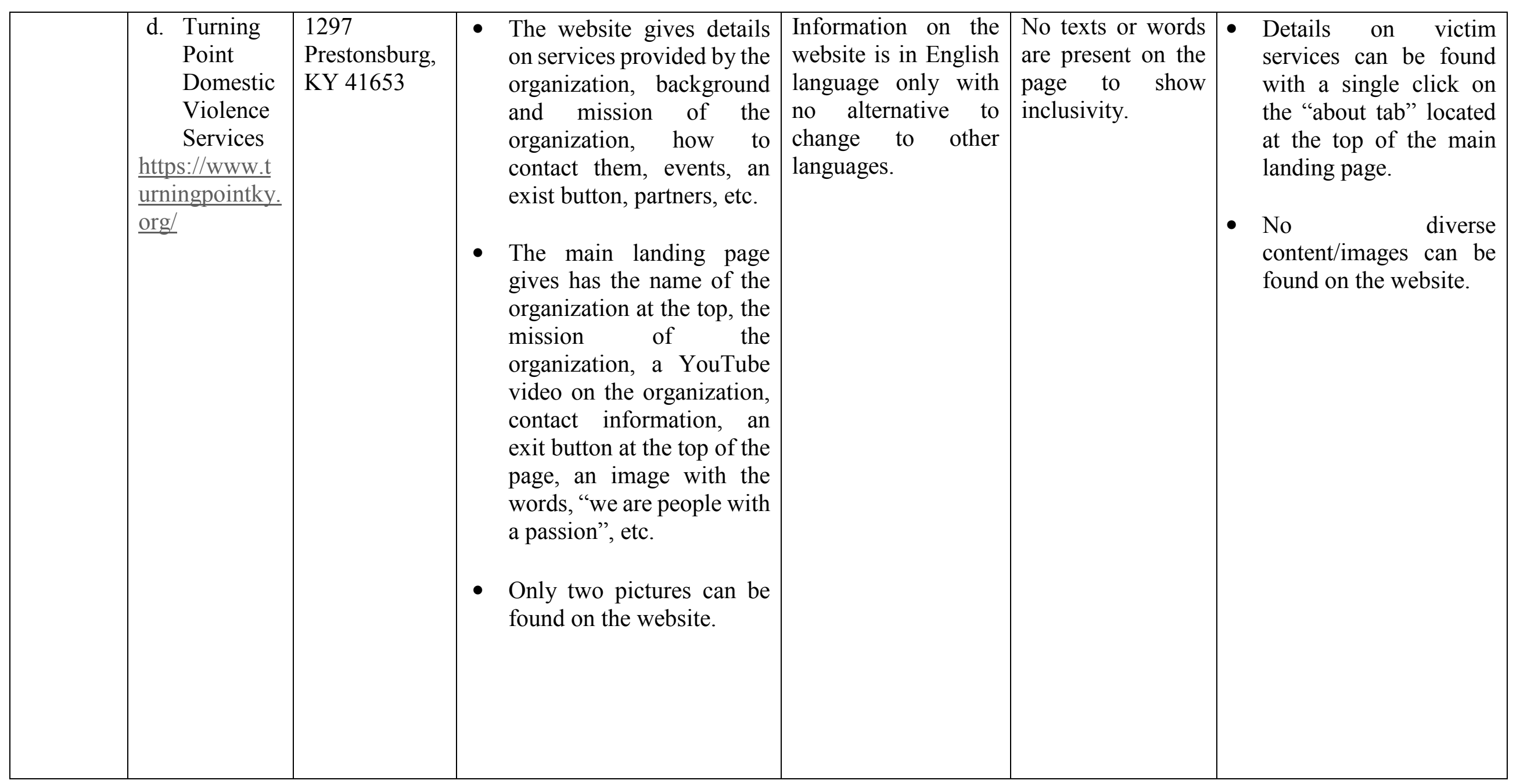




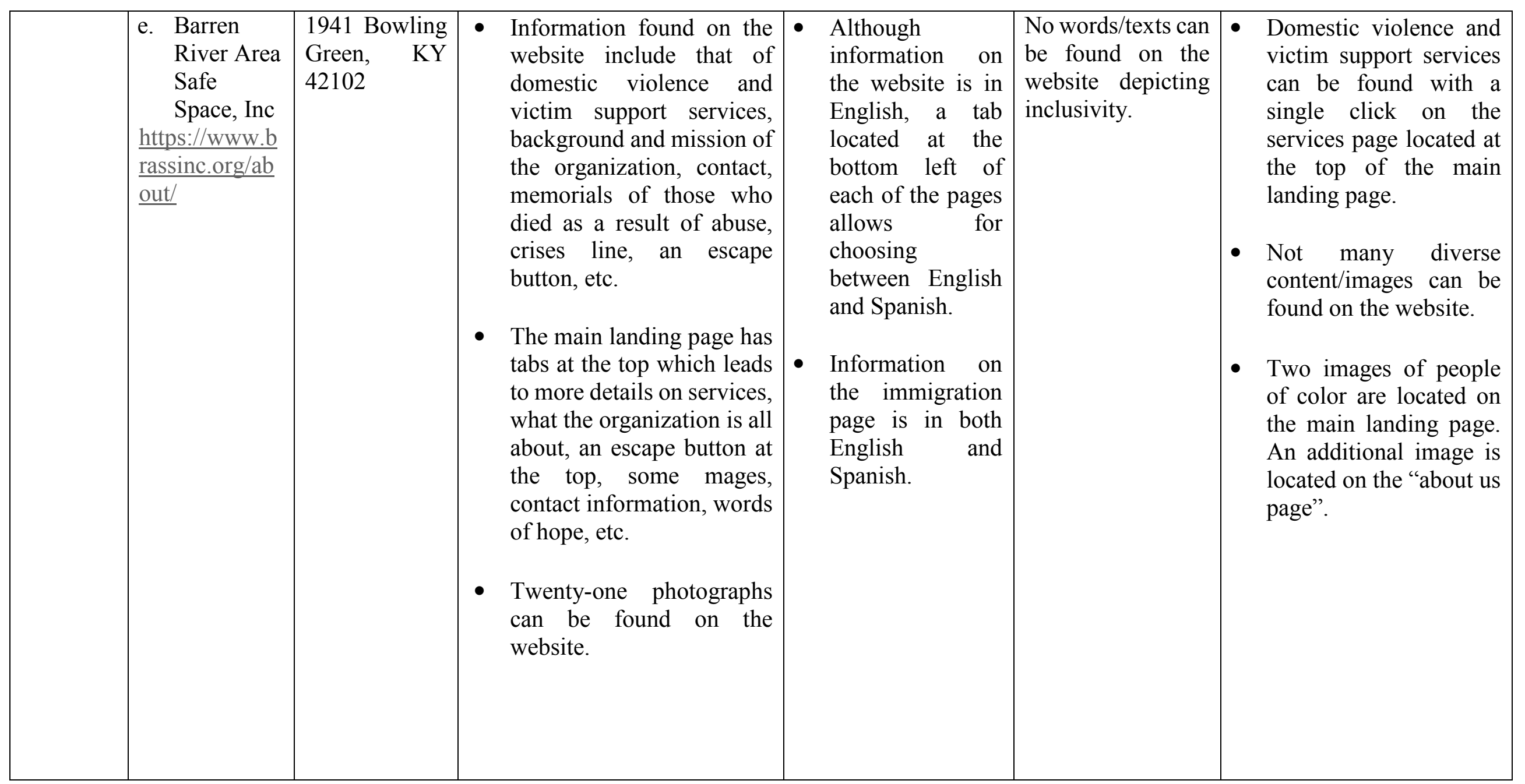




\begin{tabular}{|c|c|c|c|c|c|c|}
\hline $\begin{array}{l}\text { New } \\
\text { York }\end{array}$ & $\begin{array}{l}\text { a. Urban } \\
\text { Resource } \\
\text { Institute } \\
\text { https://urinyc. } \\
\text { org/\# }\end{array}$ & $\begin{array}{l}75 \quad \text { Broad } \\
\text { Street } \\
\text { Suite } 505 \\
\text { New York, } \\
\text { NY } 10004\end{array}$ & $\begin{array}{l}\text { - General information on the } \\
\text { organization, programs and } \\
\text { services provided, contact, } \\
\text { social media pages, images } \\
\text { etc. can be seen on the } \\
\text { website. } \\
\text { - The main landing page has } \\
\text { at its top tabs that provide } \\
\text { more information on } \\
\text { diverse topics, images, } \\
\text { mission of the organization, } \\
\text { an escape button, a portrait } \\
\text { showing the colors of the } \\
\text { LGBTQ community with } \\
\text { the words "Pride" on it, etc. } \\
\text { About twelve images can be } \\
\text { found on the website. }\end{array}$ & $\begin{array}{l}\text { Information on the } \\
\text { website is in English } \\
\text { language only, } \\
\text { however, a select } \\
\text { language tab at the } \\
\text { top of all the pages } \\
\text { allows for translating } \\
\text { into different } \\
\text { languages such as } \\
\text { Latin, French, } \\
\text { Mongolian, etc. }\end{array}$ & $\begin{array}{l}\text { - A statement at } \\
\text { the top of the } \\
\text { main landing } \\
\text { page states that } \\
\text { services are } \\
\text { provided for all } \\
\text { but with much } \\
\text { emphasis on } \\
\text { communities of } \\
\text { color and other } \\
\text { vulnerable } \\
\text { populations. } \\
\text { A non- } \\
\text { discriminatory } \\
\text { statement can } \\
\text { be found on the } \\
\text { domestic } \\
\text { violence page. }\end{array}$ & $\begin{array}{l}\text { - Information on services, } \\
\text { programs and domestic } \\
\text { violence can be } \\
\text { obtained with a single } \\
\text { click on the services and } \\
\text { programs tabs on the top } \\
\text { of the main landing } \\
\text { page. } \\
\text { - Many diverse content } \\
\text { and images runs across } \\
\text { the pages of the website; } \\
\text { images of people of } \\
\text { color are seen on almost } \\
\text { all of the pages. } \\
\text { Images of people of } \\
\text { color are not embedded } \\
\text { on the website. }\end{array}$ \\
\hline
\end{tabular}




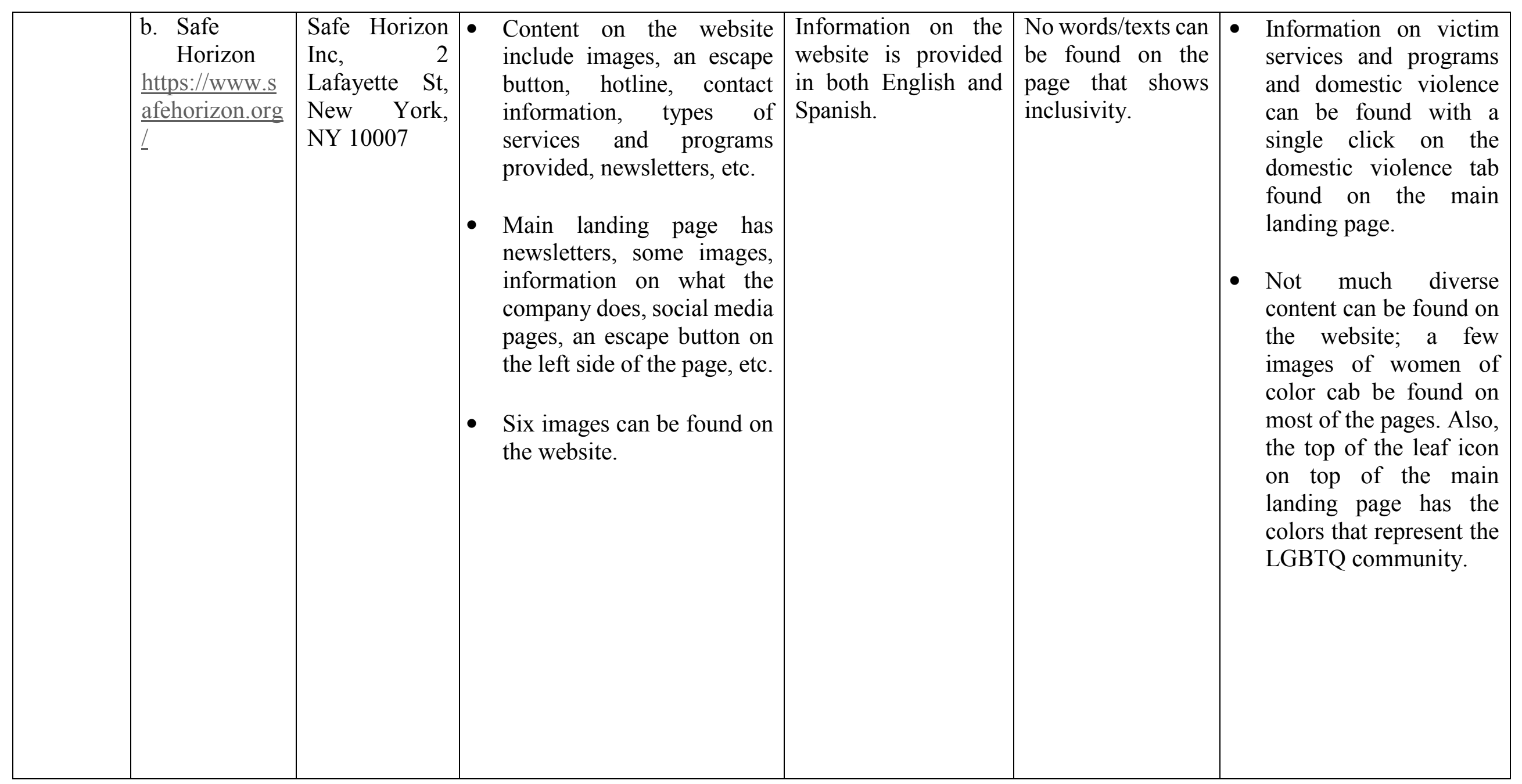




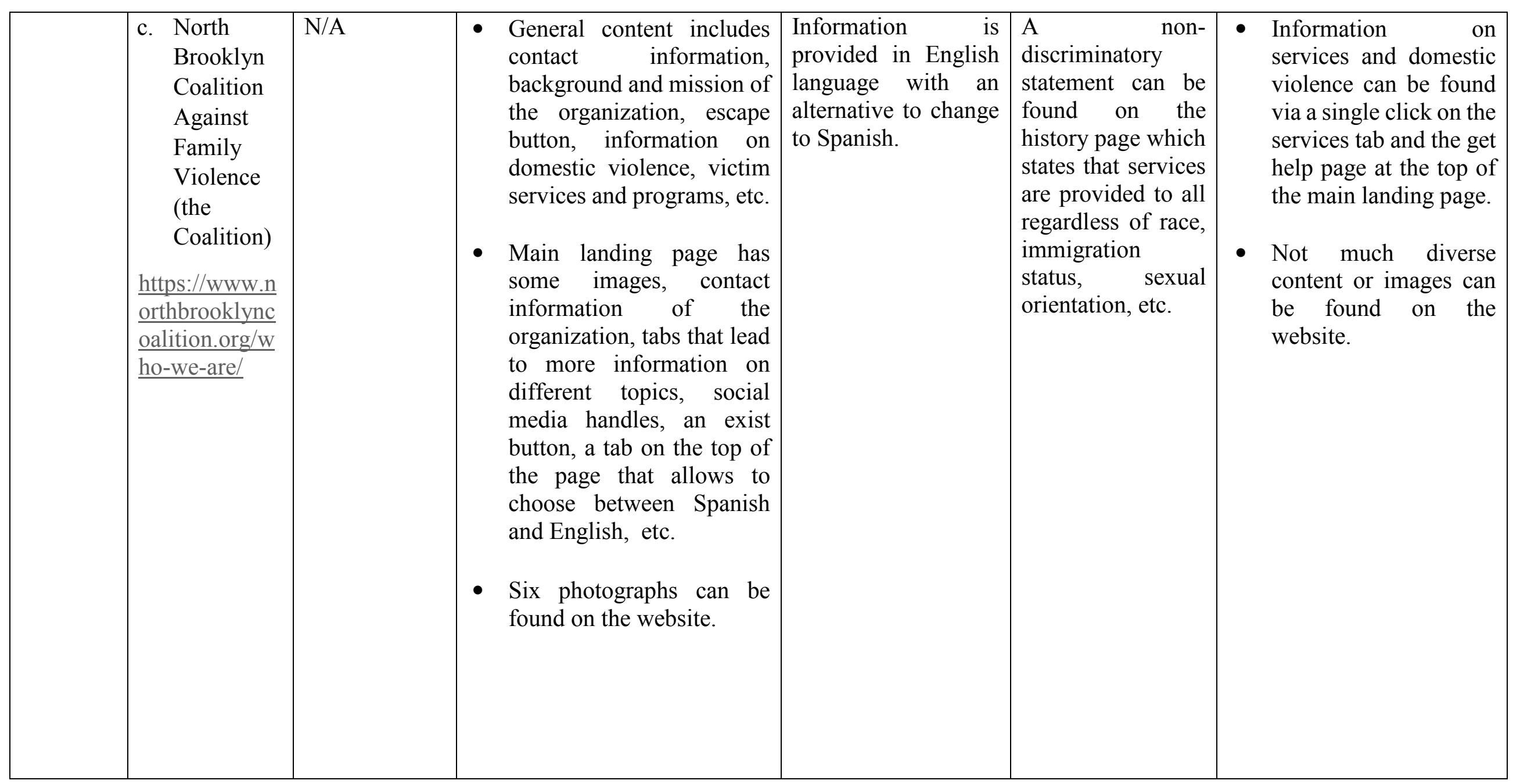




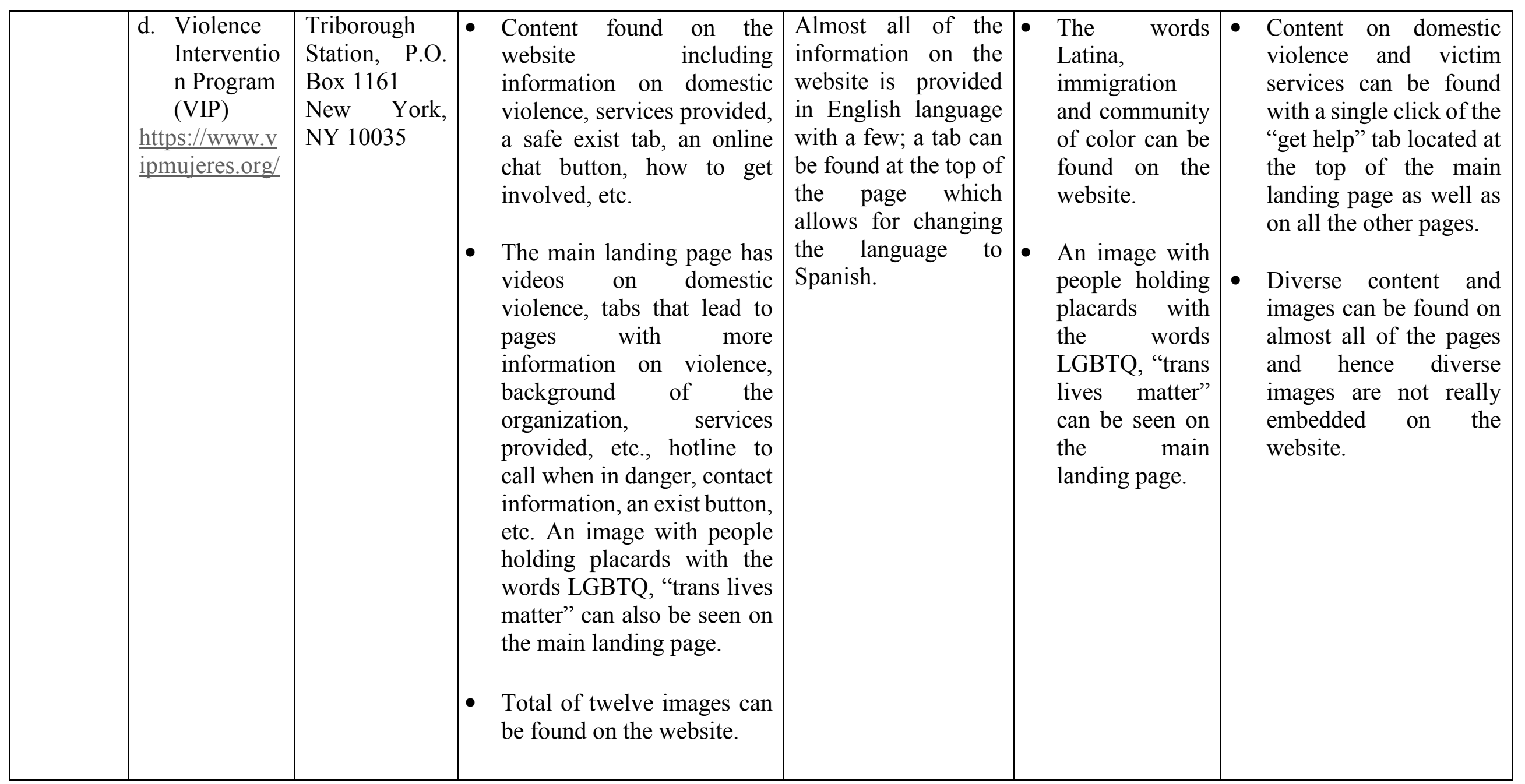




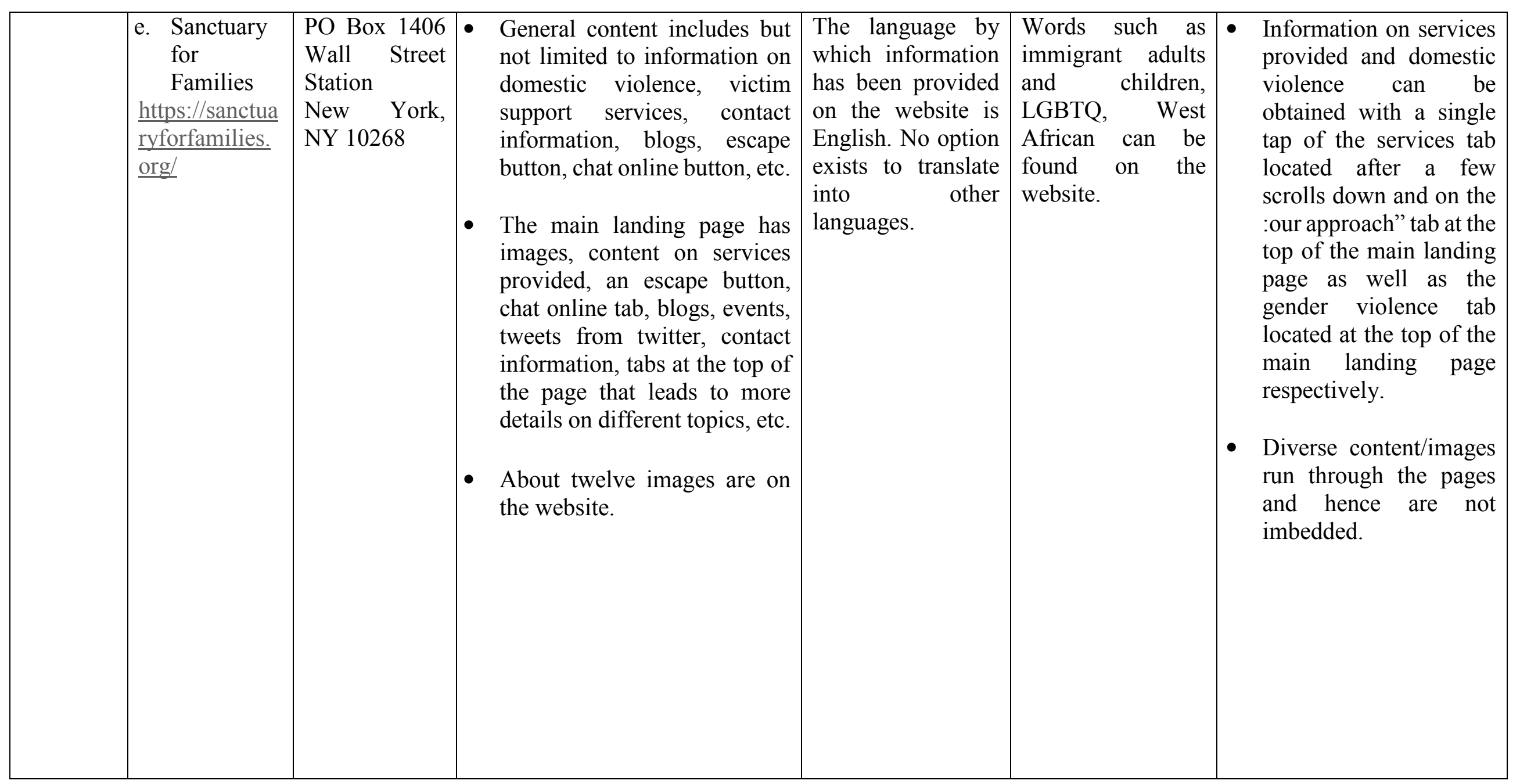




\begin{tabular}{|c|c|c|c|c|c|c|}
\hline $\begin{array}{l}\text { Rhode } \\
\text { Island }\end{array}$ & 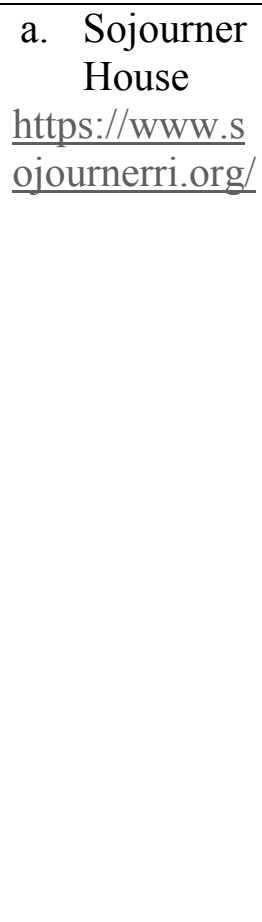 & $\begin{array}{l}386 \quad \text { Smith } \\
\text { Street, } \\
\text { Providence, } \\
\text { RI 02908 }\end{array}$ & $\begin{array}{l}\text { - Information on the website } \\
\text { includes but not limited to } \\
\text { victim support services, } \\
\text { domestic violence, teen dating } \\
\text { violence, some images, covid- } \\
19 \text { resource list and } \\
\text { emergency fund, background } \\
\text { of the organization, an escape } \\
\text { button, etc. } \\
\text { - The main landing page has on } \\
\text { it images, hotline, information } \\
\text { on Covid-19, the organization } \\
\text { and how to contact them, an } \\
\text { escape button at the top of the } \\
\text { page, social media pages, etc. } \\
\text { Total of four images can be } \\
\text { found on the website. }\end{array}$ & $\begin{array}{l}\text { Information on the } \\
\text { website is in } \\
\text { English only, but a } \\
\text { tab exists at the top } \\
\text { of each page which } \\
\text { allows for } \\
\text { translating into } \\
\text { Spanish. }\end{array}$ & $\begin{array}{l}\text { Words/texts such } \\
\text { as immigration, } \\
\text { LGBTQ can be } \\
\text { found on the } \\
\text { website. }\end{array}$ & $\begin{array}{l}\text { - Information on services } \\
\text { and domestic violence } \\
\text { can be found with a } \\
\text { single click of the } \\
\text { services tabs found on } \\
\text { the main landing page. } \\
\text { - Diverse content/images } \\
\text { can be found on almost } \\
\text { all of the pages and } \\
\text { hence are not involved. }\end{array}$ \\
\hline
\end{tabular}




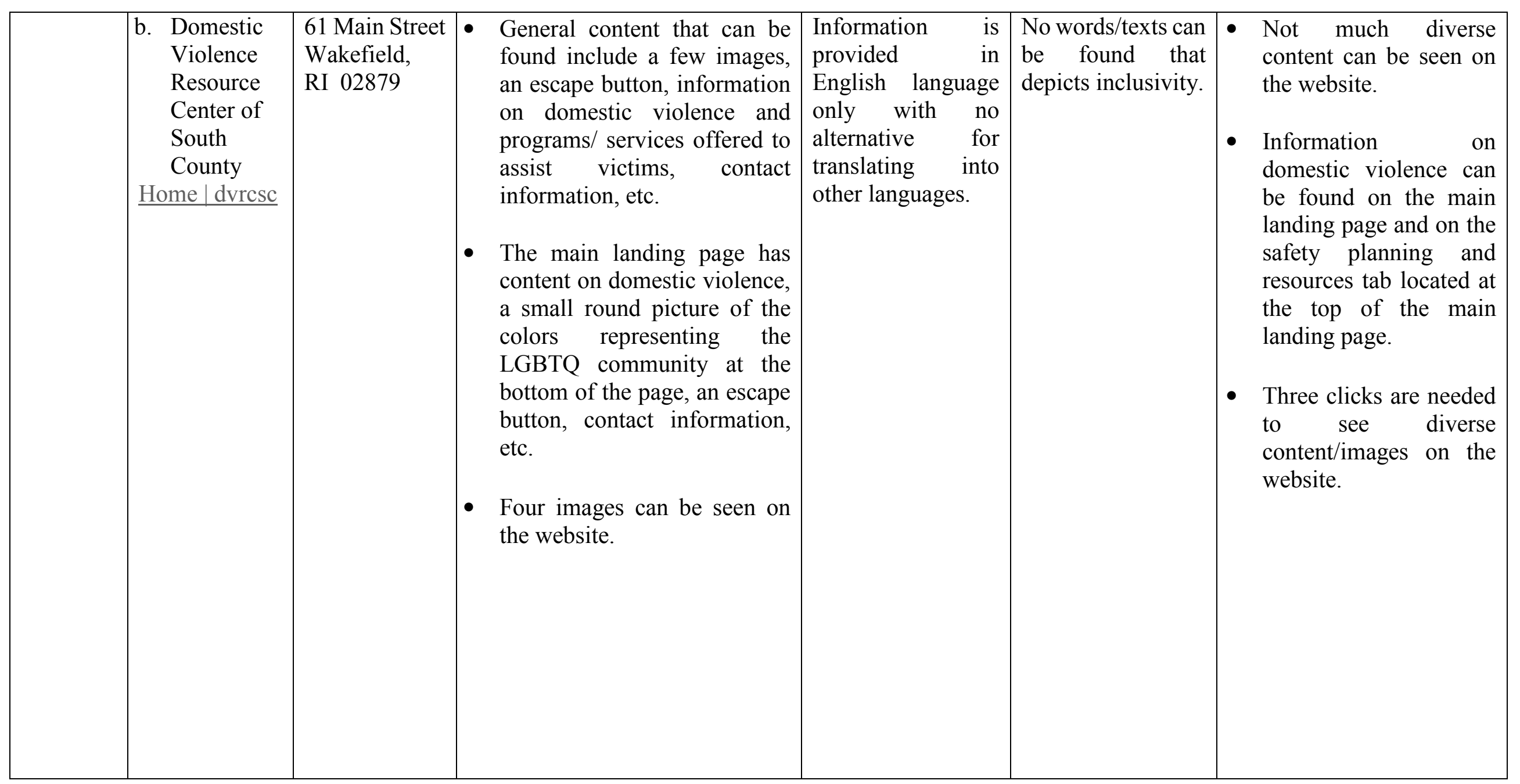




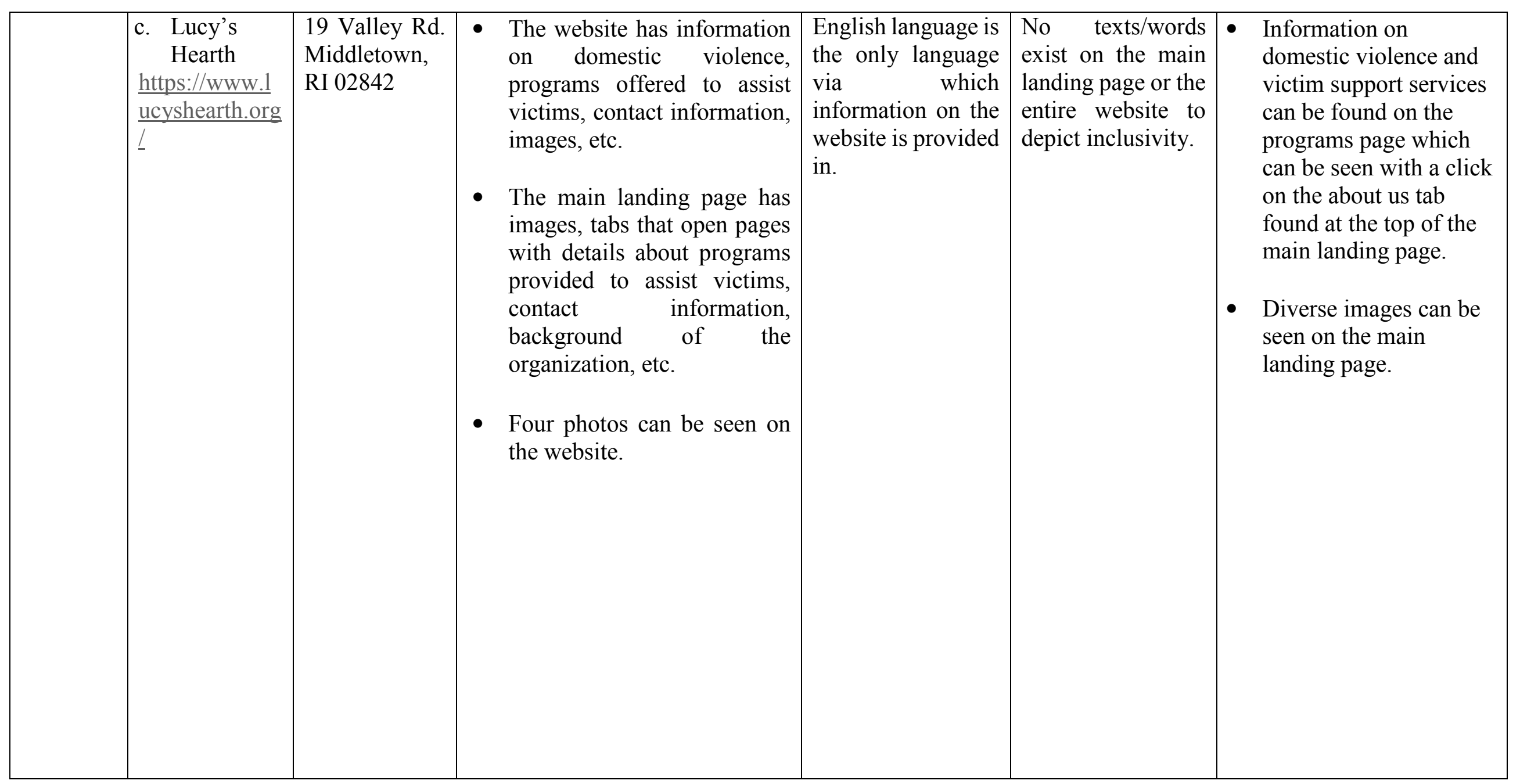




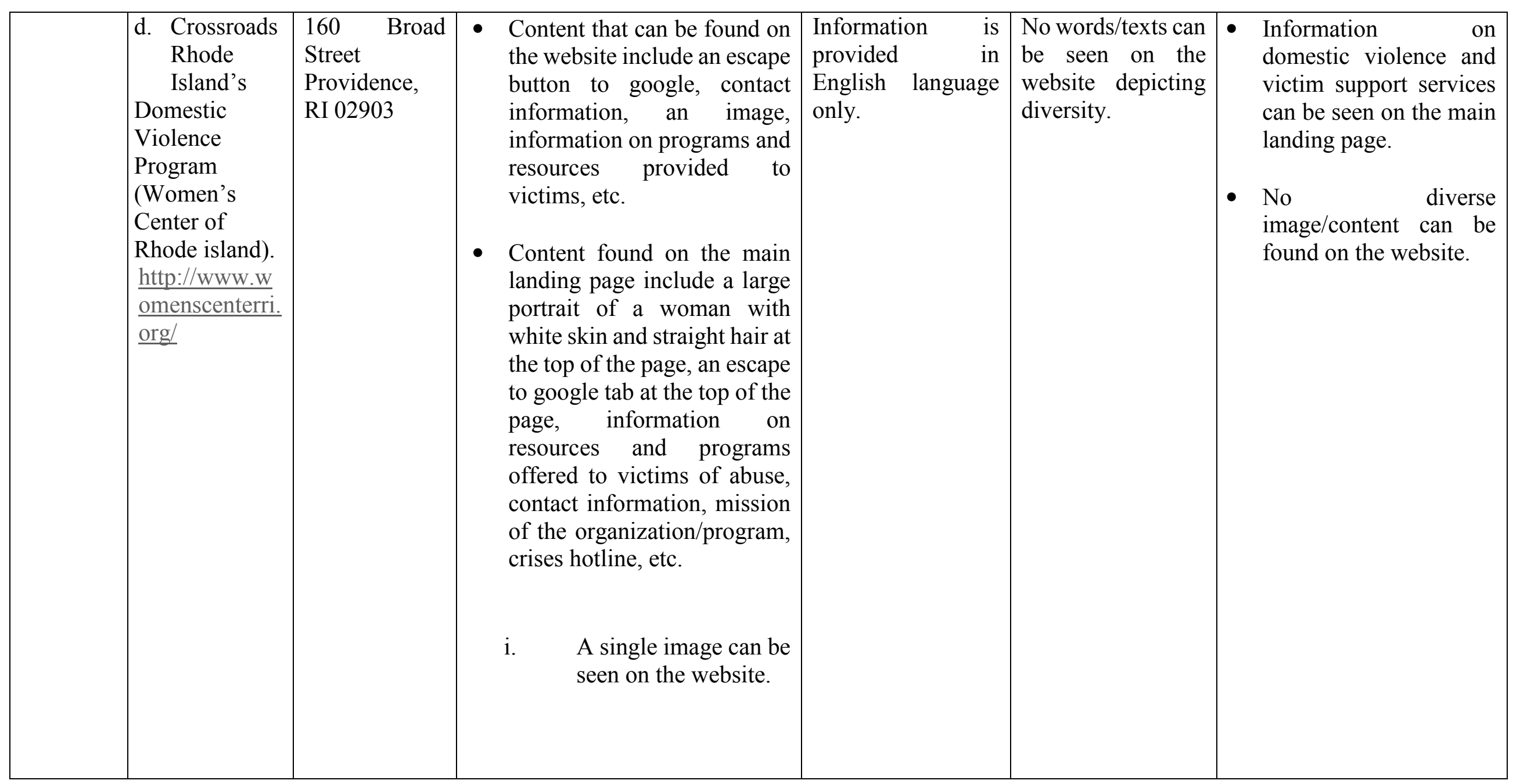




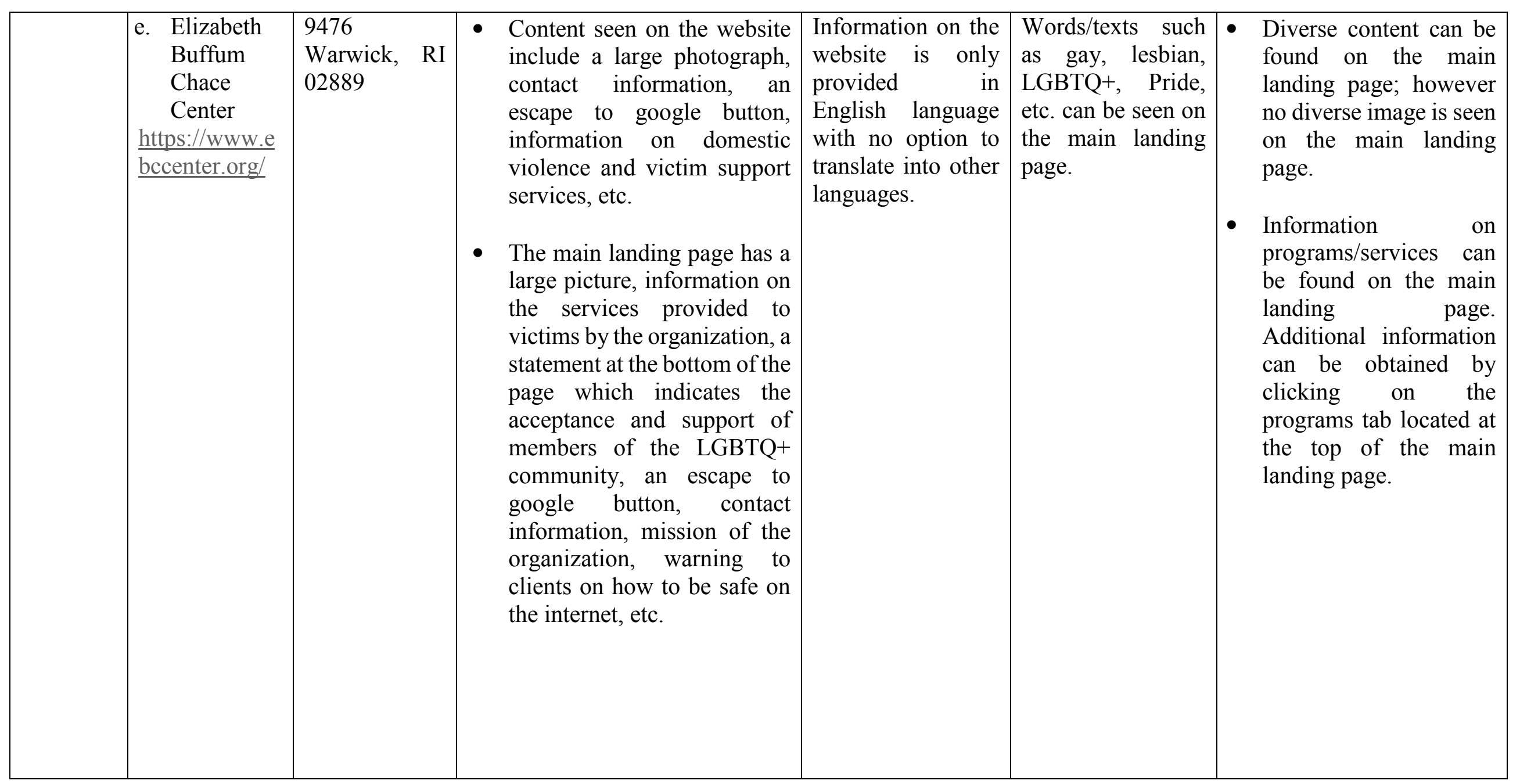




\begin{tabular}{|c|c|c|c|c|c|c|}
\hline Colorado & $\begin{array}{l}\text { a. Hilltop's } \\
\text { Latimer } \\
\text { House: } \\
\text { Domestic } \\
\text { Violence } \\
\text { and Sexual } \\
\text { Assault } \\
\text { Services } \\
\text { https://hilltopl } \\
\text { atimerhouse.o } \\
\underline{\text { rg/ }}\end{array}$ & $\mathrm{N} / \mathrm{A}$ & $\begin{array}{l}\text { - Content on the website } \\
\text { include but not limited to } \\
\text { types of services provided, } \\
\text { background and contact } \\
\text { information of the } \\
\text { organization, an escape button } \\
\text { at the top of every page, } \\
\text { images, information on } \\
\text { domestic and sexual violence, } \\
\text { survivor stories, etc. } \\
\text { - The main landing page has an } \\
\text { escape button at the top, types } \\
\text { of services provided, images, } \\
\text { tabs that open pages with } \\
\text { more information on diverse } \\
\text { topics, hotlines, etc. } \\
\text { Total of six images can be } \\
\text { found on the website. }\end{array}$ & $\begin{array}{l}\text { Information on the } \\
\text { website is in } \\
\text { English and } \\
\text { Spanish languages. }\end{array}$ & $\begin{array}{l}\text { A non- } \\
\text { discriminatory } \\
\text { statement can be } \\
\text { found on the } \\
\text { emergency } \\
\text { safehouse page } \\
\text { which indicates } \\
\text { that services are } \\
\text { provided for all } \\
\text { irrespective of } \\
\text { race, religion, } \\
\text { sexual orientation, } \\
\text { etc. }\end{array}$ & $\begin{array}{l}\text { - Content on domestic } \\
\text { violence and victim } \\
\text { services can be found on } \\
\text { the main landing page, } \\
\text { however more details } \\
\text { can be obtained with a } \\
\text { single click on the } \\
\text { shelter and support tab } \\
\text { located on the main } \\
\text { landing page. } \\
\text { Not much diverse } \\
\text { content/images can be } \\
\text { found on the website; a } \\
\text { single picture of a } \\
\text { woman of color can be } \\
\text { seen at the top of the } \\
\text { main landing page and } \\
\text { on the emergency safe } \\
\text { house page. }\end{array}$ \\
\hline
\end{tabular}




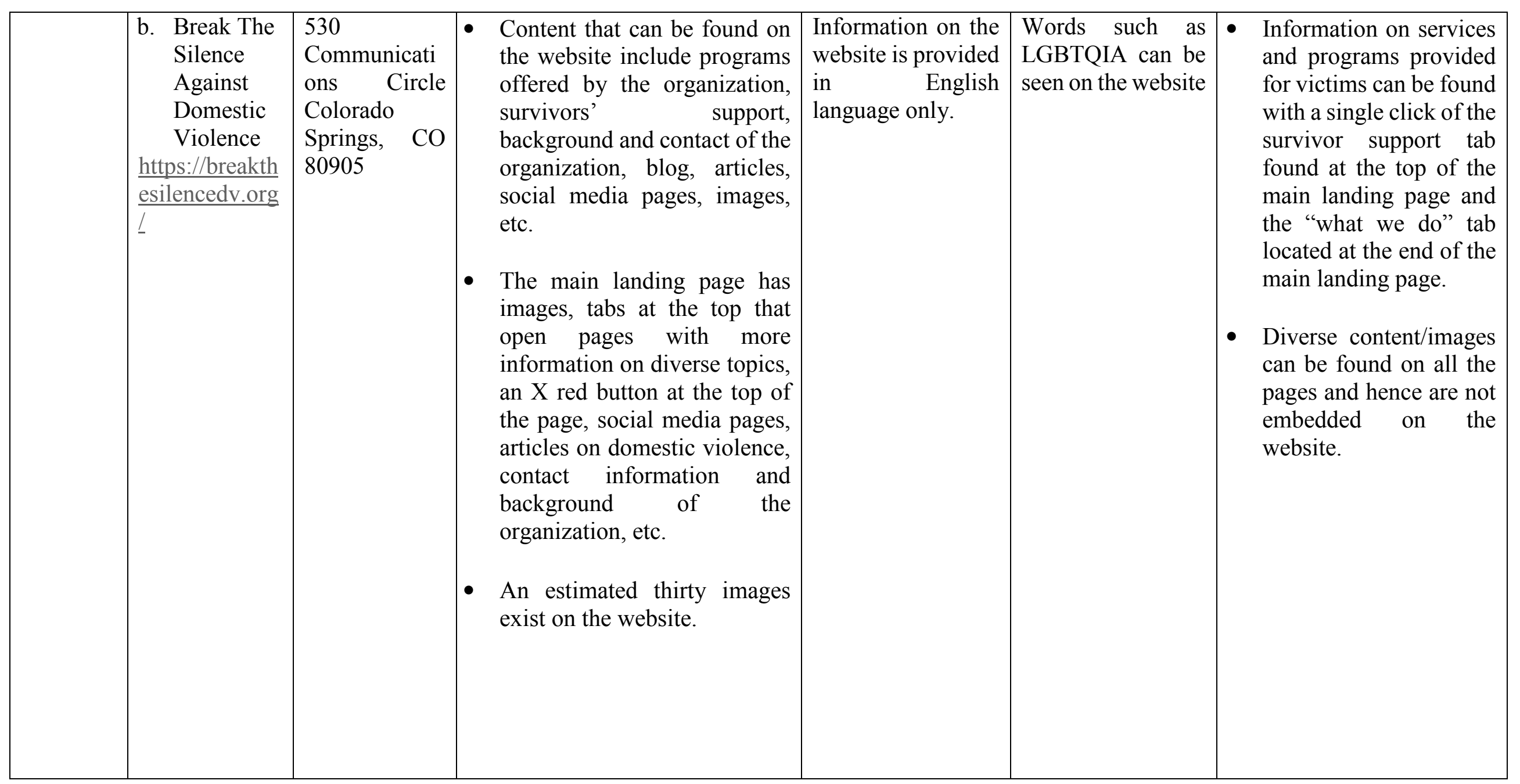




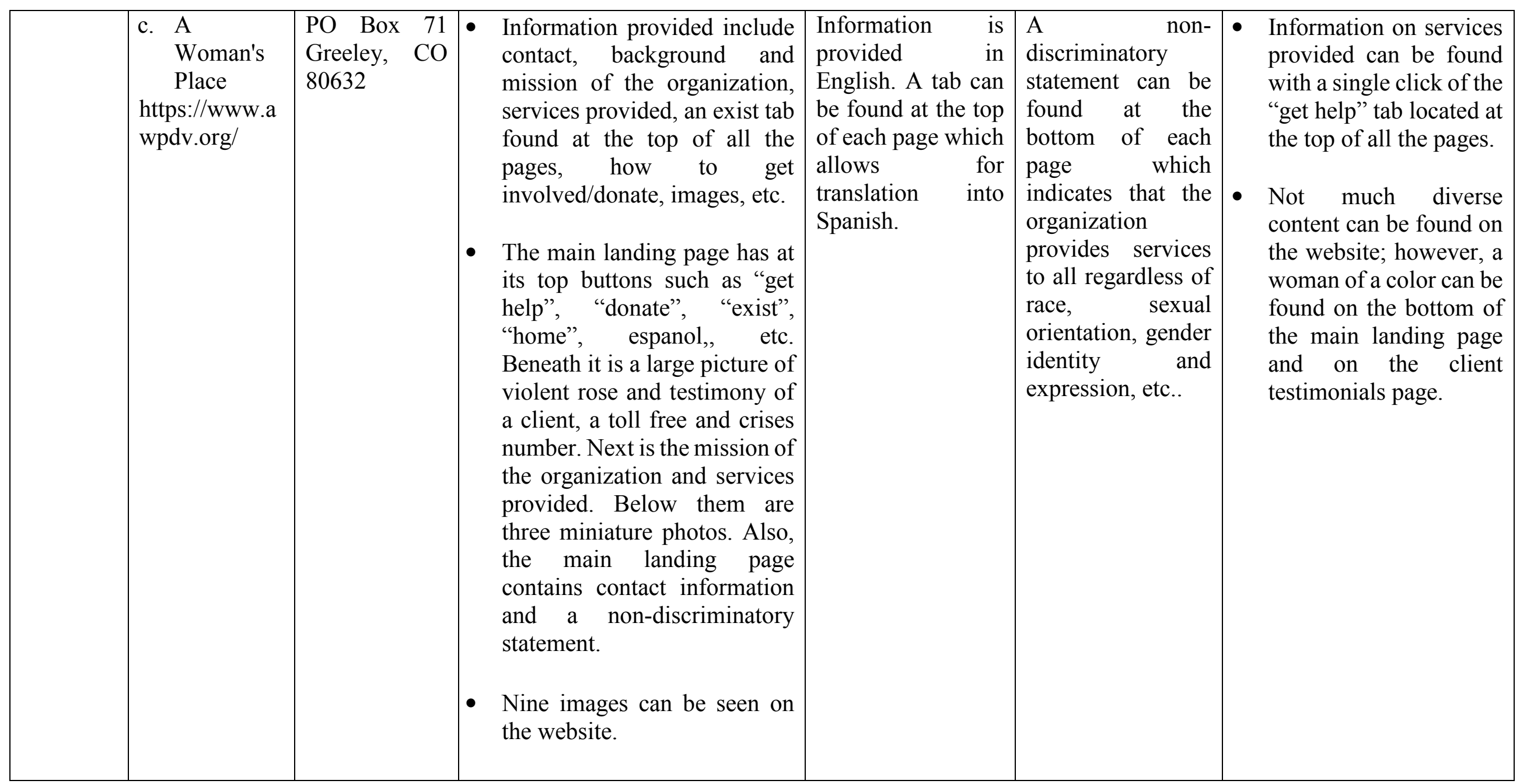




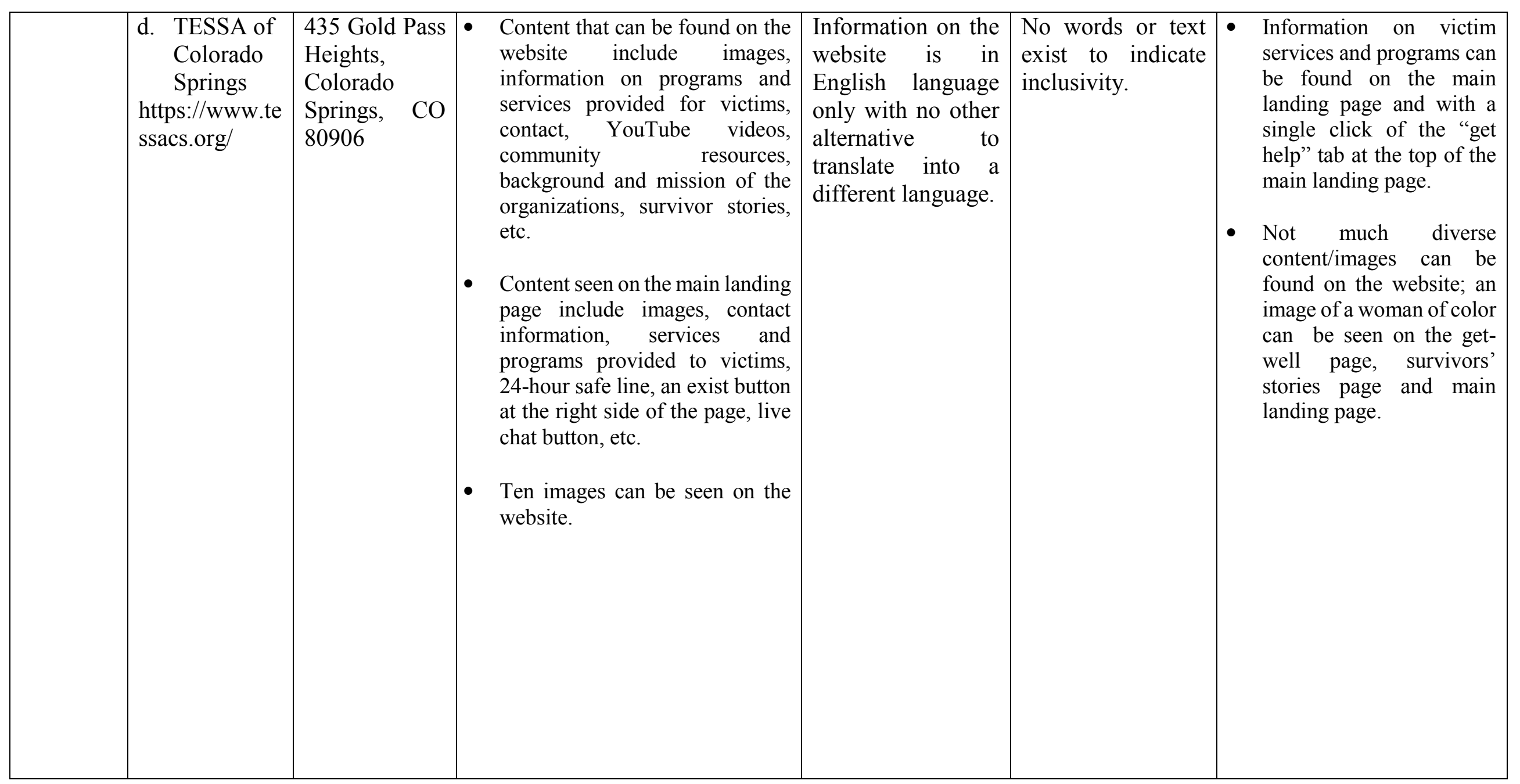




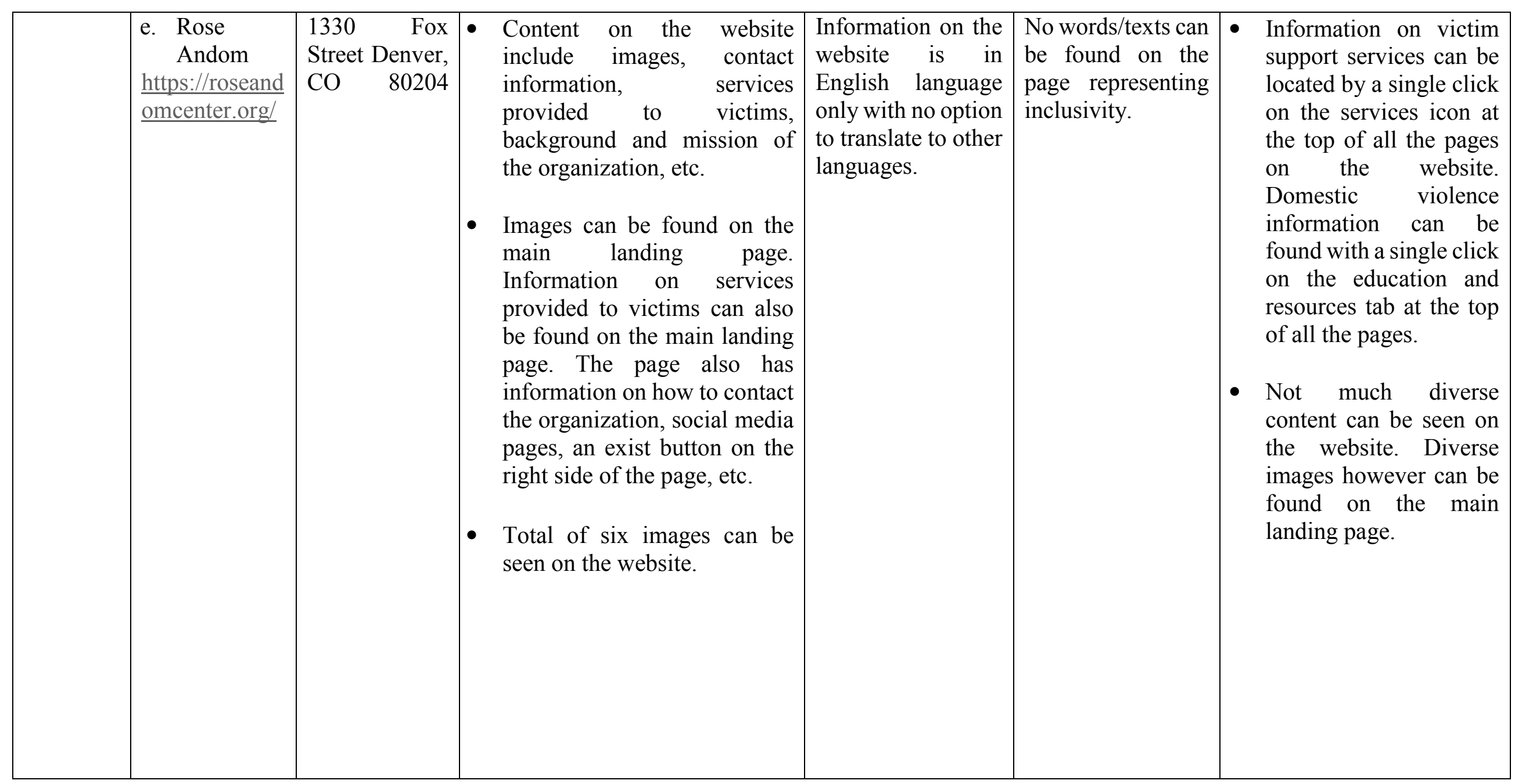




\begin{tabular}{|c|c|c|c|c|c|c|}
\hline $\begin{array}{l}\text { Californi } \\
\text { a }\end{array}$ & $\begin{array}{l}\text { a. YWCA of } \\
\text { Sonoma } \\
\text { County } \\
\text { www.ywcasc. } \\
\text { org/ }\end{array}$ & $\begin{array}{l}2755 \\
\text { Mendocino } \\
\text { Ave., Santa } \\
\text { Rosa, } \quad \text { CA } \\
95403\end{array}$ & 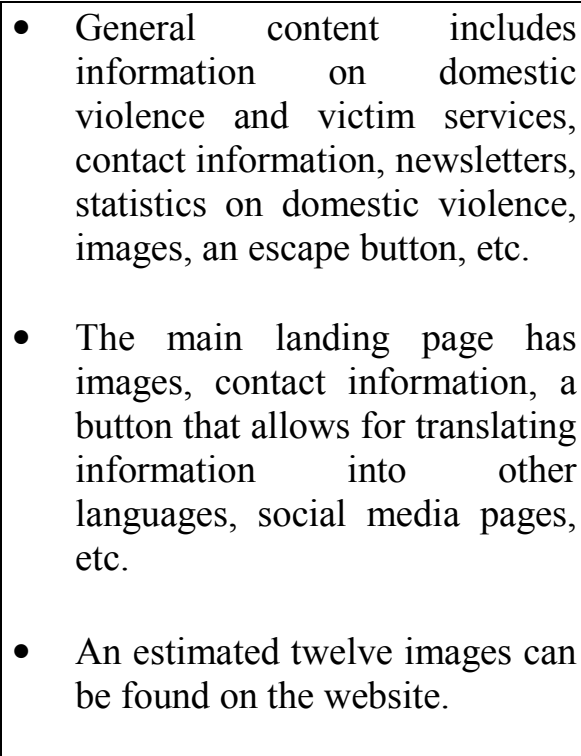 & $\begin{array}{l}\text { Details on the } \\
\text { websites } \\
\text { provided are } \\
\text { English in } \\
\text { however, an option } \\
\text { exist for translating } \\
\text { into different } \\
\text { languages. }\end{array}$ & $\begin{array}{l}\text { No words/texts can } \\
\text { be found on the } \\
\text { website which } \\
\text { shows inclusivity. }\end{array}$ & $\begin{array}{l}\text { - Information on domestic } \\
\text { violence and victim } \\
\text { services can be found on } \\
\text { the what we do tab located } \\
\text { at the top of the main } \\
\text { landing page. } \\
\text { - Not much diverse content } \\
\text { can be found on the } \\
\text { website; a picture with a } \\
\text { woman of color can be } \\
\text { seen at the end of the main } \\
\text { landing page and an image } \\
\text { showing the hands of } \\
\text { people of color can be } \\
\text { seen at the top of the } \\
\text { domestic violence page }\end{array}$ \\
\hline
\end{tabular}




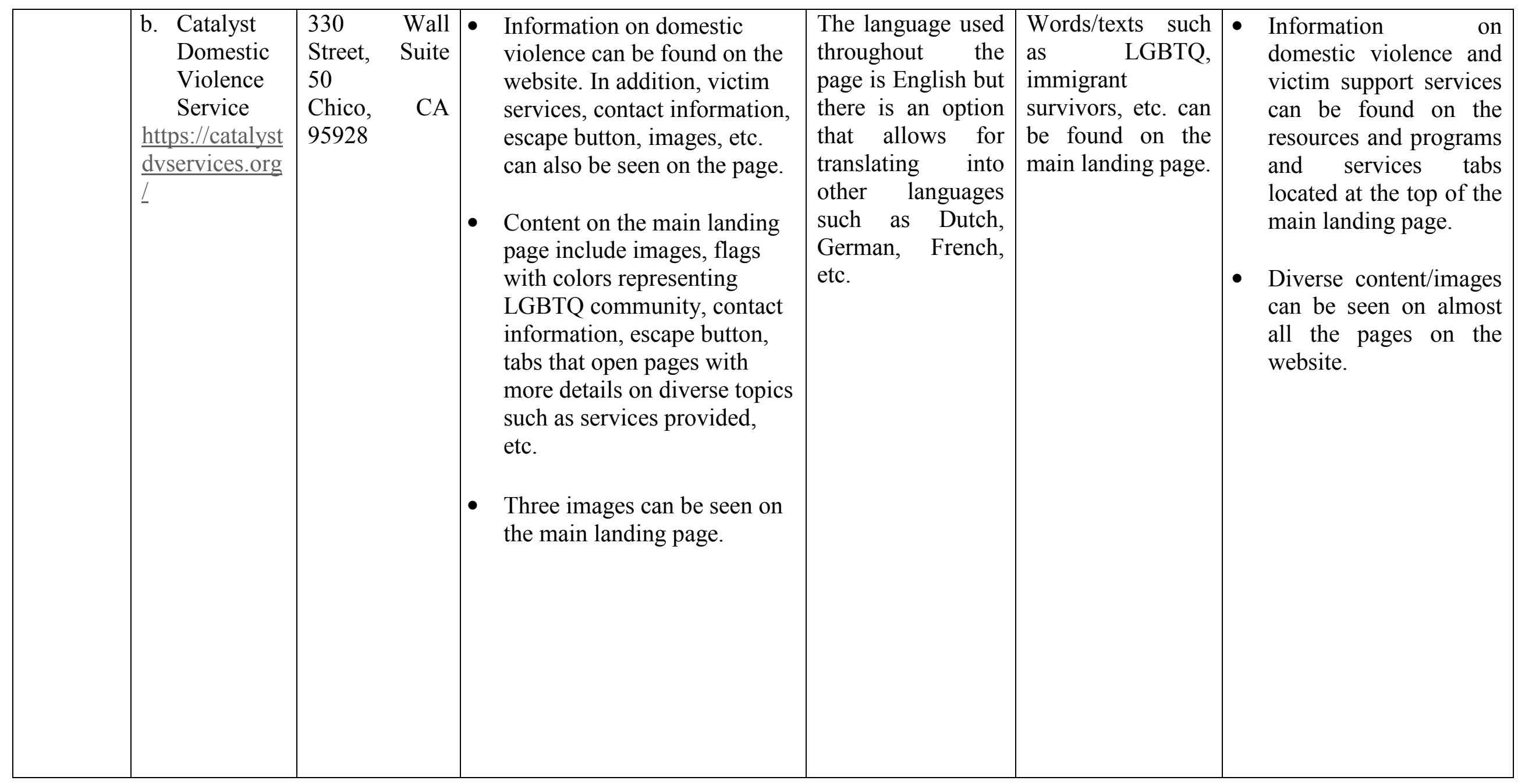




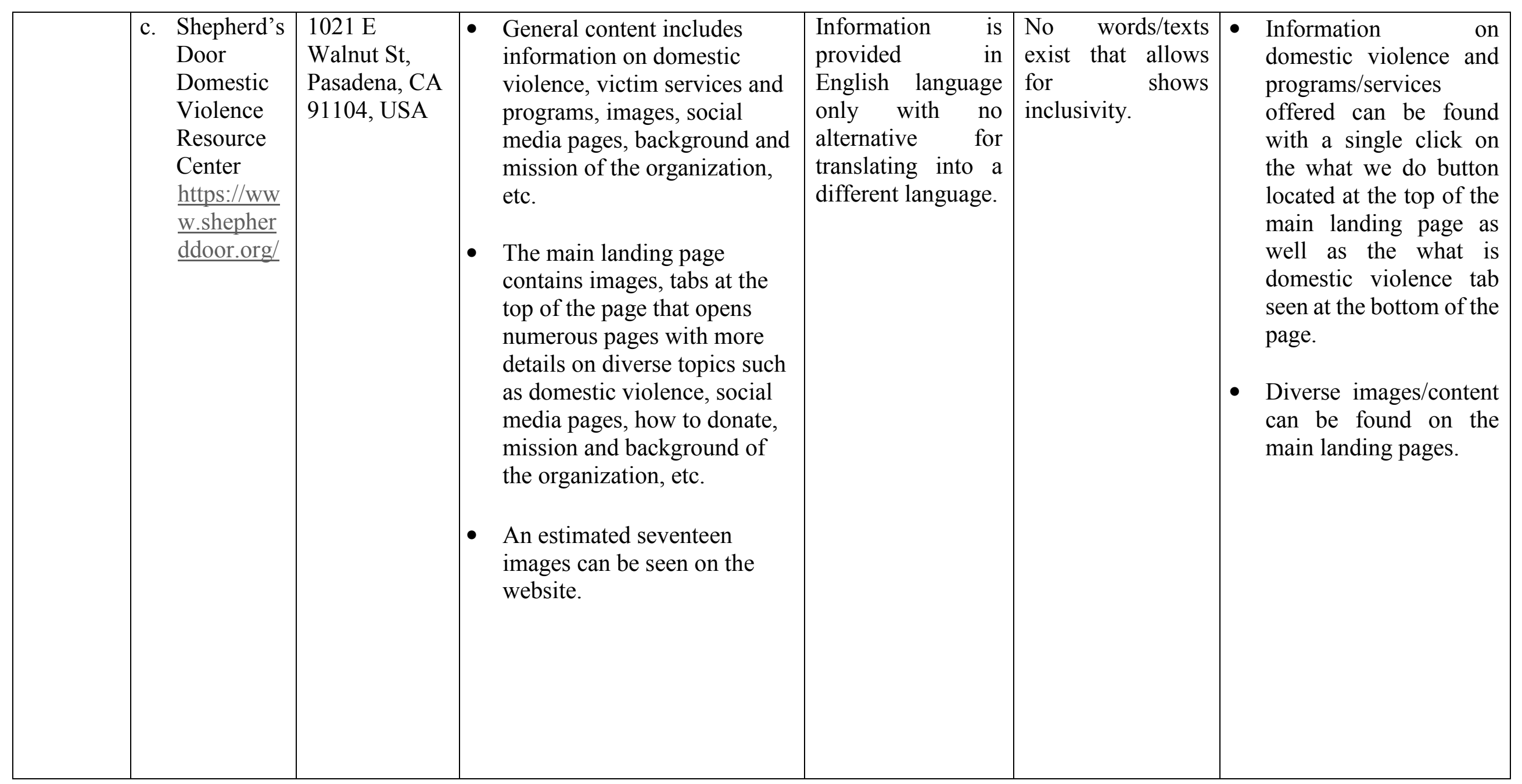




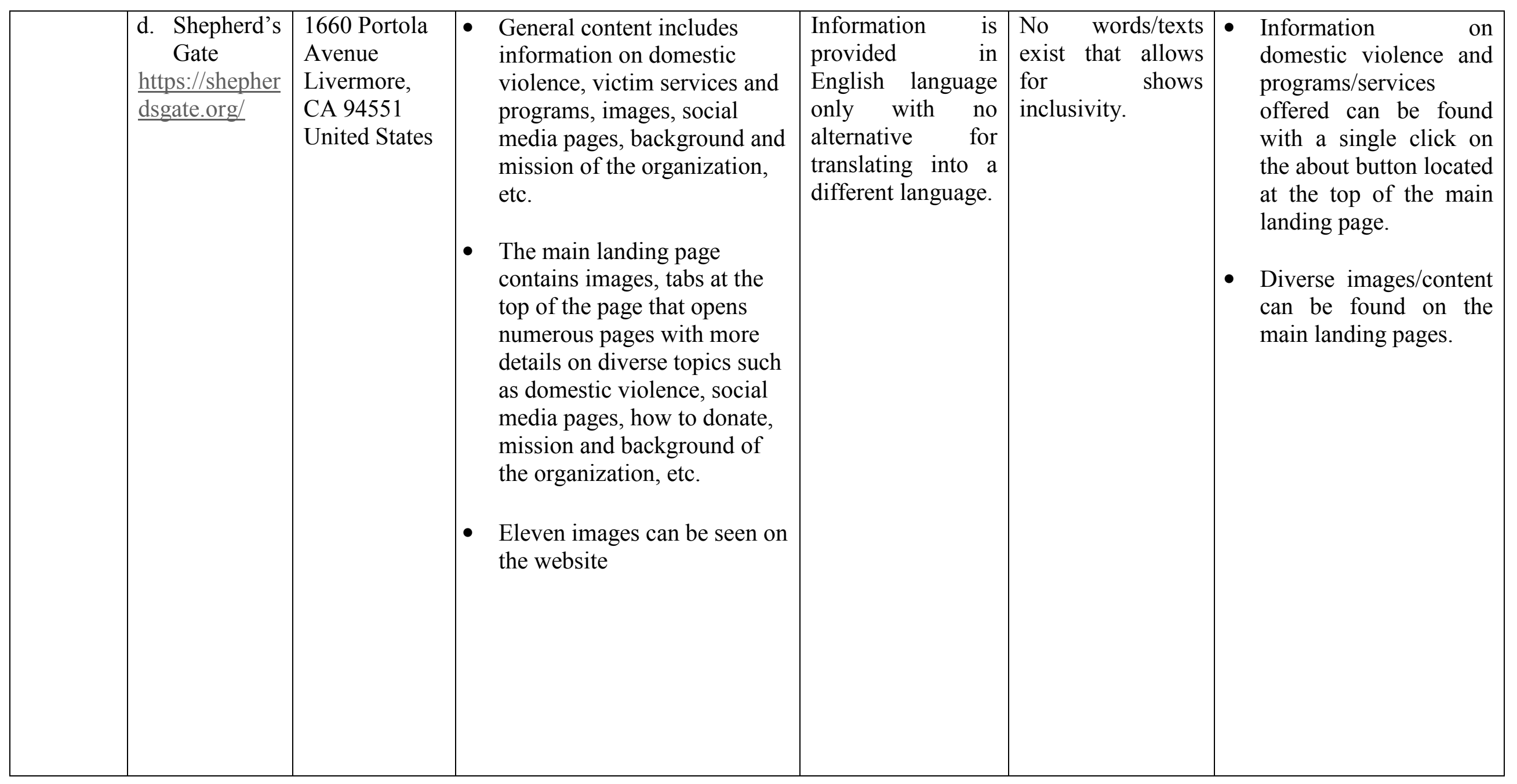




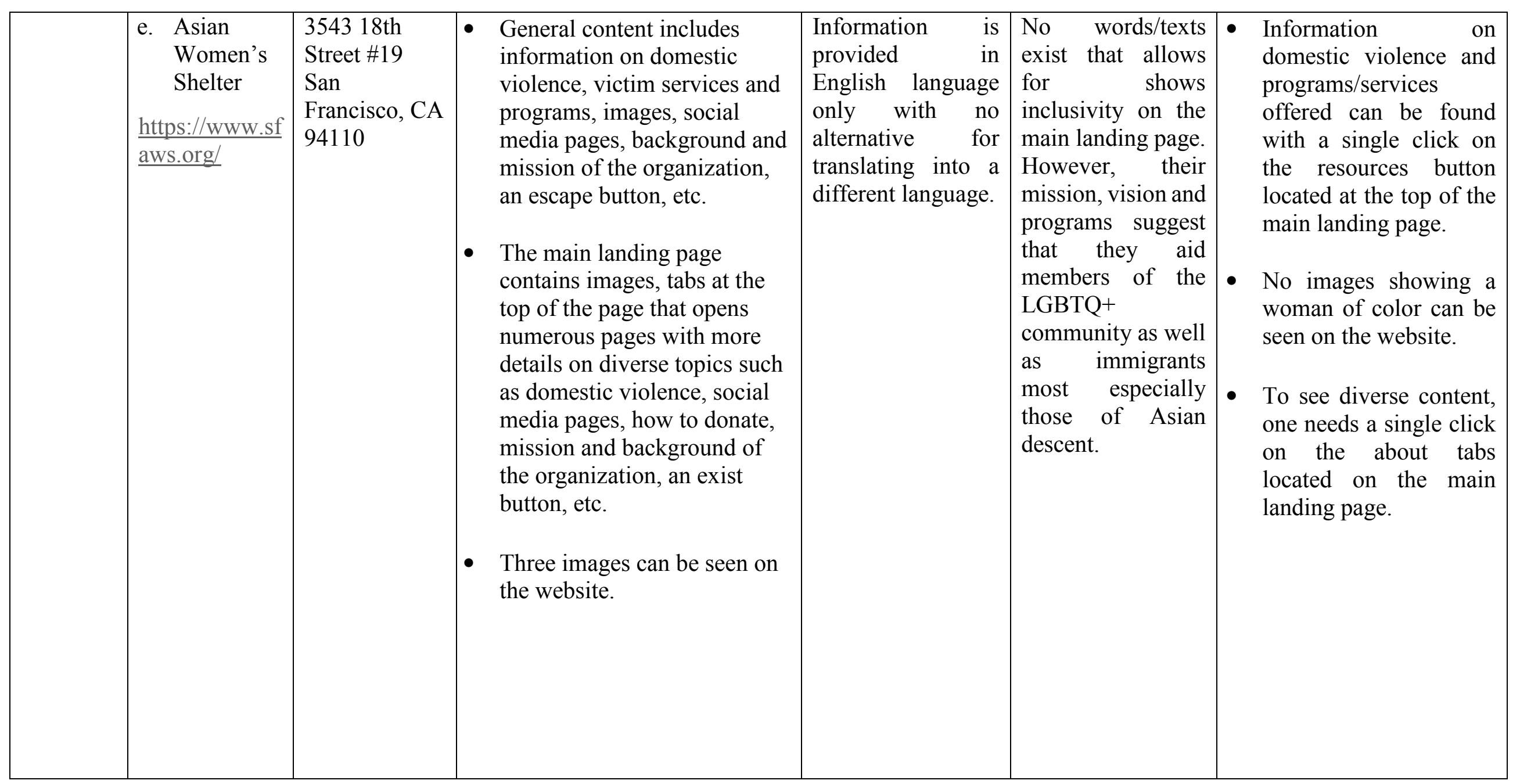




\section{APPENDIX B: RAW DATA (IMAGES)}

\section{RAW DATA (IMAGES)}

\begin{tabular}{|c|c|c|}
\hline STATE & VICTIM SUPPORT ORGANIZATION. & IMAGE/PHOTOGRAPH \\
\hline South Dakota & $\begin{array}{l}\text { a. Working against violence inc. } \\
\text { https://www.wavi.org/ }\end{array}$ & $\begin{array}{l}\text { - The first picture slide reveals an image of a white child holding the } \\
\text { hand of a white person. } \\
\text { - Second picture slide shows a picture with the words, "hope" and the } \\
\text { fingers of a white person holding the symbol for hope. } \\
\text { - The third picture slide shows a collage of photographs, each } \\
\text { depicting individuals from different racial backgrounds, gender, } \\
\text { ethnic group, religion and nationality is seen on the topmost page of } \\
\text { the main landing page. This image is wide in width. } \\
\text { - A medium sized picture can be seen below the slides of images at the } \\
\text { topmost part of the main landing page. The individuals represented } \\
\text { in this image are a middle-aged woman and a female child. Both } \\
\text { individuals have brown-skin and straight, black hair. } \\
\text { - Two medium photographs are seen at the bottom of the page. One } \\
\text { picture shows an image of a woman and child of color. Both have } \\
\text { kinky hair which may mean they are of African descent. The second } \\
\text { picture although a bit blurry, shows an image of a number of White } \\
\text { women and a White male as well as African American women. } \\
\text { - The image on the domestic violence page of this website shows an } \\
\text { image of a White man and White woman and a White female child. } \\
\text { pho image on the sexual assault page of the website shows a } \\
\text { photoph of a White woman. }\end{array}$ \\
\hline
\end{tabular}




\begin{tabular}{|c|c|}
\hline $\begin{array}{c}\text { b. River city domestic violence shelter } \\
\text { https://www.yanktondomesticviolencecenter.com/ }\end{array}$ & $\begin{array}{l}\text { - A photograph of four women can be seen on the topmost part of the } \\
\text { support group page. Three have white skin tone, however two have } \\
\text { black curly hair and one seems to have black straight hair. In } \\
\text { addition, there seems to be an image of a black woman with braids, } \\
\text { yet the image is blurry and covered with words hence making it } \\
\text { difficult to see the image clearly. } \\
\text { - There are two images on the trauma sensitive yoga page which } \\
\text { shows the feet and hands of a White woman and a full photograph } \\
\text { of a White woman stretching. } \\
\text { - All the ten medium sized images(slides) on the domestic awareness } \\
\text { page only shows pictures of White males and females. }\end{array}$ \\
\hline $\begin{array}{l}\text { c. Children's Home Society-Domestic Violence } \\
\text { https://chssd.org/childrensinn/ }\end{array}$ & $\begin{array}{l}\text { - The very first image on the topmost part of the main landing page } \\
\text { is that of a White woman and a white Male child. Both have straight } \\
\text { black hair. Immediately after this image, three pictures are seen } \\
\text { right below it. Out of the seven individuals in these photographs, six } \\
\text { of them are White women and only one is a woman of color. } \\
\text { - An image of three White women in yellow t-shirts is also seen at } \\
\text { the bottom of the main landing page. } \\
\text { - Photographs on the "get help page" for domestic violence victims } \\
\text { are six in total with one out of the five showing a picture of a } \\
\text { building. The remaining five shows pictures of White women and } \\
\text { children as well as women of color. Four of those pictures are } \\
\text { relatively small in nature with one being medium in size. } \\
\text { - The picture seen on the top of the page shows a White woman with } \\
\text { long dark-brown hair and a female child with long brown hair. A }\end{array}$ \\
\hline
\end{tabular}




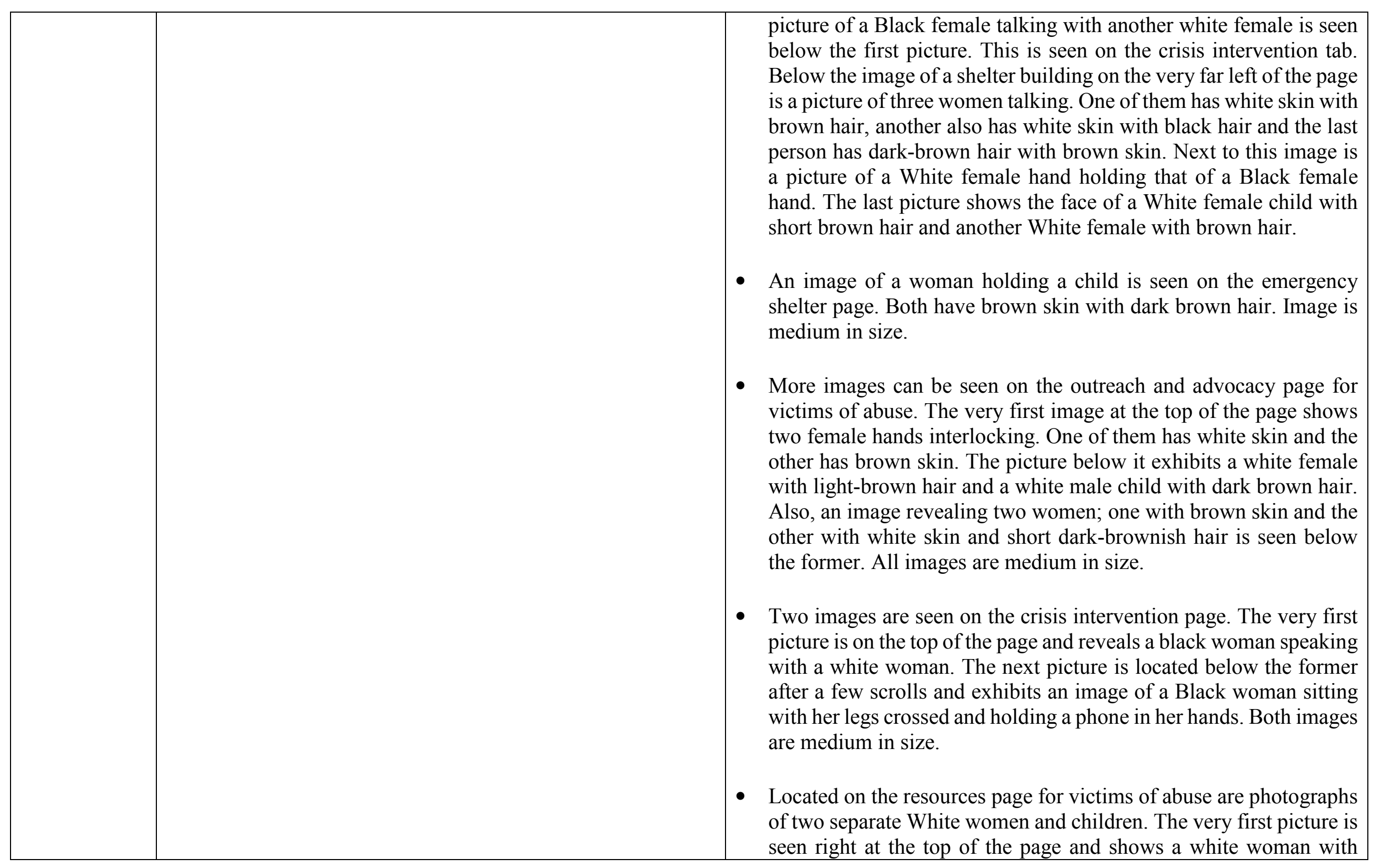




\begin{tabular}{|c|c|}
\hline & $\begin{array}{l}\text { blonde hair sitting face to face with a white female child who also } \\
\text { has blonde hair. The other picture is seen after a few scrolls down } \\
\text { the page and shows an image of a white woman with long black hair } \\
\text { carrying a female child with dark-brown hair at her back and a male } \\
\text { child with blonde hair in the front. } \\
\text { - The counselling and support group page has six images in total and } \\
\text { all of the images are medium-sized. }\end{array}$ \\
\hline $\begin{array}{l}\text { d. Compass Center. } \\
\text { https://thecompasscenter.org/ }\end{array}$ & $\begin{array}{l}\text { - A single image is seen on the support and counselling group page, } \\
\text { advocacy page, resources page, play therapy, community education } \\
\text { and adult and teen counselling pages. The image shows the hands } \\
\text { of a white individual holding a piece of Lego and is relatively large } \\
\text { in nature. } \\
\text { - An image of a group of three white women laughing/smiling can be } \\
\text { seen on the "who we are page". Photograph is relatively large in } \\
\text { nature. } \\
\text { - All the seven miniature images of staff/team members on the } \\
\text { "staff" page are that of only white women and a white male. A } \\
\text { relatively larger portrait of three white women laughing is seen at } \\
\text { the top of the page. } \\
\text { - Of all the images found on the website, only one shows a picture of } \\
\text { a black female hugging another person in black shirt. This image } \\
\text { can be located on the bystander intervention, become a volunteer } \\
\text { and internships pages. }\end{array}$ \\
\hline $\begin{array}{c}\text { e. Missouri Valley Crisis Center } \\
\text { https://missourivalley.wordpress.com// }\end{array}$ & $\begin{array}{l}\text { - A large portrait of a woman is seen on the top of the main landing } \\
\text { page below the name of the organization. The woman in the } \\
\text { photograph has curly brown hair with dark roots, brown eyes and } \\
\text { light skinned. In addition, a medium size image of another female }\end{array}$ \\
\hline
\end{tabular}




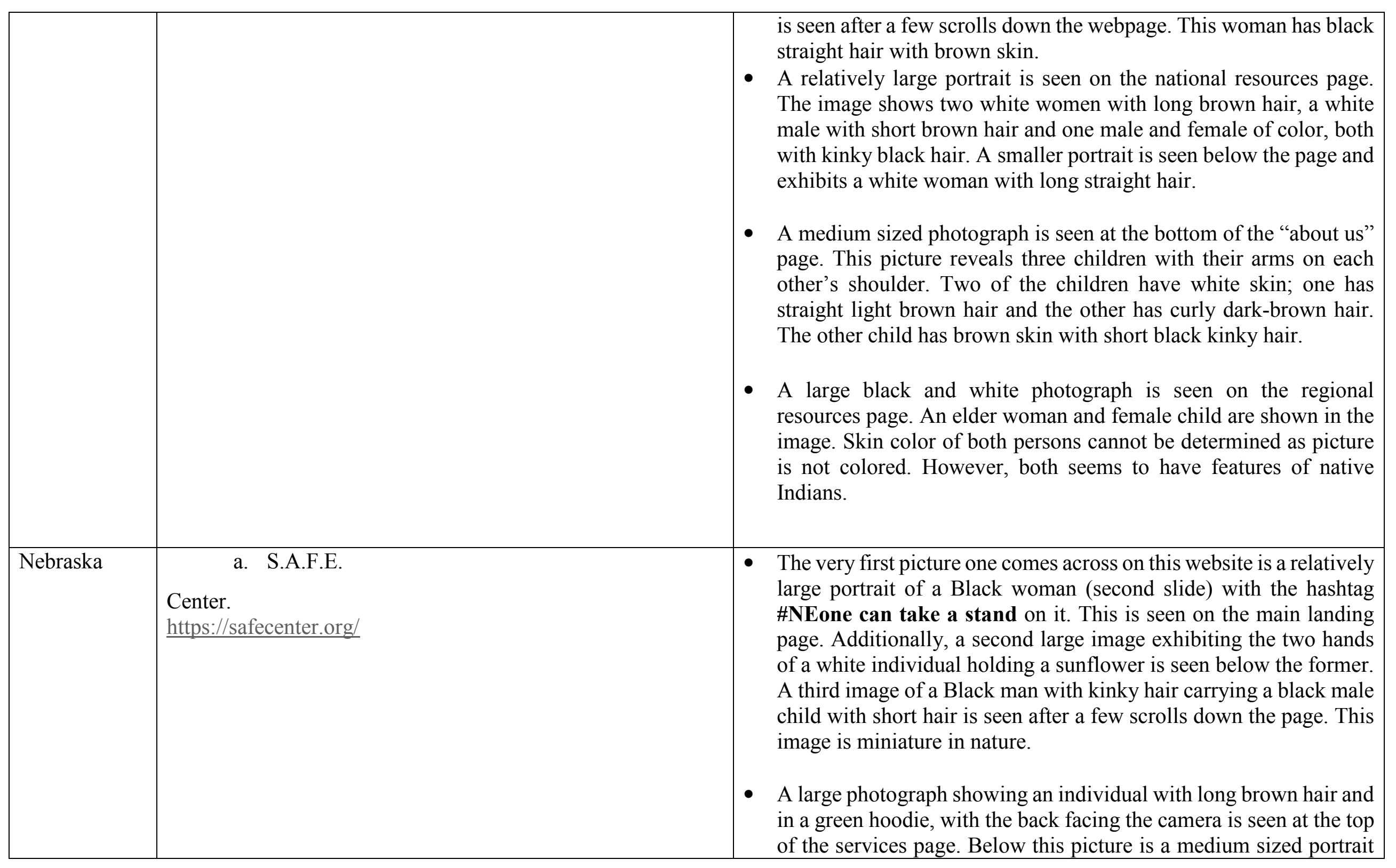




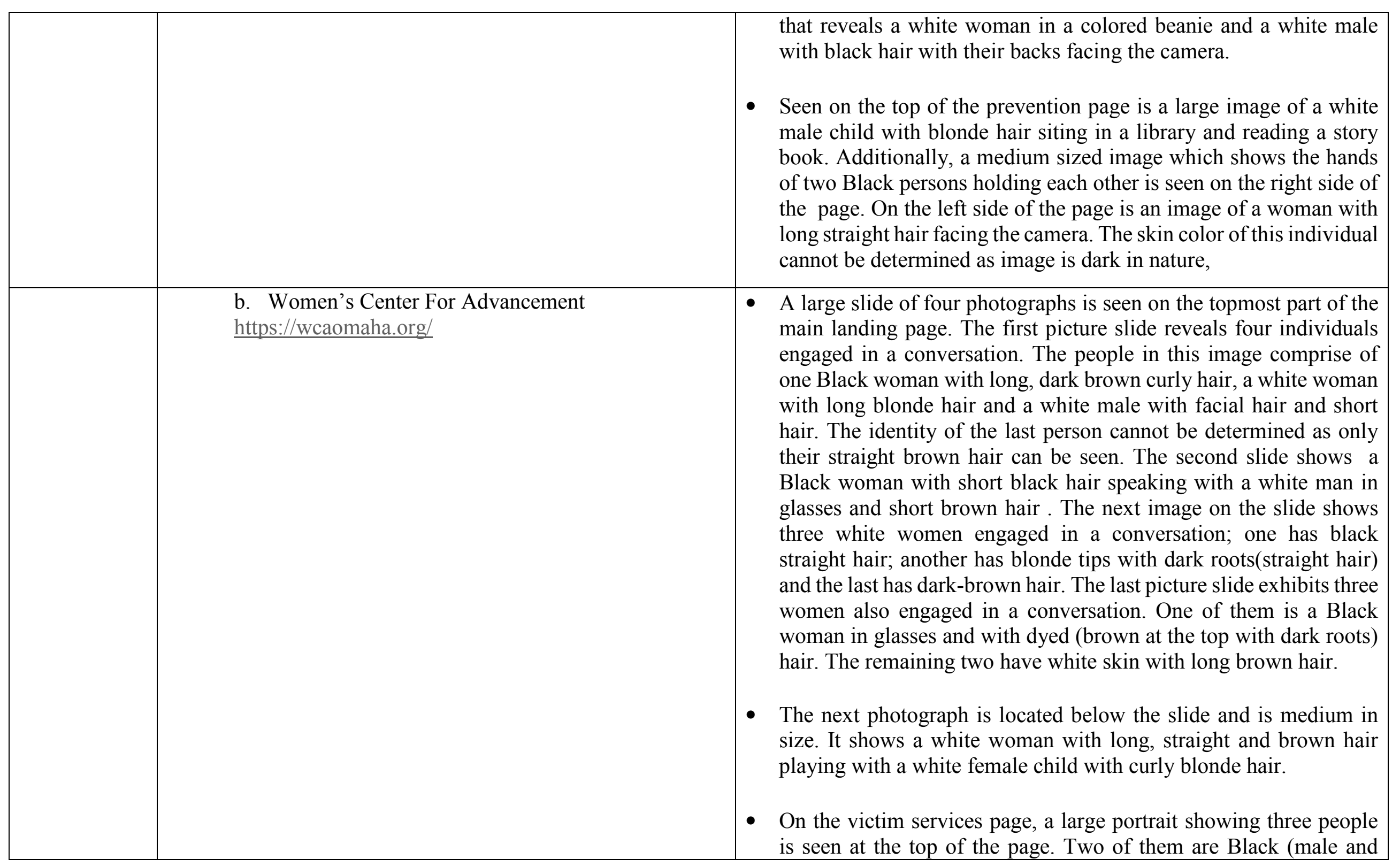









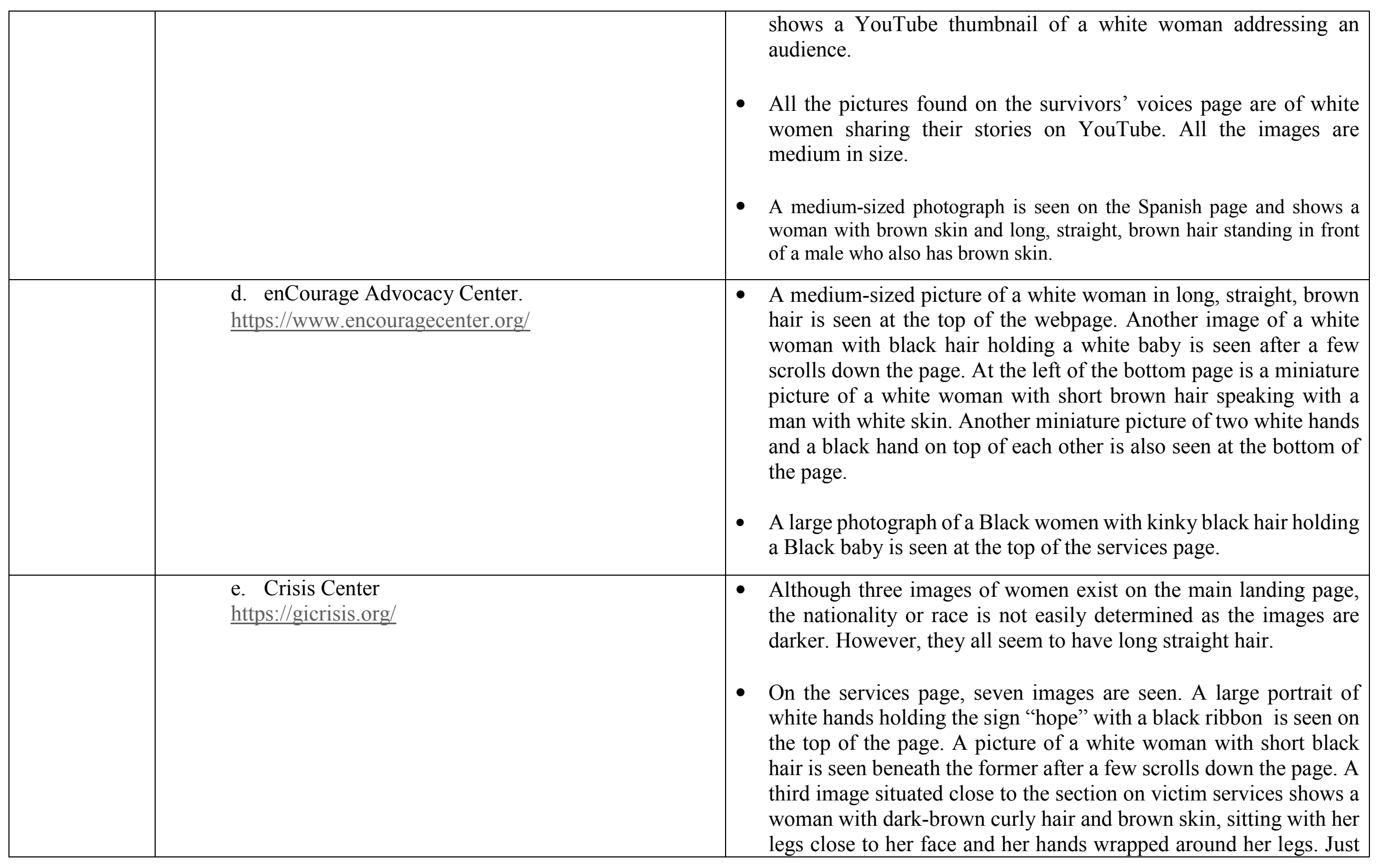




\begin{tabular}{|c|c|c|}
\hline & & $\begin{array}{l}\text { beneath it on the right side of the page is an image of three white } \\
\text { individuals in a meeting; two are males and one is a female. Next is } \\
\text { an image exhibiting five children and an adult sitting in a circle on } \\
\text { the floor. The adult has white skin and short blonde hair; three of } \\
\text { the children has white skin, one has light brown skin and the other } \\
\text { has dark brown skin. The next picture is that of a white male sitting } \\
\text { with his hands to clasped together. The last picture on this page is } \\
\text { located at the bottom and shows a white woman with long, straight } \\
\text { hair sitting in a field. } \\
\text { - Another image of a white woman with short blonde hair is seen on } \\
\text { the victims' services page. } \\
\text { - All the images are large in size. }\end{array}$ \\
\hline Maryland & $\begin{array}{l}\text { a. House of Ruth Maryland } \\
\text { https://hruth.org/get-help/ }\end{array}$ & $\begin{array}{l}\text { A large portrait of a Black woman is seen on the top of the main } \\
\text { landing page. Another image of a woman with short and straight } \\
\text { hair is seen after a few scrolls down the page. Skin color of the } \\
\text { woman is not determinable as image is a bit dark. } \\
\\
\text { - Three large images are seen on the children and youth services page. } \\
\text { The first is at the top of the page and reveals a Black woman holding } \\
\text { a baby with brown skin and short, straight hair. A few scrolls down } \\
\text { the pages discloses a picture of a Black woman with short kinky } \\
\text { hair. The last picture on the page is seen under the former and shows } \\
\text { a Black woman with short hair and a white woman with long, } \\
\text { straight hair. } \\
\text { - Eight minimalist portraits are found on the story-tellers page. Out of } \\
\text { the eight, only one has white skin color; the remaining seven all have } \\
\text { light to dark-brown skin color. Six are females and two are males. }\end{array}$ \\
\hline
\end{tabular}




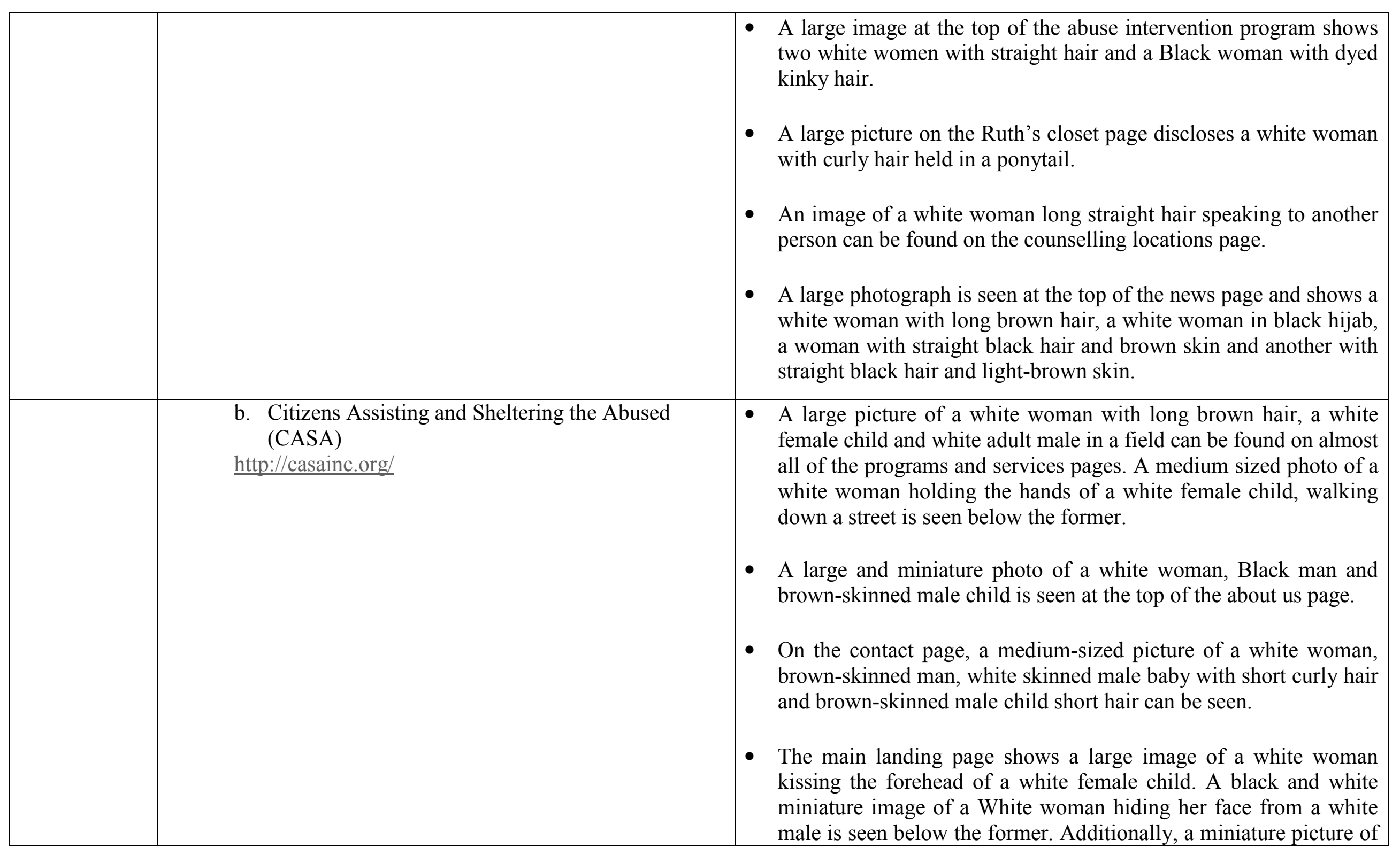




\begin{tabular}{|c|c|c|}
\hline & & $\begin{array}{l}\text { Black male and female teenagers and that of a white female with a } \\
\text { bruised eye is also seen on the main landing page. } \\
\text { - A small sized photo of a white woman with straight black hair } \\
\text { hugging a white male child with short brown hair on her laps is also } \\
\text { seen at the bottom of the main landing page. } \\
\text { - A very large image of a Black woman's face can be found on the } \\
\text { domestic violence page after a few scrolls down the page. }\end{array}$ \\
\hline & $\begin{array}{l}\text { c. TurnAround, Inc. } \\
\text { https://turnaroundinc.org/ }\end{array}$ & $\begin{array}{l}\text { - The first photo one comes across on the top of the main landing page } \\
\text { is a large photo of three Black women seated around a table; two } \\
\text { have curly hair and one has straight hair. A medium-sized picture of } \\
\text { a Black male is seen below it after a few scrolls. The next picture is } \\
\text { a medium sized picture that reveals a light skinned woman with } \\
\text { curly hair. A large picture of a White female child sitting is seen at } \\
\text { the bottom of the page. } \\
\text { - A large portrait showing a Black woman with short kinky hair and } \\
\text { two White women with long brown hair is seen on the supporting } \\
\text { survivors' page. } \\
\text { The get help page reveals at its top, a large photo of two women } \\
\text { with White Skin. A few scrolls down the page shows a picture of a } \\
\text { White woman with a prosthetic hand. } \\
\text { The services page has a large image of a Black man and White man } \\
\text { at its top. A miniature image of two white women is also seen on } \\
\text { the page. One has long straight hair and the other has on her hand a } \\
\text { black hijab head wrapper. }\end{array}$ \\
\hline & $\begin{array}{l}\text { d. Center for Abused Persons } \\
\text { https://www.centerforabusedpersonscharlescounty.org/ }\end{array}$ & $\begin{array}{l}\text { - The top of the main landing page reveals a large slide of three } \\
\text { pictures; the first although black and white, shows a Black man and }\end{array}$ \\
\hline
\end{tabular}




\begin{tabular}{|c|c|c|}
\hline & & $\begin{array}{l}\text { woman, the second is a picture of a woman with brown skin and the } \\
\text { last slide is a picture of a white woman. A few scrolls down the page } \\
\text { shows a small sized image of a White woman with straight light } \\
\text { brown hair. } \\
\text { - The victim advocacy page has a large sized image of a Black woman } \\
\text { with long curly hair at its top. } \\
\text { - The counselling page has at its top, a large image of a White woman. } \\
\text { - The abuse intervention page has a large image of a White male at its } \\
\text { top. }\end{array}$ \\
\hline & $\begin{array}{l}\text { e. YWCA of Annapolis and Anne Arundel County } \\
\text { https://www.annapolisywca.org/ }\end{array}$ & $\begin{array}{l}\text { - The main landing page has a large image of a Black woman's face } \\
\text { (half). A few scrolls down the page shows a miniature image of a } \\
\text { Black woman. Below it is a small-sized image of three white } \\
\text { females with white skin; two have long dark-brown hair and the } \\
\text { other has long blonde hair with brown roots, and a Black female } \\
\text { with short black hair. } \\
\text { - Two images are on the "how we help page." One is a picture of a } \\
\text { woman with white skin and long straight hair and a male child with } \\
\text { short straight hair. The other shows a woman with white skin and } \\
\text { long straight hair. }\end{array}$ \\
\hline Kentucky & $\begin{array}{l}\text { a. Bethany House Abuse Shelter, Inc. } \\
\text { https://bethanyhouseinc.org/ }\end{array}$ & $\begin{array}{l}\text { - Three miniature photos revealing the hands of white persons can be } \\
\text { seen on the main landing page. } \\
\text { - A medium-sized image exhibiting the arms of a Black person and } \\
\text { that of a White person is found on the services page. } \\
\text { - On the "about page" a picture of a woman with white skin and short } \\
\text { brown hair holding a baby with white skin is seen. }\end{array}$ \\
\hline
\end{tabular}




\begin{tabular}{|c|c|c|}
\hline & $\begin{array}{l}\text { b. The Center for Women and Families } \\
\text { https://www.thecenteronline.org/ }\end{array}$ & $\begin{array}{l}\text { - At the top of the main landing page is a large portrait of a Black } \\
\text { woman with curly hair. A few scrolls down the page reveals a } \\
\text { medium-sized illustration of a Black woman with black hair. Below } \\
\text { it is a medium-sized picture of a Black woman, a white man and } \\
\text { woman and a male and female with brown skin, the woman has } \\
\text { curly hair. Below it is an image of a woman with white skin and } \\
\text { brown hair. } \\
\text { - A medium sized picture of a woman with white skin and short } \\
\text { golden-brown hair can be seen on the support services page. } \\
\text { The LGBTQ page has a medium-sized photo of a Black man with } \\
\text { short kinky hair and a man with white skin and short blonde hair } \\
\text { with dark roots. }\end{array}$ \\
\hline & $\begin{array}{l}\text { c. OASIS } \\
\text { https://oasisshelter.org/ }\end{array}$ & $\begin{array}{l}\text { - A large photograph of a woman with white skin and black straight } \\
\text { hair and a baby with white skin and brown hair can be seen at the } \\
\text { top of the main landing page. } \\
\text { - A large photo of a Black woman and Black male child can be seen } \\
\text { on the donate page. } \\
\text { - An image of a woman with white skin and curly black hair is seen } \\
\text { on the Español page. }\end{array}$ \\
\hline & $\begin{array}{l}\text { d. Turning Point Domestic Violence Services } \\
\text { https://www.turningpointky.org/ }\end{array}$ & $\begin{array}{l}\text { - A medium sized image of a woman with white skin and long blonde } \\
\text { hair can be located on the "what we do" page. } \\
\text { - A medium sized picture of three woman with white skin can be } \\
\text { found on the prevention and training page. One has black straight } \\
\text { hair and the remaining two have straight brown hair. }\end{array}$ \\
\hline & $\begin{array}{l}\text { e. Barren River Area Safe Space, Inc } \\
\text { https://www.brassinc.org/about/ }\end{array}$ & $\begin{array}{l}\text { - A large photo slide can be seen on the main landing page. Slide is } \\
\text { made up of an image of a woman with white skin and long, brown, }\end{array}$ \\
\hline
\end{tabular}




\begin{tabular}{|c|c|c|}
\hline & & $\begin{array}{l}\text { straight hair, a male child with white skin and short black hair and a } \\
\text { black and white image of white hands and feet of a person. A } \\
\text { miniature image showing a woman with white skin and black hair, } \\
\text { a man with white skin and black hair, a woman with white skin and } \\
\text { blonde hair, a man with brown skin and black hair and a man with } \\
\text { white skin is seen after a few scrolls down the page. } \\
\text { - Further scrolls down the page shows a miniature image of female } \\
\text { with brown skin and black hair. Another miniature image of a } \\
\text { woman with white skin and curly brown hair and another woman } \\
\text { with white skin is also seen on the main landing page. A small-sized } \\
\text { image of a male child with white skin and golden-brown hair and a } \\
\text { woman with white skin is seen on the page. } \\
\text { Twelve images can be seen on the about page. Out of the twelve, } \\
\text { only one image exhibits a Black woman, the rest are all images of } \\
\text { males and females with white skin. }\end{array}$ \\
\hline New York & $\begin{array}{l}\text { a. Urban Resource Institute } \\
\text { https://urinyc.org/\# }\end{array}$ & $\begin{array}{l}\text { - A medium sized image of a Black woman and a Black baby lies at } \\
\text { the top of the main landing page. A small-sized image of a Black } \\
\text { female is seen below the former. A few scrolls down the page } \\
\text { reveals a small-sized picture of a woman with White skin and } \\
\text { straight black hair. Another small-sized picture of two white females } \\
\text { with brown hair and a small sized image of a Black woman with } \\
\text { short kinky hair can also be found on the main landing page. Further } \\
\text { scrolls down the page reveals a small sized photo of a Black woman. } \\
\text { - A medium sized image of a Black woman with curly hair can be } \\
\text { found at the top of the domestic violence page. Three miniature } \\
\text { pictures of a Black woman can be found on the page as well. A } \\
\text { medium sized image of a Black woman and White woman is seen } \\
\text { on this page. }\end{array}$ \\
\hline
\end{tabular}




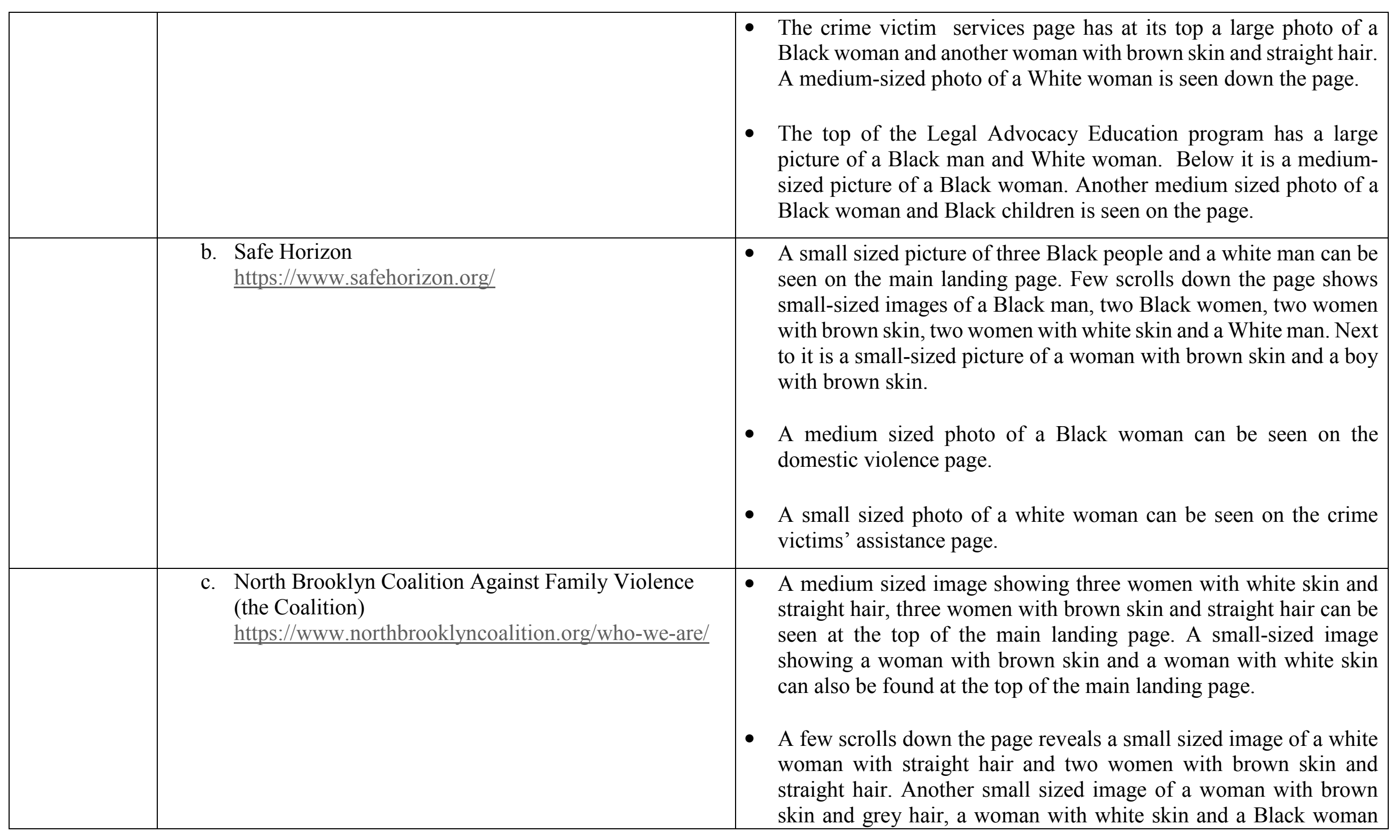




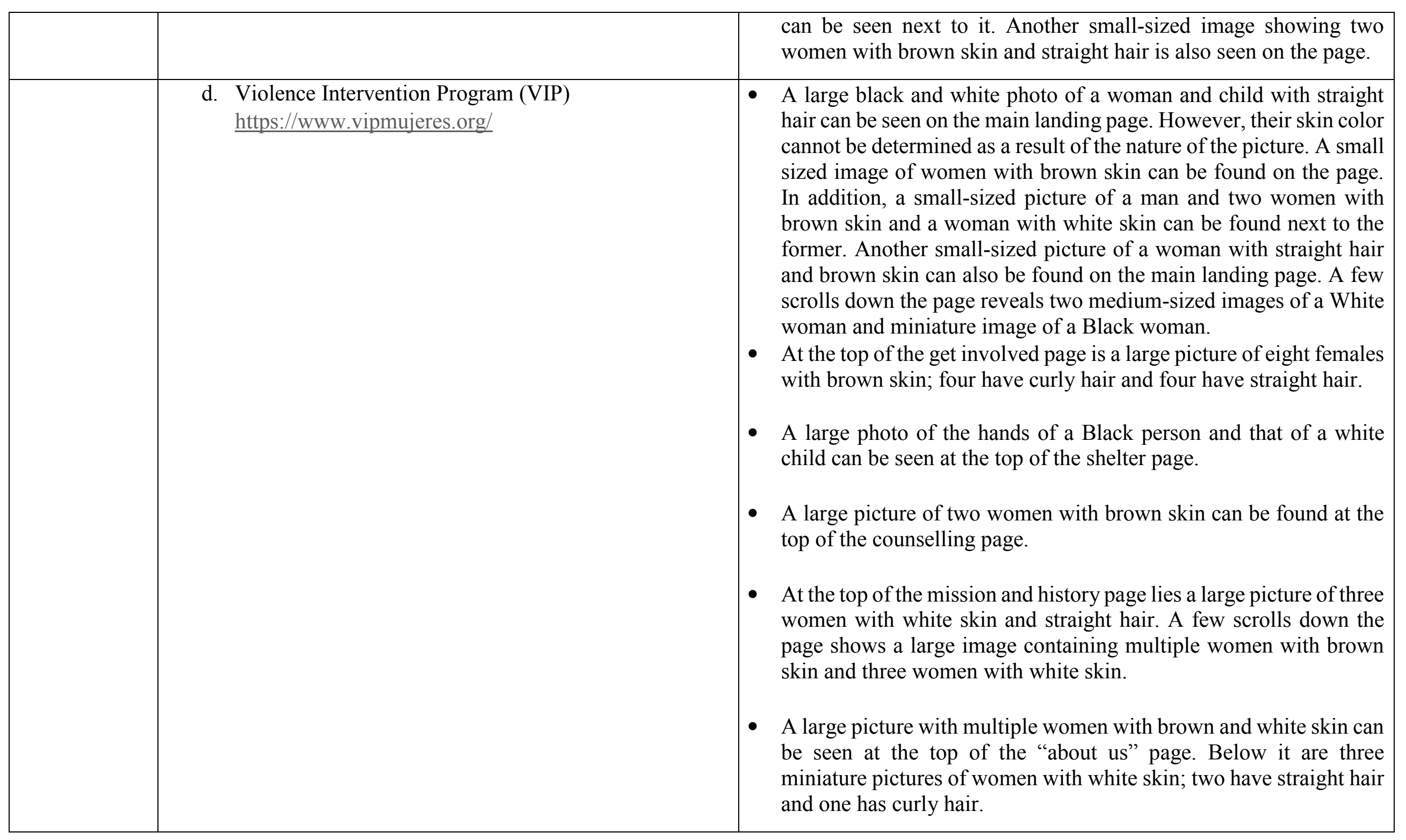




\begin{tabular}{|c|c|c|}
\hline & $\begin{array}{l}\text { e. Sanctuary for Families } \\
\text { https://sanctuaryforfamilies.org/ }\end{array}$ & $\begin{array}{l}\text { - On the top of the main landing page is a large portrait of picture } \\
\text { slides; the second picture is of a Black woman with braids. A few } \\
\text { scrolls down the page reveals a small-sized photo of a Black woman } \\
\text { and White woman. Next to it is miniature picture of a Black woman. } \\
\text { Another small sized image of a Black male child and female child } \\
\text { with brown skin can also be found on the page. Below them are two } \\
\text { images, one with a Black woman and the other with a White woman. } \\
\text { - A large picture of a woman with brown skin in a hijab and White } \\
\text { woman can be found on the legal services page. } \\
\text { - On the advocacy page is a large picture of two White women with } \\
\text { straight hair and a Black woman with short hair. } \\
\text { At the top of the survivors' page is a large image of three Black } \\
\text { women. Below it are three miniature images of a White woman and } \\
\text { a White male child. }\end{array}$ \\
\hline \multirow[t]{3}{*}{ Rhode Island } & $\begin{array}{l}\text { a. Sojourner House } \\
\text { https://www.sojournerri.org/ }\end{array}$ & $\begin{array}{l}\text { - A small sized image of three White women and a Black male can be } \\
\text { seen at the bottom of the main landing page. Next to it is a small- } \\
\text { sized image of a group of women; some have brown skin, and some } \\
\text { have white skin. A large black and white picture of a woman and a } \\
\text { child can be seen at the top of the immigration advocacy page. } \\
\text { - A large photo of two Black women and a Black child can be found } \\
\text { on the LGBTQ page. }\end{array}$ \\
\hline & $\begin{array}{l}\text { b. Domestic Violence Resource Center of South County } \\
\underline{\text { Home } \mid \text { dvrcsc }}\end{array}$ & $\begin{array}{l}\text { - No images can be found on the main landing page. } \\
\text { - A miniature image of a woman with white skin and straight hair can } \\
\text { be found at the programs page. }\end{array}$ \\
\hline & $\begin{array}{l}\text { c. Lucy's Hearth } \\
\text { https://www.lucyshearth.org/ }\end{array}$ & $\begin{array}{l}\text { - A large picture containing the hands of two people with white skin } \\
\text { can be seen at the top of the main landing page. }\end{array}$ \\
\hline
\end{tabular}




\begin{tabular}{|c|c|c|}
\hline & & $\begin{array}{l}\text { - Below it is a large picture that shows a boy and girl with white skin } \\
\text { and a woman with curly hair and brown skin. } \\
\text { - A few scrolls down the page also shows a medium sized image of } \\
\text { the hands of people with brown skin. } \\
\text { - The last image seen on the main landing page reveals two children } \\
\text { with white skin and straight hair, one with brown skin and coily hair } \\
\text { and another with white skin and curly hair. }\end{array}$ \\
\hline & $\begin{array}{l}\text { d. Crossroads Rhode Island's } \\
\text { Domestic Violence Program (Women's Center of } \\
\text { Rhode island). } \\
\text { http://www.womenscenterri.org/ }\end{array}$ & $\begin{array}{l}\text { A single portrait of a woman with white skin and straight hair can } \\
\text { be seen at the top of the main landing page. }\end{array}$ \\
\hline & $\begin{array}{l}\text { e. Elizabeth Buffum Chace Center } \\
\text { https://www.ebccenter.org/ }\end{array}$ & $\begin{array}{l}\text { - A large photo of a woman with white skin and straight hair can be } \\
\text { seen at the top of the main landing page. }\end{array}$ \\
\hline Colorado & $\begin{array}{l}\text { a. Hilltop's Latimer House: Domestic Violence and } \\
\text { Sexual Assault Services } \\
\text { https://hilltoplatimerhouse.org/ }\end{array}$ & $\begin{array}{l}\text { - A large photo slide can be found on the main landing page; the first } \\
\text { is an image of the hands of a White person and of a person with } \\
\text { brown skin color. The next image is of a woman with white skin and } \\
\text { black straight hair. The next is a video image of a woman with white } \\
\text { skin and short straight hair. The last features the image of a woman } \\
\text { with white skin and curly hair. } \\
\text { - A medium sized image of a woman with brown skin and curly hair } \\
\text { with a baby with brown skin and curly hair can be found on the } \\
\text { emergency safehouse page. } \\
\text { - A small sized image of a woman with white skin and straight hair } \\
\text { can be found on the support page. }\end{array}$ \\
\hline
\end{tabular}




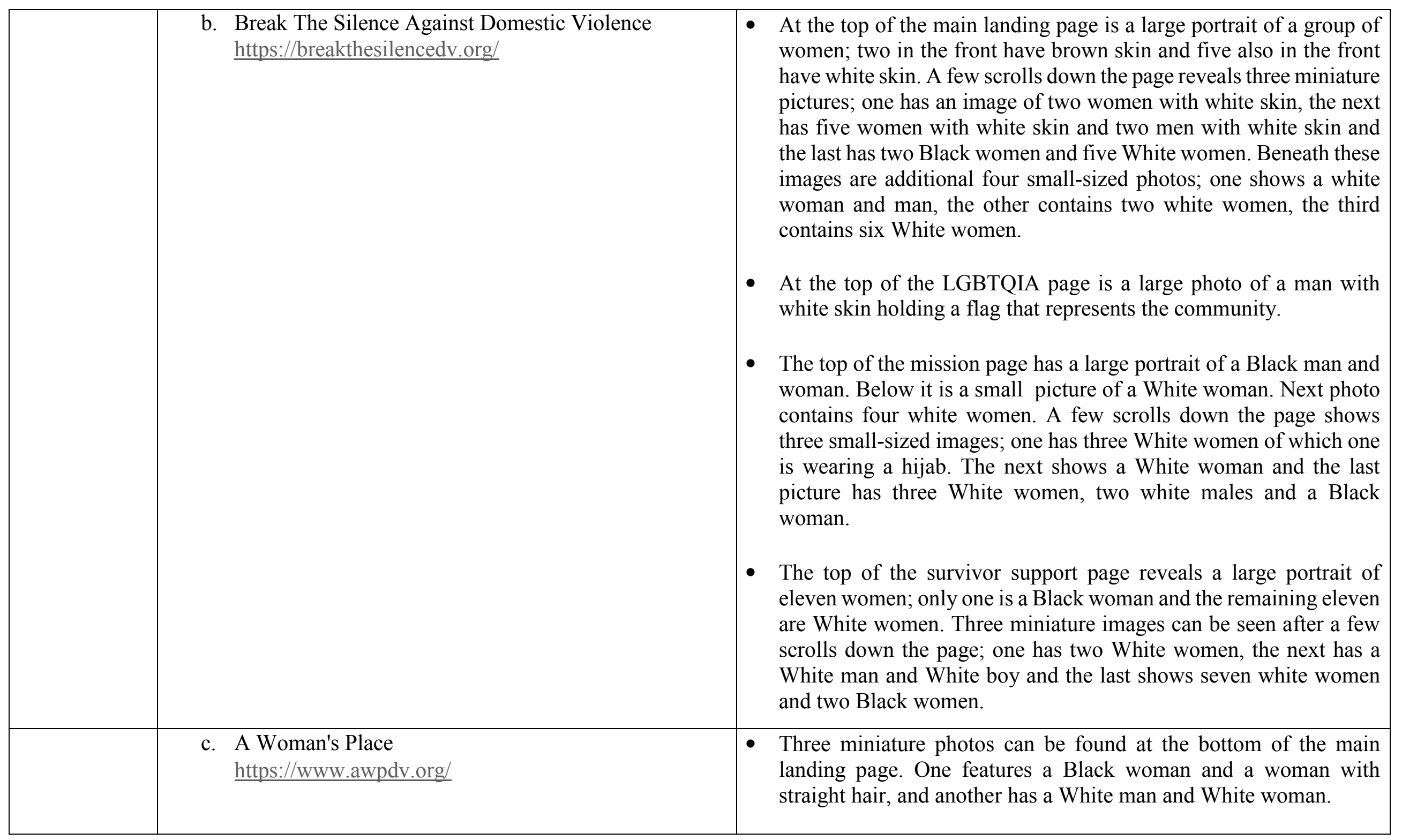




\begin{tabular}{|c|c|c|}
\hline & & $\begin{array}{l}\text { - At the bottom of the Español page lies a small-sized image of a } \\
\text { woman with white skin and straight hair. } \\
\text { - The client testimonial page has a small-sized image of a white } \\
\text { woman and two white children. Below it is a small-sized image of } \\
\text { a Black woman. A few scrolls down the page shows a small-sized } \\
\text { photo of a white man. }\end{array}$ \\
\hline & $\begin{array}{l}\text { d. TESSA of Colorado Springs } \\
\text { https://www.tessacs.org/ }\end{array}$ & $\begin{array}{l}\text { - At the top of the main landing page is a large portrait of a woman } \\
\text { with white skin and short straight hair. A medium-sized picture of } \\
\text { the arms of a Black woman is seen after a few scrolls down the page. } \\
\text { Next, a medium sized photo of a woman with white skin and straight } \\
\text { hair can be found at the bottom of the page. } \\
\text { - On the bottom of the get help page is a medium-sized image of a } \\
\text { Black woman and White woman. } \\
\text { - A large photo of a White man and Woman can be found on the } \\
\text { survivors' stories page. Another large picture of two women with } \\
\text { White skin can be found on the page. }\end{array}$ \\
\hline & $\begin{array}{l}\text { e. Rose Andom } \\
\text { https://roseandomcenter.org/ }\end{array}$ & $\begin{array}{l}\text { - The top of the main landing page has a large portrait of a Black } \\
\text { woman and baby. Few scrolls down the page reveals three medium- } \\
\text { sized pictures; one shows a woman with brown skin and straight } \\
\text { hair, another reveals a woman with white skin and straight hair and } \\
\text { the last shows a woman with white skin and straight hair. } \\
\text { Additional scrolls down the pages reveals a large photo of a woman } \\
\text { with brown skin and curly hair. Further scrolls down the page shows } \\
\text { a large image of nine women with white skin and straight hair, a } \\
\text { man with white skin and a Black woman. }\end{array}$ \\
\hline California & $\begin{array}{l}\text { a. YWCA of Sonoma County } \\
\text { www.ywcasc.org/ }\end{array}$ & $\begin{array}{l}\text { - A large photo slide can be found at the top of the main landing page } \\
\text { and the first contains two women with white skin. The next image } \\
\text { shows three men with white skin and two women with white skin. }\end{array}$ \\
\hline
\end{tabular}




\begin{tabular}{|c|c|c|}
\hline & & $\begin{array}{l}\text { Another image showing three women and two men with white skin } \\
\text { can be found in the photo slide. } \\
\text { - The next picture on the main landing page shows three women with } \\
\text { white skin and straight hair. Two miniature images showing a } \\
\text { woman and man with white skin can also be seen on the main } \\
\text { landing page. Additional two miniature images of two women with } \\
\text { white skin can be seen as well. } \\
\text { - A few scrolls reveal a miniature image of a woman and baby with } \\
\text { white skin. } \\
\text { At the end of the main landing page is a large photo of three women } \\
\text { with white skin and one woman with brown skin. }\end{array}$ \\
\hline & $\begin{array}{l}\text { b. Catalyst Domestic Violence Service } \\
\text { https://catalystdvservices.org/ }\end{array}$ & $\begin{array}{l}\text { - A large picture of a woman and child with brown skin and curly hair } \\
\text { can be seen at the top of the main landing page. } \\
\text { - A medium sized image of a man with white skin and a woman in } \\
\text { green jacket can be found on the main landing page. }\end{array}$ \\
\hline & $\begin{array}{l}\text { c. Shepherd's Door Domestic Violence Resource Center } \\
\text { https://www.shepherddoor.org/ }\end{array}$ & $\begin{array}{l}\text { - A large photo slide can be found on the main landing page. All of } \\
\text { the eleven slides contain images of both people with white skin and } \\
\text { brown skin. }\end{array}$ \\
\hline & $\begin{array}{l}\text { d. Shepherd's Gate } \\
\text { https://shepherdsgate.org/ }\end{array}$ & $\begin{array}{l}\text { - A large picture of a woman and baby with white skin can be seen } \\
\text { on the main landing page. } \\
\text { - Below are small miniature images; two contains women with white } \\
\text { skin and one contains women with brown skin. } \\
\text { - A large picture of a woman and boy with white skin and straight } \\
\text { hair can be seen on the main landing page also. }\end{array}$ \\
\hline
\end{tabular}




\begin{tabular}{|l|l|l|}
\hline & & $\begin{array}{l}\text { Below the picture are three miniature pictures; one shows two } \\
\text { women with white skin, and two show two women with brown skin. }\end{array}$ \\
\hline $\begin{array}{l}\text { e. Asian Women's Shelter } \\
\text { https://www.sfaws.org/ }\end{array}$ & $\begin{array}{l}\text { A large picture is seen at the top of the main landing page and } \\
\text { reveals multiple women; some have brown skin and others have } \\
\text { white skin. }\end{array}$ \\
\hline
\end{tabular}

RAW DATA (WHITE VS. BLACK IMAGES)

\begin{tabular}{|l|l|l|l|}
\hline STATE & WEBSITE & NO. OF IMAGES \\
& & $\begin{array}{l}\text { SHOWO. OF IMAGES } \\
\text { PEOPLE }\end{array}$ \\
\hline
\end{tabular}




\begin{tabular}{|c|c|c|c|}
\hline South Dakota & $\begin{array}{l}\text { a. Working against violence inc. } \\
\text { https://www.wavi.org/ } \\
\text { b. River city domestic violence shelter } \\
\text { https://www.yanktondomesticviolencecenter.com/ } \\
\text { c. Children's Home Society-Domestic Violence } \\
\text { https://chssd.org/childrensinn/ } \\
\text { d. Compass Center. } \\
\text { https://thecompasscenter.org/ } \\
\text { e. Missouri Valley Crisis Center } \\
\text { https://missourivalley.wordpress.com/ }\end{array}$ & $\begin{array}{l}\text { a. Six } \\
\text { b. Three } \\
\text { c. Sixteen } \\
\text { d. Four } \\
\text { e. Three }\end{array}$ & $\begin{array}{l}\text { a. Four } \\
\text { b. One } \\
\text { c. Eleven } \\
\text { d. One } \\
\text { e. Five }\end{array}$ \\
\hline Nebraska & $\begin{array}{l}\text { a. S.A.F.E. } \\
\text { Center. } \\
\text { https://safecenter.org/ } \\
\\
\text { b. Women's Center For Advancement } \\
\underline{\text { https://wcaomaha.org/ }}\end{array}$ & $\begin{array}{l}\text { a. Three } \\
\text { b. Nine }\end{array}$ & $\begin{array}{l}\text { a. Three } \\
\text { b. Six }\end{array}$ \\
\hline
\end{tabular}




\begin{tabular}{|c|c|c|c|}
\hline & $\begin{array}{l}\text { c. The Bridge } \\
\text { http://www.bridgefromviolence.com/ } \\
\text { d. enCourage Advocacy Center. } \\
\text { https://www.encouragecenter.org/ } \\
\text { e. Crisis Center } \\
\underline{\text { https://gicrisis.org/ }}\end{array}$ & $\begin{array}{l}\text { c. Six } \\
\text { d. Six } \\
\text { e. Seven }\end{array}$ & $\begin{array}{l}\text { c. Two } \\
\text { d. Two } \\
\text { e. Two }\end{array}$ \\
\hline Maryland & $\begin{array}{l}\text { a. House of Ruth Maryland } \\
\text { https://hruth.org/get-help/ } \\
\text { b. Citizens Assisting and Sheltering the Abused (CASA) } \\
\underline{\text { http://casainc.org/ }} \\
\text { c. TurnAround, Inc. } \\
\text { https://turnaroundinc.org/ } \\
\text { d. Center for Abused Persons } \\
\text { https://www.centerforabusedpersonscharlescounty.org/ } \\
\text { e. YWCA of Annapolis and Anne Arundel County } \\
\text { https://www.annapolisywca.org/ }\end{array}$ & $\begin{array}{l}\text { a. Six } \\
\text { b. Eight } \\
\text { c. Six } \\
\text { d. Four } \\
\text { e. Three }\end{array}$ & $\begin{array}{l}\text { a. Seven } \\
\text { b. Four } \\
\text { c. Five } \\
\text { d. Three } \\
\text { e. Three }\end{array}$ \\
\hline Kentucky & $\begin{array}{l}\text { a. Bethany House Abuse Shelter, Inc. } \\
\text { https://bethanyhouseinc.org/ } \\
\text { b. The Center for Women and Families } \\
\text { https://www.thecenteronline.org/ }\end{array}$ & $\begin{array}{l}\text { a. Three } \\
\text { b. Four }\end{array}$ & $\begin{array}{l}\text { a. Two } \\
\text { b. Four }\end{array}$ \\
\hline
\end{tabular}




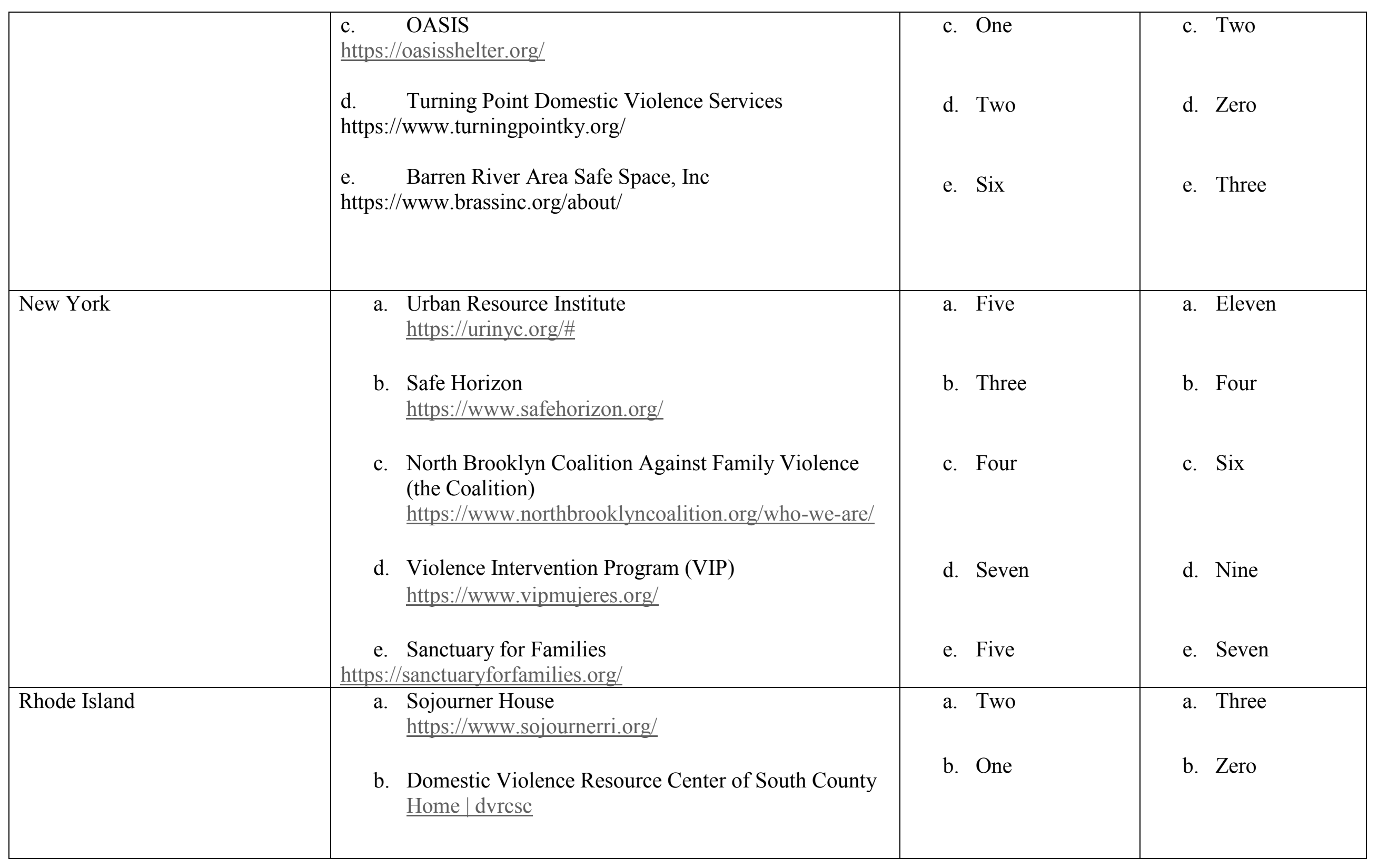




\begin{tabular}{|c|c|c|c|}
\hline & $\begin{array}{l}\text { c. Lucy's Hearth } \\
\text { https://www.lucyshearth.org/ } \\
\text { d. Crossroads Rhode Island's } \\
\text { Domestic Violence Program (Women's Center of } \\
\text { Rhode island). } \\
\text { http://www.womenscenterri.org/ } \\
\text { e. Elizabeth Buffum Chace Center } \\
\text { https://www.ebccenter.org/ }\end{array}$ & $\begin{array}{l}\text { c. Three } \\
\text { d. One }\end{array}$ & $\begin{array}{l}\text { c. Three } \\
\text { d. Zero }\end{array}$ \\
\hline Colorado & $\begin{array}{l}\text { a. Hilltop's Latimer House: Domestic Violence and } \\
\text { Sexual Assault Services } \\
\text { https://hilltoplatimerhouse.org/ } \\
\text { b. Break The Silence Against Domestic Violence } \\
\text { https://breakthesilencedv.org/ } \\
\text { c. A Woman's Place } \\
\text { https://www.awpdv.org/ } \\
\text { d. TESSA of Colorado Springs } \\
\text { https://www.tessacs.org/ } \\
\text { e. Rose Andom } \\
\text { https://roseandomcenter.org/ }\end{array}$ & $\begin{array}{l}\text { a. Five } \\
\text { b. Fourteen } \\
\text { c. Four } \\
\text { d. Five } \\
\text { e. Three }\end{array}$ & $\begin{array}{l}\text { a. Two } \\
\text { b. Six } \\
\text { c. Two } \\
\text { d. Two } \\
\text { e. Four }\end{array}$ \\
\hline California & $\begin{array}{l}\text { a. YWCA of Sonoma County } \\
\text { www.ywcasc.org/ } \\
\text { b. Catalyst Domestic Violence Service }\end{array}$ & $\begin{array}{l}\text { a. Ten } \\
\text { b. One }\end{array}$ & $\begin{array}{l}\text { a. One } \\
\text { b. One }\end{array}$ \\
\hline
\end{tabular}




\begin{tabular}{|l|l|l|c|}
\hline https://catalystdvservices.org/ & c. Eleven \\
c. Shepherd's Door Domestic Violence Resource Center \\
https://www.shepherddoor.org/ \\
d. Shepherd's Gate \\
$\begin{array}{l}\text { https://shepherdsgate.org/ } \\
\text { e. Asian Women's Shelter } \\
\text { https://www.sfaws.org/ }\end{array}$ & d. Five & d. Three \\
\hline & e. One One \\
\hline
\end{tabular}

